Portland State University

PDXScholar

Fall 12-5-2014

\title{
Cascades Island Lamprey Passage Structure: Evaluating Passage and Migration Following Structure Modifications
}

Siena Marie Lopez-Johnston

Portland State University

Follow this and additional works at: https://pdxscholar.library.pdx.edu/open_access_etds

Part of the Aquaculture and Fisheries Commons

Let us know how access to this document benefits you.

Recommended Citation

Lopez-Johnston, Siena Marie, "Cascades Island Lamprey Passage Structure: Evaluating Passage and Migration Following Structure Modifications" (2014). Dissertations and Theses. Paper 2082.

https://doi.org/10.15760/etd.2080

This Thesis is brought to you for free and open access. It has been accepted for inclusion in Dissertations and Theses by an authorized administrator of PDXScholar. Please contact us if we can make this document more accessible: pdxscholar@pdx.edu. 


\title{
Cascades Island Lamprey Passage Structure:
}

Evaluating Passage and Migration Following Structure Modifications

$$
\text { by }
$$

Siena Marie Lopez-Johnston

\begin{abstract}
A thesis submitted in partial fulfillment of the requirements for the degree of

\author{
Master of Science \\ in \\ Environmental Science and Management
}

Thesis Committee:

Yangdong Pan, Chair

Eugene Foster

Joseph Maser

Mary Moser

Portland State University

2014 


\begin{abstract}
Pacific lamprey (Entosphenus tridentatus), an endemic species to the Columbia River Basin, U.S.A, has experienced staggering decreases in returns to spawning territories in recent decades. As lamprey are threatened severely by a lack of passage at mainstem dams, lamprey specific passage structures have been designed and constructed to address the problem. The Cascades Island Lamprey Passage Structure (LPS) at Bonneville Dam is the longest and steepest structure of its type, following the addition of an exit pipe which allows lampreys to travel from the tailrace of the dam to the forebay.

The intent of this study was to assess lamprey use of the structure and whether the structure hinders lamprey migration to subsequent dams. The study was carried out during the 2013 migration season. The study used three different treatment groups of lampreys released on five dates spanning the migration season ( $\mathrm{n}=75$ lamprey). Two of these groups ( $n=50)$, with different tagging methods, were released directly into the LPS to assess passage success, travel time, and tagging effect. The third group $(n=25)$ was released into the forebay to test whether the structure impedes migration upstream. Fish were monitored via receiver arrays on the LPS and at dams on the river system.

Overall passage efficiency was 74\% (37 of 50 used the CI LPS successfully). Mean travel time to navigate the structure was $12 \mathrm{~h}$. Fish size had no significant effect on travel time in the LPS. Water temperature had a significant effect on travel time in the LPS. There was no statistically significant effect of tagging on passage efficiency or travel time. The groups that used the LPS performed slightly better migrating upstream to the next dam than the group that bypassed the structure, but the difference was not
\end{abstract}


significant. The groups that used the LPS traveled to more subsequent dams upstream than did the group that bypassed the LPS.

It can be concluded that lamprey passed the structure successfully. Temperature (proxy for seasonality) had an effect on travel time in the LPS; however fish size and tagging had no effect. The LPS does not affect the ability of migrating lampreys to continue migration to subsequent dams. Such findings have important implications for management of lamprey in the region. 


\section{Acknowledgments}

I would like to thank the following: Bonneville Power Administration for providing support throughout the process and allowing me the time I need to complete my program. The Army Corps of Engineers for badging, visits, technical questions, and direction at the Bonneville Dam project. The University of Idaho for providing animal handling and care permits, lamprey permits for scientific use, allowing me to use tags and equipment and lending a hand when needed at the dam. Portland State University’s Department of Environmental Science and Management for guiding me along the way, providing an encouraging learning environment, specifically, Gene Foster and Yangdong Pan for their valuable time and assistance, Sherie Huffman for her amazing work in managing the department office, and my peers who many I have gone through this process with. NOAA Fisheries, specifically Kinsey Frick for data mining and instruction, Steve Corbett for all his time in the field spent tagging, downloading data, releasing fish, and providing assistance whenever needed, and Mary Moser for her willingness to include me on such an interesting and novel project, taking the time to take me on as a student thesis project in general, and the unmatched direction and knowledge provided, this project would not have been possible without her. Tuition and scholarship resources for believing in me enough to pay my way through graduate school, giving me one less thing to be stressed about. And finally to my family and friends who have supported me through rain and shine on this emotional roller coaster they call grad school! Thank you all so much. 


\section{Table of Contents}

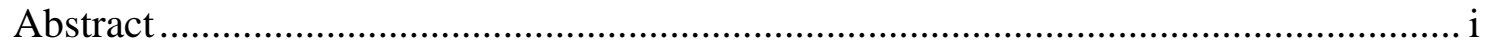

Acknowledgments..................................................................................................ii

List of Tables ............................................................................................................ vii

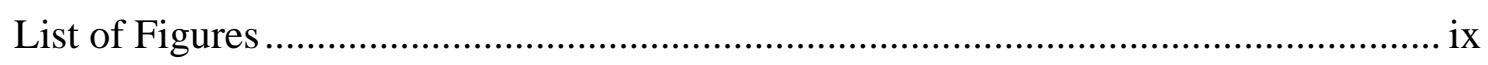

Chapter 1: Introduction and Background................................................................... 1

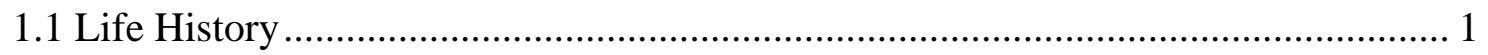

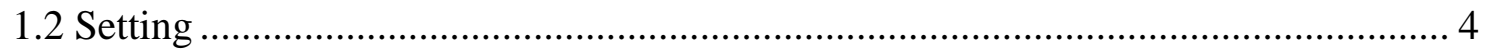

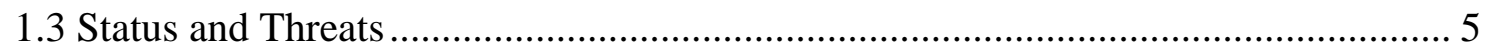

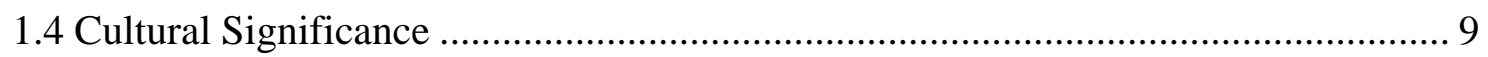

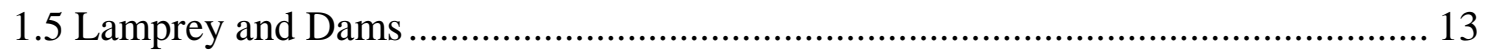

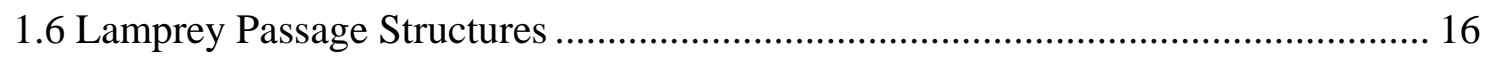

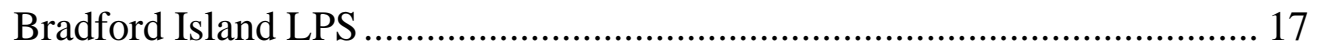

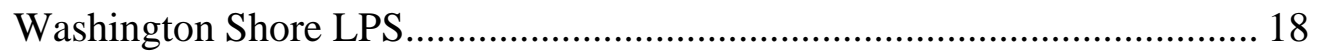

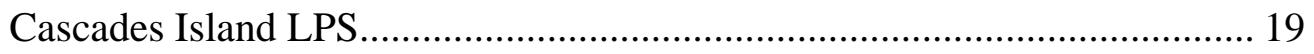

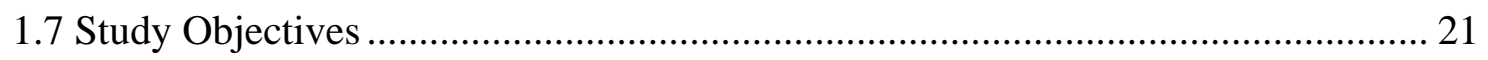

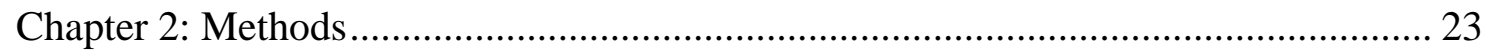

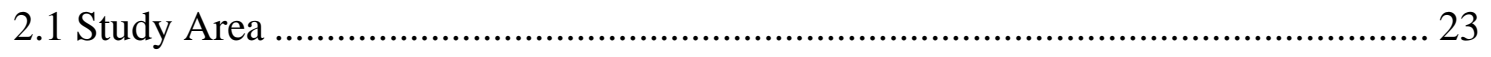

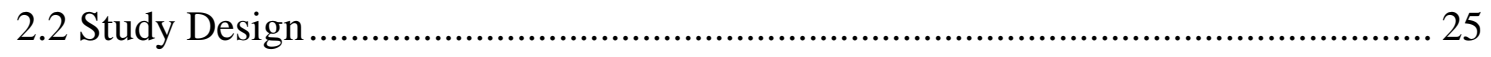

2.3 Lamprey Collection ...................................................................................... 27

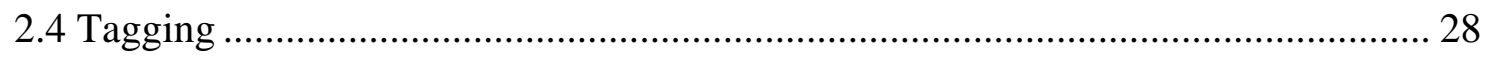

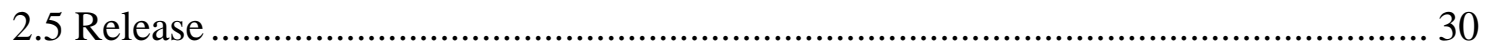




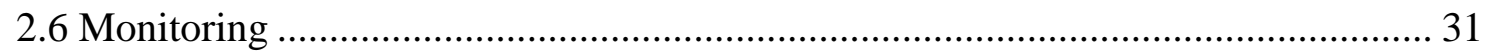

2.7 Data Collection and Analysis................................................................................ 32

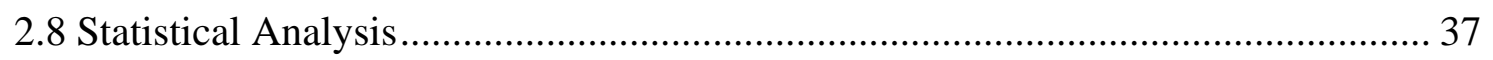

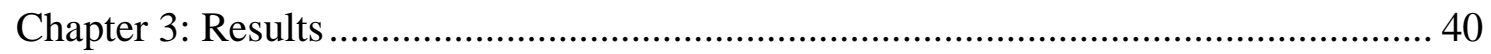

3.1 Environmental Conditions at Bonneville Dam .......................................................... 40

3.2 Morphology of Lampreys ................................................................................... 43

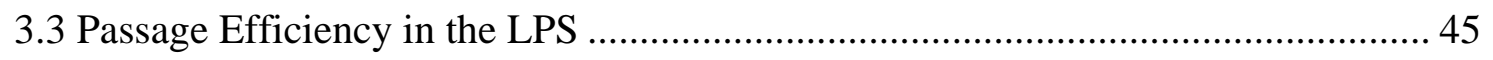

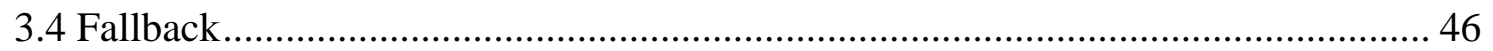

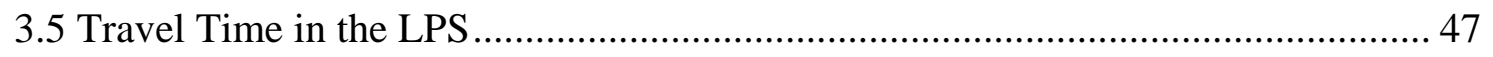

Effect of Fish Morphology on Travel Time in LPS ...................................... 48

Environmental Effect on Travel Time in LPS............................................... 53

3.6 Migration through Bonneville Reservoir ................................................................ 54

3.7 Travel Time through Bonneville Reservoir ............................................................. 54

Fish Morphology Effect on Travel Time through Bonneville Reservoir...... 58

Environmental Effects on Travel Time through Bonneville Reservoir......... 61

3.8 Migration Upstream from The Dalles Dam .............................................................. 63

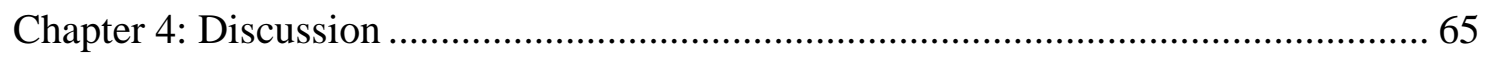

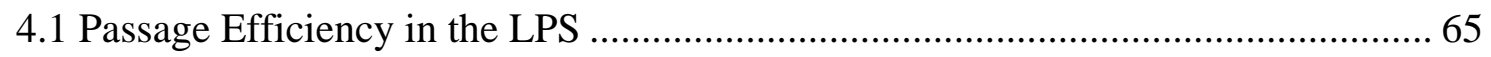

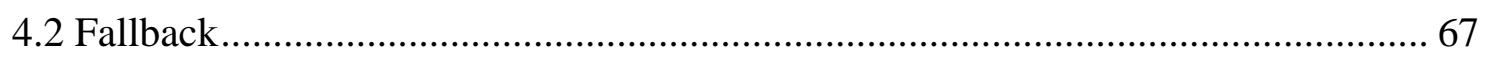

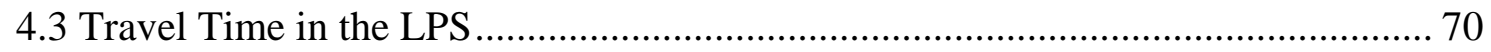

Fish Morphology Effect on Travel Time in LPS........................................... 74

Environmental Effect on Travel Time in LPS................................................ 75 
4.4 Migration through Bonneville Reservoir....................................................... 78

4.5 Travel Time through Bonneville Reservoir ..................................................... 80

Fish Morphology Effects on Travel Time through Bonneville Reservoir .... 81

Environmental Effects on Travel Time through Bonneville Reservoir......... 82

4.6 Migration Upstream from The Dalles Dam ....................................................... 83

4.7 Conclusions and Implications for Lamprey Management ................................... 86

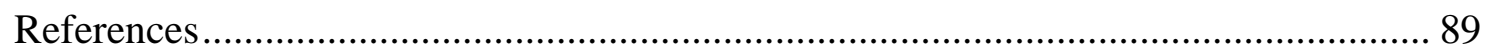




\section{List of Tables}

Table 2.2.1 Study design identifying tag type, release site, and numbers of fish in each Group and Release (n=75) for the Cascades Island study at Bonneville Dam in 201326

Table 3.1.1 Weekly averages of water temperature (degrees celsius) in the Bonneville forebay, and flow (thousand cubic feet per second) downstream from The Dalles Dam over the duration of the study 2013

Table 3.2.1 Length (centimeters) of groups and releases for all fish tagged at Bonneville Dam for use in the Cascades Island LPS 2013 study (Mean, standard deviation, and median).

Table 3.2.2 Weight (grams) of groups and releases for all fish tagged at Bonneville Dam for use in the Cascades Island LPS 2013 study 9 (Mean, standard deviation, and median).....

Table 3.2.3 Girth (centimeters) of groups and releases for all fish tagged at Bonneville Dam for use in the Cascades Island LPS 2013 study (Mean, standard deviation, and median)

Table 3.3.1 Numbers of fish in groups and releases that successfully passed and exited the CI LPS after release into rest box 3 in 2013.

Table 3.4.1 Number of fish in groups and releases that experienced fallback within the LPS to the tailrace of Bonneville Dam after release into rest box 3 at CI LPS in 201346

Table 3.4.2 Numbers of fish in groups and releases that experienced partial fallback after release into rest box 3 at CI LPS but were able to re-ascend and exit the CI LPS in 2013

Table 3.5.1 Travel time (days) of groups and releases for all fish that successfully passed and exited the CI LPS after release into rest box 3 in 2013 (Mean, standard deviation, and median)

Table 3.5.2 Length (centimeters) of groups and releases for all fish that successfully passed and exited the CI LPS after release into rest box 3 in 2013 (Mean, standard deviation, and median)

Table 3.5.3 Weight (grams) of groups and releases for all fish that successfully passed and exited the CI LPS after release into rest box 3 in 2013 (Mean, standard deviation, and median) 
Table 3.5.4 Girth (cm) of groups and releases for all fish that successfully passed and exited the CI LPS after release into rest box 3 in 2013 (Mean, standard deviation, and median).

Table 3.7.1 Travel time (days) for groups and releases of all fish that successfully passed the Bonneville reservoir after release in 2013 (Mean, standard deviation, and median).

Table 3.7.2 Travel time (days) for fish that passed the CI LPS and traveled through Bonneville reservoir and for fish that bypassed the CI LPS and traveled through the Bonneville reservoir in a 2013 CI LPS study (Mean, standard deviation, and median)55

Table 3.7.3 Bins of travel time ( $<5$ days, 5-10 days, and $>10$ days) with numbers of fish for all groups and releases for fish that passed the Bonneville reservoir in a 2013 CI LPS study

Table 3.7.4 Length (centimeters) of groups and releases for all fish that successfully passed the Bonneville reservoir after release in 2013 (Mean, standard deviation, and median)

Table 3.7.5 Weight (grams) of groups and releases for all fish that successfully passed the Bonneville reservoir after release in 2013 (Mean, standard deviation, and median)

Table 3.7.6 Girth (centimeters) for groups and releases of all fish that successfully passed the Bonneville reservoir after release in 2013 (Mean, standard deviation, and median) 


\section{List of Figures}

Figure 1.1.1 Pacific lamprey lifecycle includes four distinct phases - the ammocoete (larval) stage occurs in freshwater following hatching, the macrophthalmia (smolt) stage occurs in freshwater as migration to the ocean takes place, the adult (trophic) stage occurs as lampreys enter salt water and become parasitic in the estuary and ocean (not pictured), and the adult (spawning) stage occurs in freshwater after return from the ocean (Adapted from Ralph Lampman Yakama Nation Lamprey presentation 2014)... 3

Figure 1.2.1 Columbia Basin including ceded lands of the four Columbia River treaty tribes and their present-day boundaries, with major dams on the Columbia and Snake rivers. Not pictured are other tribal territories within the basin (Source: CRITFC 2011)

Figure 1.3.1 Adult Pacific lamprey counts at Bonneville and McNary Dam. Counts from 1938-1969 were visual counts taking place only during the daytime hours. There is a gap in data from 1969-1993. Visual daytime counts resumed in 1994 to the present with nighttime counts in 1998 and 1999 (Source: CRITFC 2011).

Figure 1.5.1 Dams of the Federal Columbia River Power System on the Columbia and Snake River (Courtesy of NOAA Fisheries) ......................................................... 14

Figure 1.6.1 Aerial view of Bonneville Dam with approximate locations of LPSs - a) Washington Shore LPS, b) Cascades Island LPS, c) Bradford Island LPS (Source: Corbett et al. 2013)....

Figure 1.6.2 Side view of Bradford Island LPS showing vertical and horizontal lengths and rest boxes (Source: Moser et al. 2011a)

Figure 1.6.3 Side view of Washington Shore LPS showing vertical and horizontal lengths, location of rest boxes, and the upwelling box (Source: Moser et al. 2011a)... 19

Figure 1.6.4 Side view of Cascades Island LPS (2009-2012) including locations of six resting boxes and the upwelling terminal trap box. The tailrace of the dam is below Rest Box 1 and the forebay level of the dam is at the Upwelling Box and Trap (Corbett

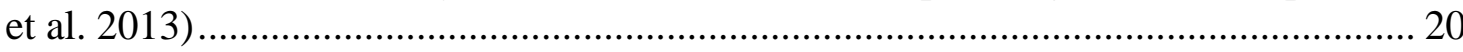

Figure 1.6.5 Side view of Cascades Island LPS depicting the structure during experimental operation from 2009-2012 and the addition of the upper portion including the upwelling boxes, the pipe, and the exit to the forebay, with a picture showing the exit pipe emptying into the forebay (Courtesy of NOAA Fisheries) ........................... 21 
Figure 2.1.1 Overhead view of Bonneville Dam - Cascades Island LPS highlighted in red, Group 3 release site at the end of Cascades Island (green dot), the Adult Fish Facility outlined in blue, and trap locations identified with arrows (structures and locations not drawn to scale, Courtesy of NOAA Fisheries, modified 2014).............. 24

Figure 2.1.2 Image of Bonneville Dam at rkm 235.1, The Dalles Dam at rkm 308.1, and the area considered Bonneville reservoir highlighted (Google Earth) ........................ 24

Figure 2.2.1 Side view schematic of CI LPS 2013 study design............................... 26

Figure 2.4.1 (Left) Half-duplex passive integrated transponder (PIT) tag implanted in all study fish ( $\mathrm{n}=75)$ for the CI LPS Study in 2013. Figure 2.4.1 (Right) Radio tag model NTC-4-2L implanted in Group 1 and Group 3 study fish $(n=50)$ for

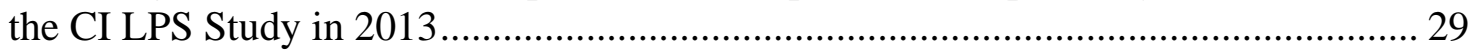

Figure 3.1.1 Daily average water temperature $\left({ }^{\circ} \mathrm{C}\right)$ in the Bonneville Dam forebay from July 7, 2013 to September 14, 2013 (blue diamonds), average water temperature $\left({ }^{\circ} \mathrm{C}\right.$ ) on days of release (red squares) and water temperature $\left({ }^{\circ} \mathrm{C}\right)$ in the CI LPS on release days at time of release (green triangles)

Figure 3.1.2 Daily average flow (thousand cubic feet per second) $1.6 \mathrm{~km}$ downstream from The Dalles Dam from July 7, 2013 to September 14, 2013 (blue diamonds), average flow (thousand cubic feet per second) on days of release (red squares)......... 42

Figure 3.1.3 Day length (hours of daylight/24 h) in Cascade Locks, OR from July 7, 2013 to September 14, 2013 (blue diamonds), day length (hours of daylight/24 h) on days of release (red squares)

Figure 3.5.1 Length (centimeters) and travel time (days) simple linear regression analysis for all fish that successfully passed and exited the CI LPS after release into rest box 3 in 2013 .

Figure 3.5.2 Weight (grams) and travel time (days) simple linear regression analysis for all fish that successfully passed and exited the CI LPS after release into rest box 3 in 2013

Figure 3.5.3 Water temperature (degrees celcius) and travel time (days) simple linear regression analysis for all fish that successfully passed and exited the CI LPS after

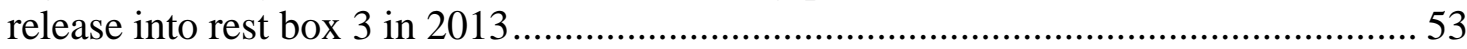

Figure 3.5.4 Day length (day light hours/24 hours) and travel time (days) simple linear regression analysis for all fish that successfully passed and exited the CI LPS after release into rest box 3 in 2013 
Figure 3.7.1 Travel time (days) for fish that passed the CI LPS and traveled through Bonneville reservoir and for fish that bypassed the CI LPS and traveled through the Bonneville reservoir in a 2013 CI LPS study

Figure 3.7.2 Numbers of fish that passed the Bonneville reservoir in each bin of travel time ( $<5$ days, $5-10$ days, and $>10$ days) for fish that passed the Bonneville reservoir in a 2013 CI LPS study.....

Figure 3.7.3 Length (centimeters) and travel time (days) simple linear regression for all fish that successfully migrated through the Bonneville reservoir in 2013 ................... 59

Figure 3.7.3 Weight (grams) and travel time (days) simple linear regression analysis for all fish that successfully migrated through the Bonneville reservoir in 2013 .............. 60

Figure 3.7.4 Water temperature (degrees Celsius) and travel time (days) simple linear regression analysis for all fish that successfully migrated through the Bonneville reservoir in 2013.

Figure 3.7.5 Flow (thousands of cubic feet per second) downstream from The Dalles Dam and travel time (days) simple linear regression analysis for all fish that successfully migrated through the Bonneville reservoir in 2013.

3.7.6 Day length (hours of day light/24 hours) and travel time (days) simple linear regression analysis for all fish that successfully migrated through the Bonneville reservoir in 2013. 


\section{Chapter 1: Introduction and Background}

\subsection{Life History}

Pacific lamprey (Entosphenus tridentata) is a jawless, boneless species of fish ranging from Baja California, Mexico all the way to Alaska and Japan and is endemic throughout their range (Ruiz-Campos and Gonzalez-Guzman 1996; Keefer et al. 2009a; Clemens et al. 2013). Their existence spans over 450 million years and has outlasted five mass extinctions and yet they have remained relatively unchanged physiologically (Keefer et al. 2009b; CRITFC 2011). It has been proposed that Pacific lamprey existence creates an intricate balance in ecosystems. Lamprey freshwater activities largely overlap with Pacific salmonids, they are preyed on by many of the same species, they are a part of the food web, and they bring back vital nutrients to watersheds that otherwise lack them (CRITFC 2011; Keefer et al. 2013a).

Pacific lamprey life history is complex and still lacks full understanding (Clemens et al. 2013). It is unique in that they are anadromous, meaning they are hatched in freshwater, migrate to the ocean, and travel back to freshwater to spawn and die, much like salmon. However, the lamprey lifecycle is about three times as long as salmonid species, they are parasitic in their ocean phase, and require very specific habitat types and conditions to foster growth (CRITFC 2011). This species experiences very high fecundity (98,000-238,400 eggs), with about 13-150 times that of steelhead (CRITFC 2011; Clemens et al. 2013). They are periodic strategists meaning that their offspring are small and numerous, owing to their extremely high fecundity, and they must take 
advantage of infrequent opportunities to spawn in variable spatial and temporal environments (Clemens et al. 2013).

Upon hatching, lamprey drift downstream to suitable habitat where they spend 4-7 years as larvae, referred to as ammocoetes. During this time they burrow into soft sediment and organic materials where they are blind, sedentary, and filter feed on diatoms in low velocity, and low gradient water. Following this phase they metamorphose and travel from freshwater to the ocean. In this stage they develop eyes, an oral disc, a tongue, and teeth, and change from a brown color to silver. When their metamorphosis is complete they are referred to as macrophthalmia and enter an estuary. However, their use and duration of residence in estuary habitat is uncertain. After they move through the estuary and enter the ocean they have reached their adult phase, which lasts 1-3 years. In this phase they feed parasitically and their migration, depths, and distribution are relatively unknown (CRITFC 2011). They feed on Pacific hake (Merluccius productus), walleye pollock (Theragra chalcogramma), Pacific cod (Gadus macrocephalus), Pacific salmon (Oncorhynchus species = pink, sockeye, coho, Chinook), Pacific herring (Clupea pallasii), Pacific halibut (Hippoglossus stenolepis), steelhead (Salmo gairderi), lingcod (Ophiodon elongates), sablefish (Anoplopoma fimbria), rockfish (Sebastes species), and whales (Beamish 1980; Murauskas et al. 2013).

Following this stage, they return to freshwater to spawn (Figure 1.1.1). It has been determined, however, that a single life history does not exist for returning adults. Instead the species exhibits some fish that mature fully in the ocean and spawn within several weeks of returning to freshwater as well as fish who return to freshwater, likely later in 
the migration season, and overwinter, waiting until they are fully mature to spawn in the next year's spawning season (Clemens et al. 2013). Their creation of nests is very similar to that of salmonids. It occurs in deep river pools with small boulders and organic debris present, where the male and female perform rock-lifting movements and digging, after which the females drop their eggs as males compete to fertilize and cover the nest. Both sexes die shortly thereafter. Although they do not return to natal streams to spawn as salmonids do, making their population structure largely unknown, their return to freshwater from the marine phase and their subsequent death allows their decomposing carcass to serve as a nutrient- rich source in regularly nutrient poor systems (Close et al. 2002; CRITFC 2011).

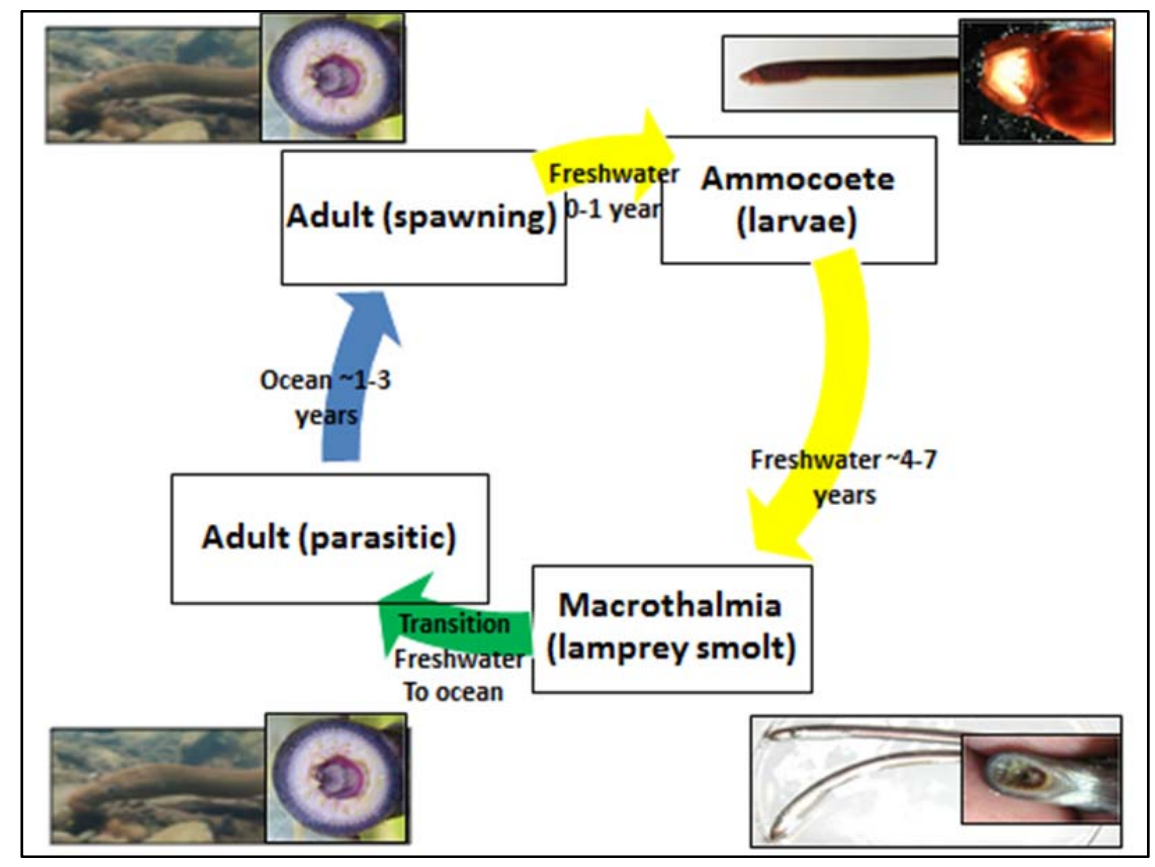

Figure 1.1.1 Pacific lamprey lifecycle includes four distinct phases - the ammocoete (larval) stage occurs in freshwater following hatching, the macrophthalmia (smolt) stage occurs in freshwater as migration to the ocean takes place, the adult (trophic) stage occurs as lampreys enter salt water and become parasitic in the estuary and ocean (not pictured), and the adult (spawning) stage occurs in freshwater after return from the ocean (Adapted from Ralph Lampman Yakama Nation Lamprey presentation 2014) 


\subsection{Setting}

Broadly, this research pertains to the Columbia River and its basin, with headwaters in Canada. The river travels through seven states and 13 federally recognized Indian reservations, four of which are recognized as the treaty tribes of the basin. The river provides a suite of uses including flood control, recreation, irrigation, power, fish and wildlife habitat, navigation, water supply, and cultural resources; it is 1,930 kilometers $(\mathrm{km})$ long and is highly regulated, flowing through numerous federal dams and storage reservoirs on the mainstem as it drains 673,397 square km into the Pacific Ocean (Figure 1.2.1). The river is nestled between The Rocky Mountains and the Cascades and receives a great amount of recharge via precipitation mainly as snowmelt, making river flow extremely variable depending on the season. Most rain and snowfall occur in the winter; rainfall is delivered directly to the system via runoff maintaining a relatively constant flow in the river while snowpack is stored in the winter months and released during the spring and early summer. The river and its surrounding habitat are home to a diversity of fauna including resident and migrating fish, several of which, excluding lamprey, have been federally listed under the Endangered Species Act (ESA) (USACE 2001). 


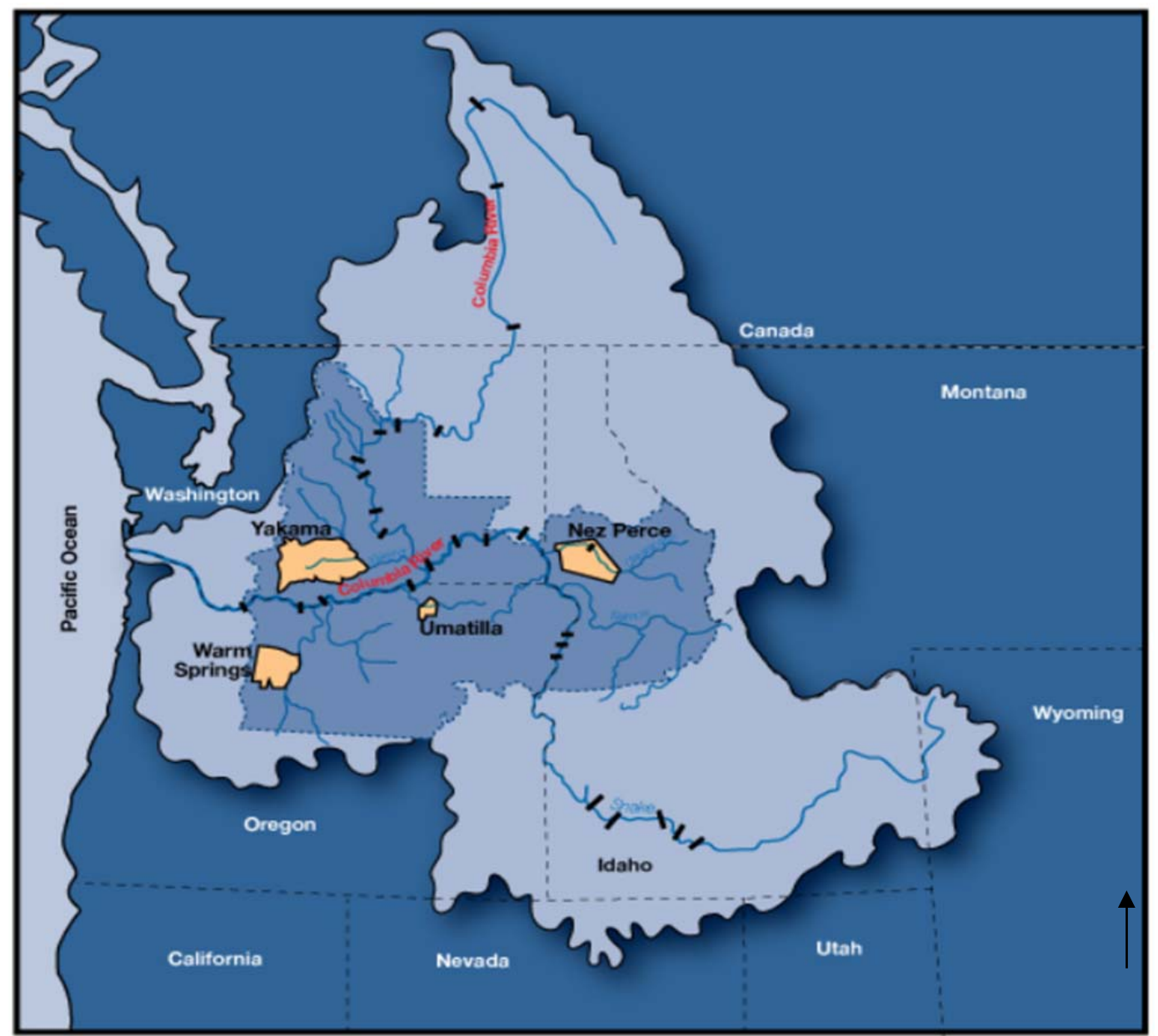

Columbia River basin

Present-day reservation boundaries

Ceded lands of the four Columbia River treaty tribes

I Major dams on the Columbia/Snake rivers

Figure 1.2.1 Columbia Basin including ceded lands of the four Columbia River treaty tribes and their present-day boundaries, with major dams on the Columbia and Snake rivers. Not pictured are other tribal territories within the basin (Source: CRITFC 2011)

\subsection{Status and Threats}

In the last 50 years an alarming decline in Pacific lamprey populations returning to freshwater to spawn has become apparent. Adult abundance counts were collected as an add-on to salmonid visual counts at Bonneville Dam in the late 1930s and were 
estimated between 50,000-400,000 annually between 1938 and 1969 (Kostow 2002). There is a gap in data between 1969 and the late 1990s; however, since counts have resumed numbers have exhibited a declining trend, with 117,000 at Bonneville in 2003, and this number dwindling to 6,200 in 2010 (Figure 1.3.1) (CRITFC 2011). Historical counts for lamprey over the years have been haphazard and unsystematic, lacking protocols specific for lamprey; salmonid counts do not coincide with lamprey migration behavior as lamprey migrate primarily at night (Moser and Close 2003). According to Moser and Close (2003), 67\% of lamprey in 2000 would have been missed using previous counting protocols. Lampreys at count windows often congregate together and behave in an inconsistent manner, making counts difficult and often in error (Moser and Close 2003). These miscounts and lack of lamprey specific protocols have contributed to our poor understanding of migration patterns and population trends.

Smaller tributaries in the region such as the Umpqua River experienced as few as 34 fish returning in a single year and numbers in the single digits are seen as far upstream in the Snake River as Idaho (Close et al. 2002). Electrofishing surveys to document larval recruitment in recent years have shown little to no recruitment in several Columbia River tributaries (Moser et al. 2002a; Moser and Close 2003). 


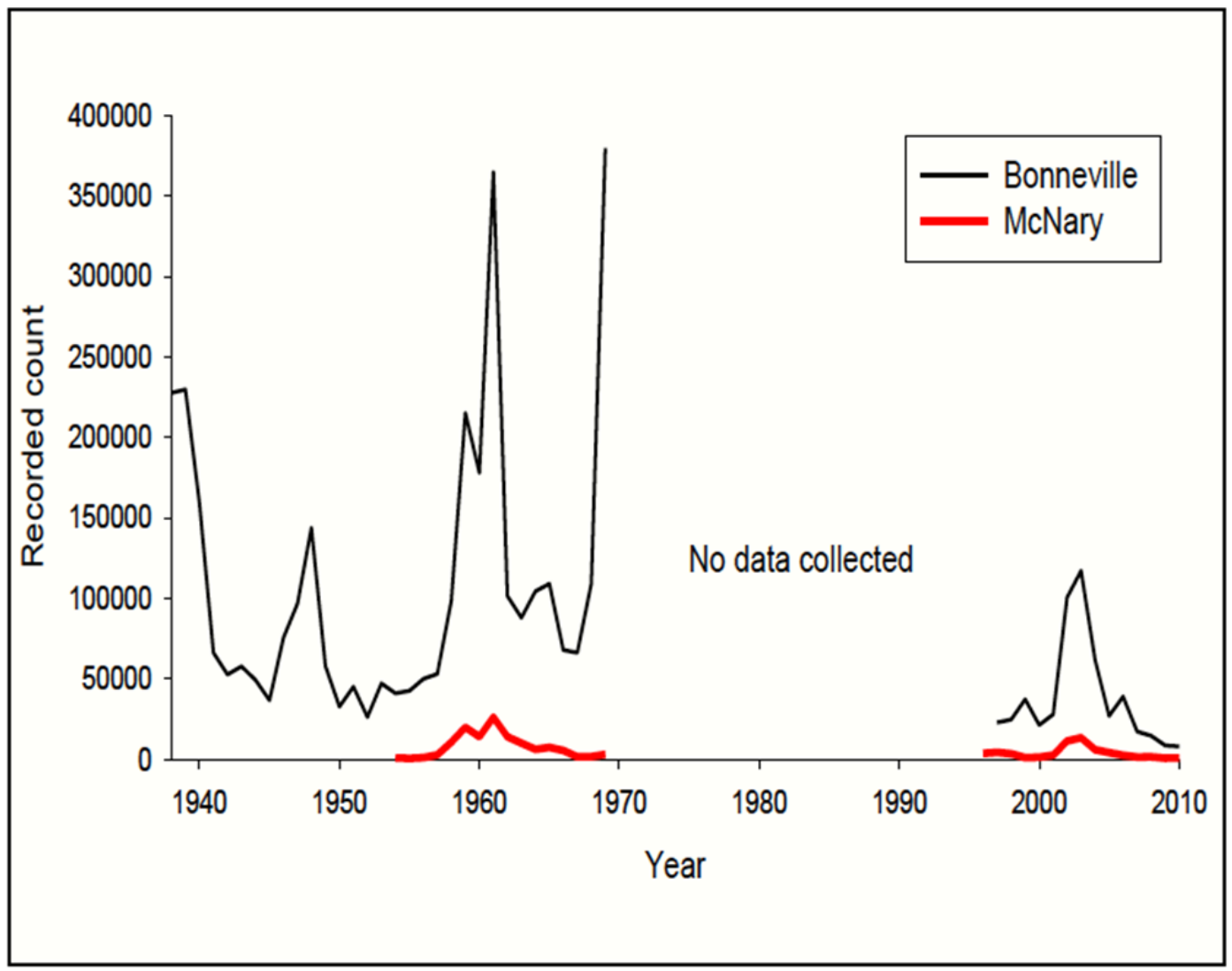

Figure 1.3.1 Adult Pacific lamprey counts at Bonneville and McNary Dam. Counts from 1938-1969 were visual counts taking place only during the daytime hours. There is a gap in data from 1969-1993. Visual daytime counts resumed in 1994 to the present with nighttime counts in 1998 and 1999 (Source: CRITFC 2011)

Declines have been attributed to many threats, mostly anthropogenic, including habitat degradation, water quality impairments, passage barriers (such as low-elevation dams, culverts, irrigation diversion dams, weirs and large-scale mainstem hydropower dams), and entrainment through irrigation screens (Moser and Mesa 2009). Other major threats include predation, invasive species, marine conditions, climatic conditions, and predator-prey dynamics (Close et al. 2002; CRITFC 2011; USFWS 2011). Legacy contaminants of concern to Pacific lamprey include mercury, PCBs, pesticides, flame 
retardants, and heavy metals, as well as contaminants of emerging concern such as pharmaceuticals and hygienic care products which have been found at alarming levels in Columbia River sediments and pose a serious threat to juvenile and adult lamprey, and human consumption of adult lamprey (Nilsen and Temple 2012).

Clemens et al. (2009) found that water temperatures exceeding $20^{\circ} \mathrm{C}$ can cause lamprey to experience significant loss of body mass and energetic reserves. Water temperatures of $22^{\circ} \mathrm{C}$ in the lab have resulted in mortalities and deformation of eggs following spawning (USFWS 2011). With dam passage already a serious risk to spawning lampreys, climate change effects and the resultant increases in water temperatures earlier in the spring and summer could exacerbate lamprey declines. Thus, lamprey losses during migration to and reproduction in tributaries of the middle and upper Columbia River could render these populations functionally extinct.

These threats go hand in hand with an ill-fated misunderstanding in the nonscientific community that Pacific lamprey is not indigenous to the ecosystem, as is the case in the Great Lakes for the nonnative sea lamprey (Petromyzon marinus). The invasive sea lamprey has contributed to declines in local fisheries and created landscapelevel trophic effects (Clemens et al. 2010). This misconception has resulted in little attention and support being given to Pacific lamprey by the non-scientific community (Close et al. 2002).

In 2003, efforts to protect the Pacific lamprey via listing under the federal Endangered Species Act were denied due to lack of scientific evidence outlining historic and current abundance, population structure and trends, stock structure, and biology 
(Keefer et al. 2009b). Listing of the species would be a coup for scientists and managers in the region and could help increase populations of adult lampreys returning to freshwater to spawn, as we have seen with many other listed species in the past (CRITFC 2011).

The former discussion of species status, threats, gaps in understanding life history and biology provide a portrait highlighting the need for further research concerning the species. Without further scientific efforts the species could continue to decline in numbers and a shift in ecosystem function may become apparent. For these reasons it is imperative that these threats be addressed by the larger scientific community in hopes of restoring populations.

\subsection{Cultural Significance}

The persistence of Pacific lamprey since time immemorial has been of great importance to Native American tribes' subsistence and culture for thousands of years, with continuing significance in the present. In the past lamprey, referred to as eels, were used as medicine, traditionally harvested and prepared, featured in stories, and used in ceremonies and celebrations (Close et al. 2002). For example, when preparing lamprey after harvesting, they were first hung to dry. While drying, oil was collected from the skin and used as an ointment of sorts and partnered with purifying sweat ceremonies. The oil collected from the drying skin was also used in cooking, while the body of the fish was roasted and eaten. None of the fish was wasted. Since lamprey have a body fat content nearly three times that of salmon, their caloric value is very significant to tribal diets (Close et al. 2002; CRITFC 2011). 
Oral accounts of historical runs, distribution and abundance of Pacific lamprey prior to the existence of dams have been given by many tribal members. Elders have shared stories of returns numbering in the millions and reaching as far as Shoshone Falls on the Snake River at river kilometer (rkm) 1500 (Bonneville is rkm 235) (Keefer et al. 2009b; CRITFC 2011). Spawning grounds and harvesting sites were described as being black with eels (CRITFC 2011).

Tribes today still hold a deep bond and connection to the species. This deep bond stems from traditional ecological knowledge (TEK). TEK can be defined as, "a cumulative body of knowledge, practice, and belief, evolving by adaptive processes handed down through generations by cultural transmission, about the relationship of living beings with one another and with the environments, it is cumulative and dynamic, building on experiences and adapting to changes” (Senos et al. 2006). TEK requires complex knowledge that is gained through direct experience, thus fostering a relationship that is intimate and spiritual in nature. This bond with ecosystems and the knowledge it produces highlights certain species as being vital to cultural identity from ceremony to language. Coming from perhaps the most important tribal elder in lamprey restoration work, Elmer Crow of the Nez Perce tribe, who recently passed away, the native perspective on the decline of lamprey is that the loss of the species will create an unbalanced circle of life (CRITFC 2011). This embodies the cyclical nature of the way of life that many tribes practice in the region and the fear that losing lamprey will affect the whole ecosystem. 
Pacific lamprey, however, has been given very little attention by the scientific community or general public until recently. The attention that it has gained can be attributed to Native American tribes in the Pacific Northwest. The cultural importance of Pacific lamprey in the region has jump-started a movement to rescue and restore the species at large. Seeing as the species is now severely threatened and abundance has been declining for the last five decades (Moser et al. 2002a), harvest restrictions have been put in place and tribes have struggled to carry on their traditional practices (CRITFC 2011). The lamprey decline, and the factors that have led to it, threaten a loss of culture, language, and tradition. By limiting the tribes' ability to harvest and make use of this cultural keystone species, TEK and the associated cultural values, language, and traditions are not being passed down to the younger generations (Close et al. 2002). Sharing oral traditions is of utmost importance to carrying on TEK, but with very few places to give youth the experience with this species, elders fear that youth will lose interest. However, efforts to expose the youth to these traditions are still being made. Although harvesting areas have been severely limited, tribal members now travel the hundreds of miles required to collect fish when they return to freshwater in the summer months and then allow for elders to prepare them as they have been prepared for thousands of years and share stories of the fish (Close et al. 2002; CRITFC 2011).

These efforts, from a tribal perspective, aim to ensure that this vital resource is available for future generations (Close et al. 2002). The integration of TEK and science has allowed for the creation of initiatives and partnerships with state and federal agencies in the region that are essential in further restoration of the species (USFWS 2011). These 
would not be possible without the tribes' involvement in conservation and restoration projects and efforts. The study of Pacific lamprey and the knowledge that surrounds it is still in its conception. The species has not seen enough of an increase to have a substantial impact to date on contributing to tribal economies. And although cultural practices are still being carried out, tribal members are not satisfied. They must outlay an immense amount of time, money, and effort to maintain traditions and cultural practices involving lamprey (E. Crow 2013).

Currently tribes are engaged in many preservation and restoration efforts for Pacific lamprey populations. The Confederated Tribes of Warm Springs are carrying out a multi-year study at Willamette Falls to collect adult counts, which is of great importance because this location is one of the last and largest tribal harvest sites for lampreys (CRITFC 2011; Sheoships 2014). The Nez Perce, Umatilla, Warm Springs, and Yakama tribes have developed plans for tributary passage and habitat improvements. The Yakama Nation also has a Pacific Lamprey Restoration Project that varies from artificial propagation to looking at factors limiting juvenile lampreys in the Yakima Basin. The Umatilla tribe has also developed lamprey specific passage structures to address low elevation impediments to upstream passage, and is investigating juvenile entrainment effects, among other projects (Jackson and Moser 2012). The Yakama, Umatilla, and Nez Perce tribes all currently have translocation programs in place for adult lampreys. This effort in the Umatilla River began in 2000 with hopes of re-establishing populations that are severely reduced and, in some cases, functionally extinct. Educational outreach is also being developed and performed and will be vital for tribes in 
the basin to spread the word about this enigmatic, ecologically and culturally important species (CRITFC 2011). There is a suite of other projects being carried out, many of which are in partnership with federal and state agencies. This highlights the tribes' dedication and focus on the species, which is ultimately what brought Pacific lamprey to the attention of regional resource managers and scientists.

\subsection{Lamprey and Dams}

The creation of the Federal Columbia River Power System (FCRPS) and operation of hydroelectric dams presents perhaps the greatest threat to Pacific lamprey. Dams can slow migrating lamprey down by delaying passage and possibly reducing their fitness and energetic reserves. They also can expose them to increased predation (CRITFC 2011).

Lampreys must pass four hydropower dams to reach the Snake and upper Columbia rivers, five more to reach spawning grounds in the upper reaches of the Columbia, and four more to reach spawning grounds in the upper reaches of the Snake, thus fish are required to pass eight and nine dams on the Snake and Columbia rivers to reach spawning sites in the furthest reaches (Moser et al. 2002b). Fish are unable to pass upstream from Chief Joseph Dam on the Columbia and Hells Canyon Dam on the Snake as these dams do not possess any passage facilities (Figure 1.5.1) (Keefer et al. 2009b). With complete lack of passage facilities at such dams, populations of lamprey are in danger of extinction in the reaches above (Beamish and Northcote 1989). 


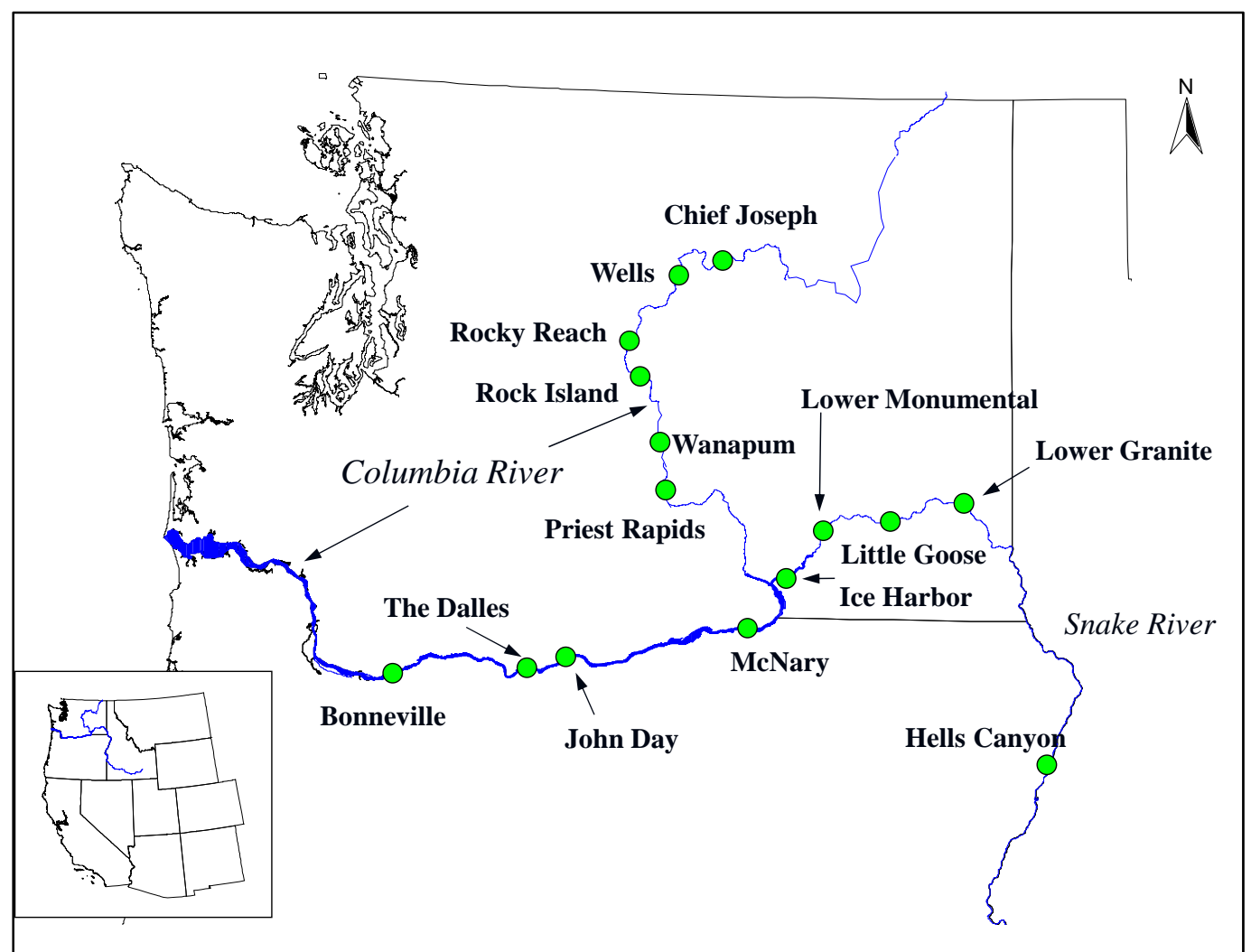

Figure 1.5.1 Dams of the Federal Columbia River Power System on the Columbia and Snake River (Courtesy of NOAA Fisheries)

Success at passing mainstem dams, however, is a challenge. Traditional fishways were designed for species with strong swimming capabilities that can endure high velocities, turbulent conditions, and negotiate sharp corners and edges (Johnson et al. 2012). These physical and hydraulic conditions impede lamprey passage (Keefer et al. 2013a). Although most Columbia and Snake river hydropower dam fishways have similar components, there are different features at each dam and even at different fishways at the same dam. Consequently, lamprey passage success through fishways is not the same for each individual fishway nor at each dam (Keefer et al. 2013a). Pacific lamprey exhibit distinctive swimming behaviors that prevent them from using these 
traditional fishways with ease. They use burst and attach behavior while swimming and exhibit vertical climbing in which they attach their oral suction disc to an attachment surface, rest briefly, shrink their body into a w-shape and gain the momentum to burst upward and reattach (Reinhardt et al. 2008; Zhu et al. 2011). This climbing behavior is unique to Pacific lamprey and has not been observed for any other species (Reinhardt et al. 2008). Lampreys using traditional fishways are forced to attach on the bottom or sides and attempt to make their way up the channel using their unique burst and attach methods. The fishways often lack adequate attachment surfaces and thus lampreys have trouble navigating these sections (Moser et al. 2002b).

From 1997 to 2000 lampreys were evaluated passing through traditional fishways at Bonneville and The Dalles Dams using radio tags. At Bonneville Dam passage efficiency was $38-47 \%$ with a median passage time of 4.4 to $5.7 \mathrm{~d}$, compared to salmonid passage efficiency of 96\% in $1996(\mathrm{n}=837)$ with a median passage time of $1.0 \mathrm{~d}$ (similar results for salmonids in following years). Lamprey passage efficiency at The Dalles Dam was $50-82 \%$ and median time was 2.0 to $4.0 \mathrm{~d}$. At Bonneville Dam, $60 \%$ of lampreys made multiple attempts after failure to enter the fishway (Moser et al. 2002a, 2002b). In the same study, lamprey had the highest difficulty navigating collection channels and transition areas due to lack of adequate attachment surfaces. They also were obstructed by count station areas. Similarly, another study found 51\% passage efficiency of tagged lamprey at Bonneville Dam over 10 years, with increased passage at night, and multiple entrances after failures (Keefer et al. 2013b). That study found that lamprey passage increased as flow decreased and temperature increased (up to $20^{\circ} \mathrm{C}$ ). 
PIT tag studies have shown very low dam passage over the multiple successive mainstem dams, especially as fish move farther up the Columbia River. Studies have found as low as $<5 \%$ of fish passing the four lower Columbia dams and $<1 \%$ reaching the Snake River (Figure 1.5.1). A great deal of quality spawning and rearing habitat is not being reached beyond the lower mainstem of the Columbia River, likely due to poor passage at dams (Johnson et al. 2012; Keefer et al. 2013a). Migration is a fundamental component of the lamprey life cycle and thus addressing barriers to migration and solutions to barriers is vital to the survival of this species (Moser et al. 2002a). Poor passage at mainstem dams by Pacific lampreys, especially at Bonneville Dam (the first mainstem dam they encounter), and declining counts prompted the creation of lamprey specific passage structures.

\subsection{Lamprey Passage Structures}

Lamprey-specific passage structures were designed and tested both in the lab and in the field at Bonneville Dam over a 5-year period in compliance with federal, state, and tribal fisheries managers. Doing so allowed for testing and improvement of specific elements, prototypes, and designs (Moser et al. 2011a). Such structures are called Lamprey Passage Structures (LPSs). LPSs are designed specifically to take advantage of lamprey swimming and climbing behavior, provide adequate attachment surfaces, and appropriate velocities (Moser et al. 2011a, 2011b). When passing the dam via an LPS, lamprey must climb the structure via a number of aluminum wetted vertical ramps (supplied with water by upwelling boxes), resting boxes, and horizontal flumes. The LPS can lead lamprey all the way from the downstream side of the dam to forebay level above 
the dam (Corbett et al. 2013; Reinhardt et al. 2008). There are currently three LPSs at Bonneville Dam that allow lampreys to pass from downstream locations at the dam to the forebay level upstream of the dam (Figure 1.6.1).

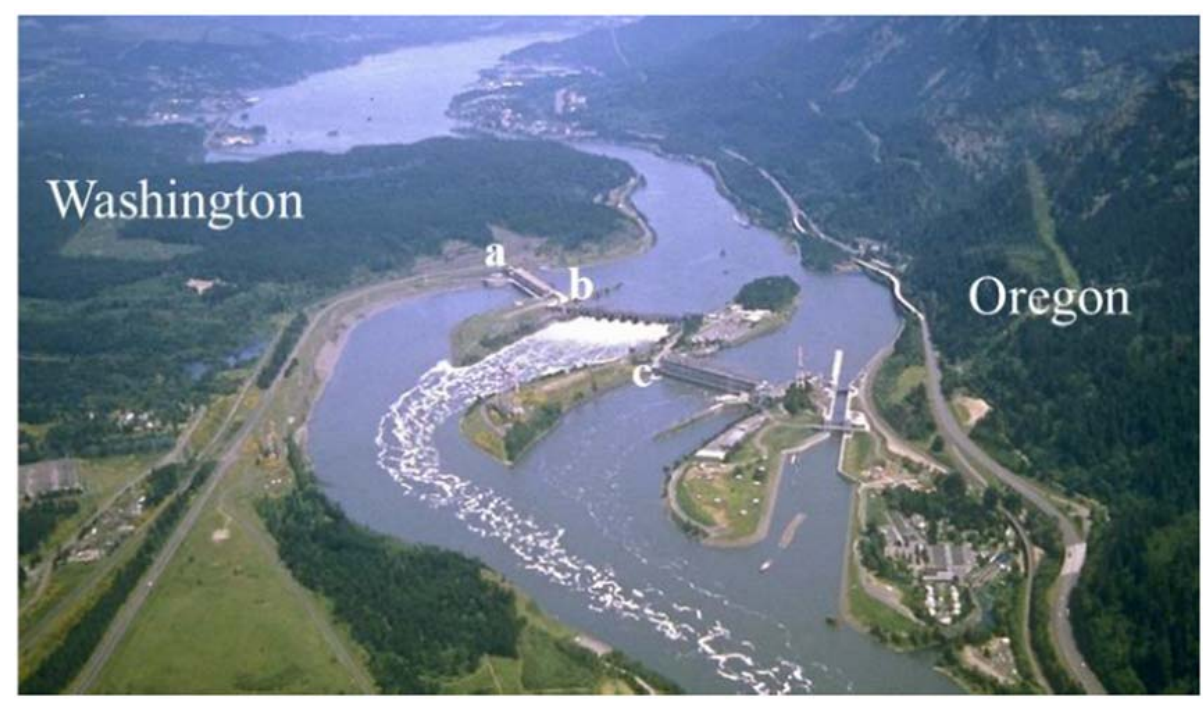

Figure 1.6.1 Aerial view of Bonneville Dam with approximate locations of LPSs - a) Washington Shore LPS, b) Cascades Island LPS, c) Bradford Island LPS (Source: Corbett et al. 2013)

\section{Bradford Island LPS}

The first LPS installed at Bonneville Dam was the Bradford Island LPS (BI LPS) in 2004. The overall length of the structure was $35.6 \mathrm{~m}$ with a slight elevation gain and consisted of two entrance ramps, several $45^{\circ}$ ramps, rest boxes, horizontal flumes, and a PVC exit slide that led to a volitional exit into the forebay at Powerhouse 1. The LPS was located in an auxiliary water supply channel (AWS) at Bradford Island and was supplied by water pumped from the forebay (Figure 1.6.2). In the years following installation, passage in the LPS by lampreys that entered was $90-100 \%$, with a median passage time of $1 \mathrm{~h}$ (Corbett et al. 2013). 


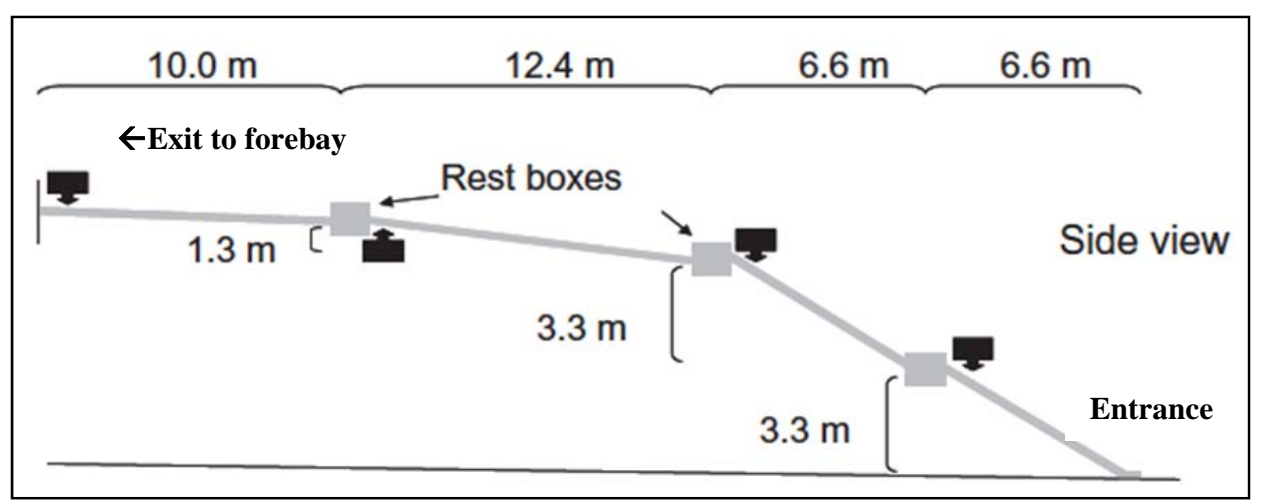

Figure 1.6.2 Side view of Bradford Island LPS showing vertical and horizontal lengths and rest boxes (Source: Moser et al. 2011a)

\section{Washington Shore LPS}

The installation of the second LPS at Bonneville Dam was prompted by the high passage efficiency rates at the BI LPS mentioned previously. In 2007 the Washington Shore LPS (WAS LPS) was installed. The overall length of the structure was $19.0 \mathrm{~m}$ with a 9.0 m elevation gain and consisted of two entrance ramps, several aluminum $45^{\circ}$ ramps in a switchback design, rest boxes, and a PVC exit slide that led to a volitional exit into the forebay at Powerhouse 2. Located in an AWS channel at Washington shore fishway, the LPS was supplied by river water by pumps in the upper part of the fishway (Figure 1.6.3). In the first few years of operation the passage efficiency was 90-100\%, and then dropped to 71-80\% (Moser et al. 2011a; Corbett et al. 2013).

Although it is unclear why the change in passage efficiency occurred at WAS LPS, improvements continue to be made following monitoring in each year. Some of these improvements include installing refuge boxes for lampreys to rest in as they make their way through the AWS to the LPS, and extending exit slides to prevent fallback after 
exiting the structures (Corbett et al. 2013). Different ramp angles and flow velocities were also tested at BI LPS and the results indicated that steeper angles and lower water flows provided the best conditions for lamprey climbing the structure (Reinhardt et al. 2008).

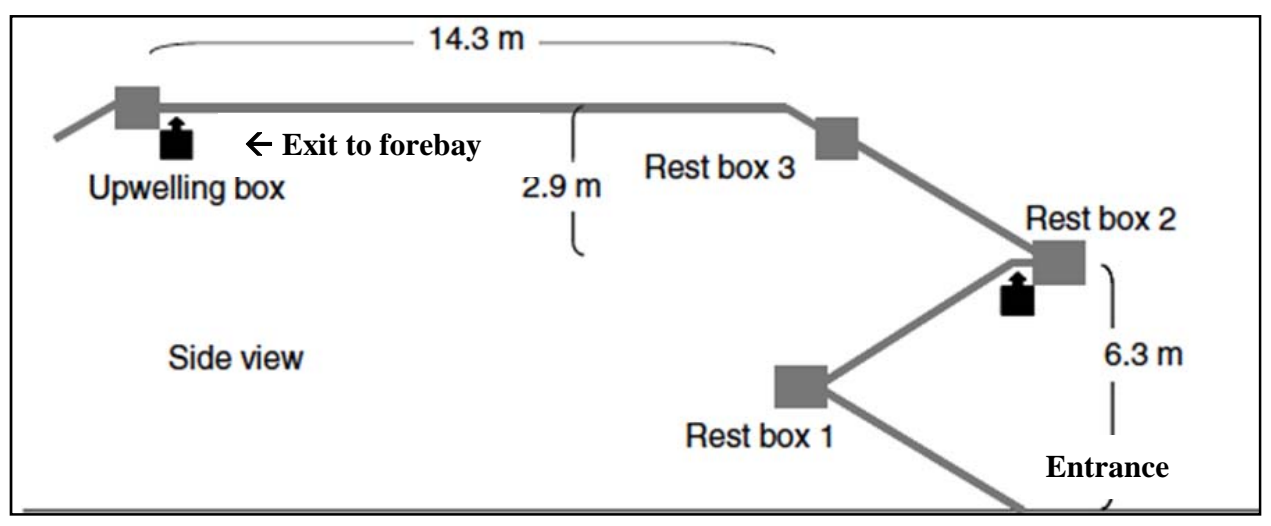

Figure 1.6.3 Side view of Washington Shore LPS showing vertical and horizontal lengths, location of rest boxes, and the upwelling box (Source: Moser et al. 2011a)

\section{Cascades Island LPS}

The success of both the BI LPS and WAS LPS prompted the installation of the Cascades Island (CI) LPS in 2009. From 2009 until 2012 it was operated as an experimental structure. The overall length of the structure during this time was $92.4 \mathrm{~m}$ with an elevation gain of $27.0 \mathrm{~m}$ and it was located in the Cascades Island fishway, which is adjacent to the spillway (Figure 1.6.4).

The CI LPS consisted of a series of aluminum ramps from $45^{\circ}$ to $60^{\circ}$ in a switchback and climbing design, and six resting boxes allowing lamprey to rest in dark pools as they traveled from the tailrace to the forebay level. At forebay level it ended in a terminal trap/upwelling box that provided river water to the structure via submersed 
pumps (Figure 1.6.2). Fish were collected daily and transported via truck $13.0 \mathrm{~km}$ upriver and released. Despite being the longest and steepest LPS with the most directions changes of any LPS, usage in 2012 increased $(n=2,472)$ providing support for the idea that a volitional exit was needed to eliminate handling stress associated with lamprey transport (Corbett et al. 2013).

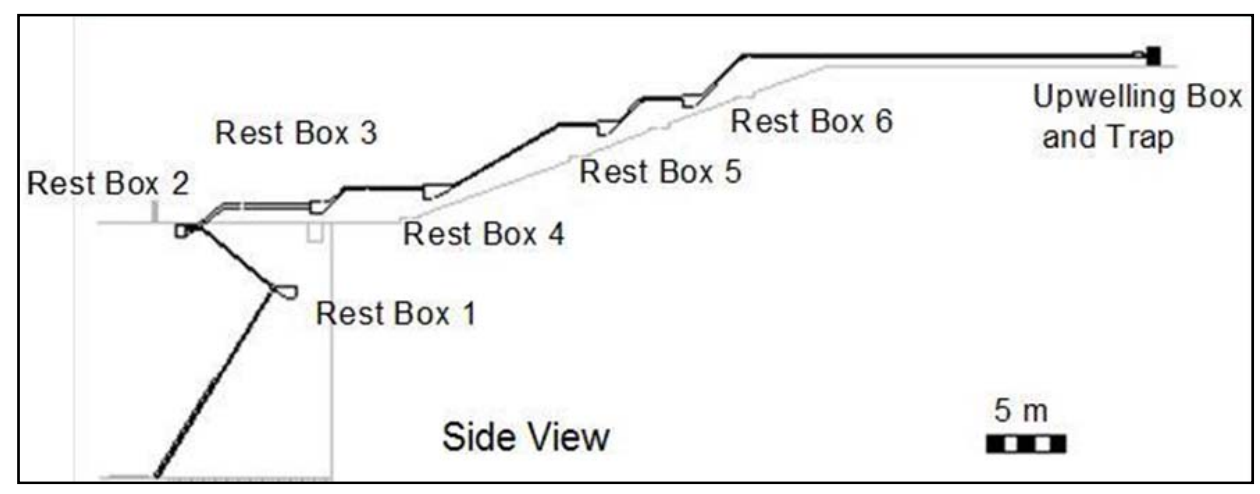

Figure 1.6.4 Side view of Cascades Island LPS (2009-2012) including locations of six resting boxes and the upwelling terminal trap box. The tailrace of the dam is below Rest Box 1 and the forebay level of the dam is at the Upwelling Box and Trap (Corbett et al. 2013)

So, in 2013 the terminal trap was removed and replaced with an approximately 70.0 m exit pipe constructed of $25.4 \mathrm{~cm}$ diameter PVC. The trap was removed and a new structure was installed in its place at forebay elevation. It still served to pump water to the bottom portion of the structure. Another upwelling box was installed at the distal end of the exit pipe to supply water from the forebay to the upper portion of the structure via submersible pumps. The structure ended in a $10.0 \mathrm{~m}$ exit slide, which employed a switch-counter on the exit door to record the number of fish using the LPS. These additions made it possible to avoid excess handling of fish by allowing them to exit directly from the LPS into the forebay above the spillway, mimicking a more natural path 
of travel, and making this the first full-elevation volitional passage LPS. As a result fish are now able to travel from the tailrace of the dam over the spillway exiting into the forebay above (Figure 1.6.5) (Corbett et al. 2013).

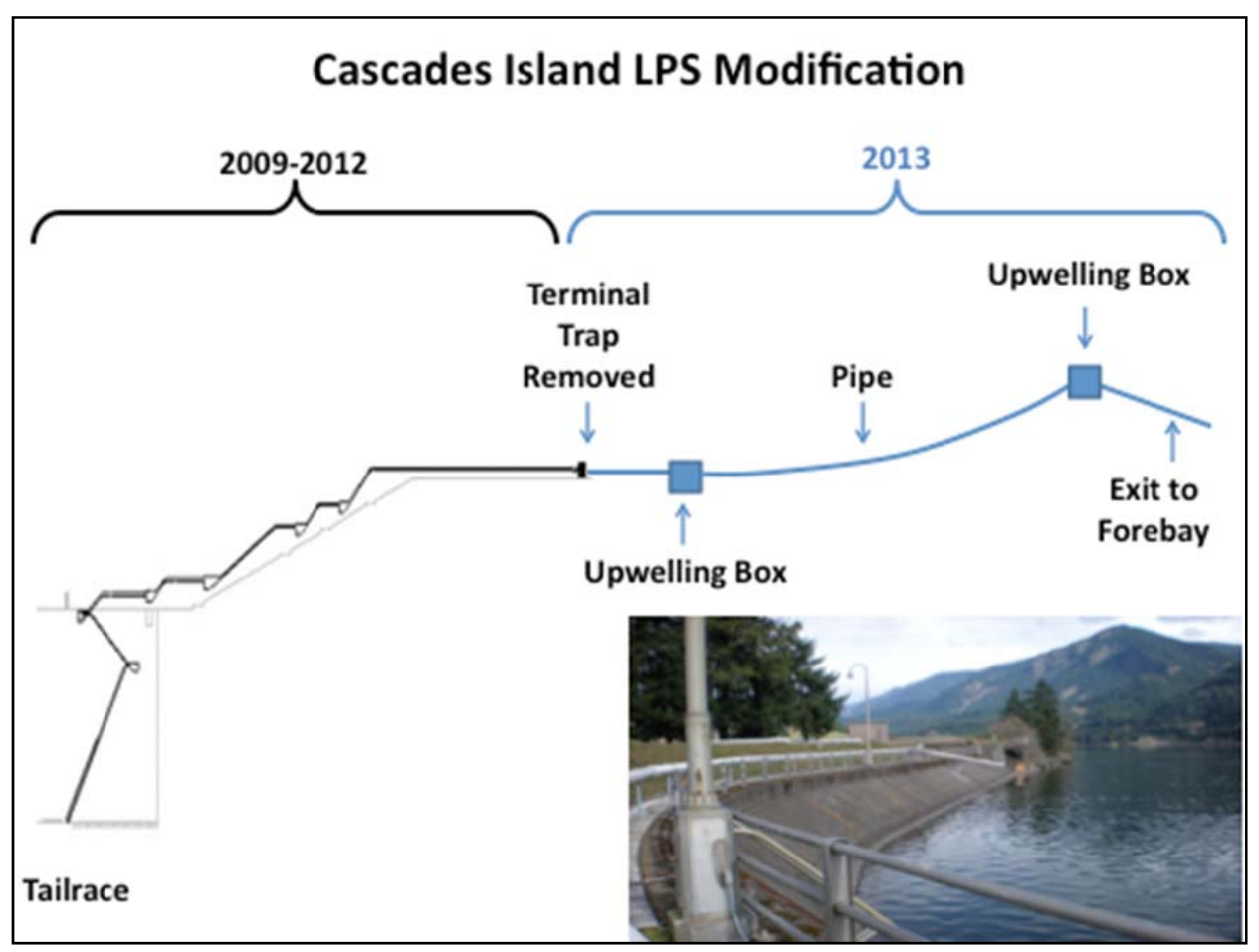

Figure 1.6.5 Side view of Cascades Island LPS depicting the structure during experimental operation from 2009-2012 and the addition of the upper portion including the upwelling boxes, the pipe, and the exit to the forebay, with a picture showing the exit pipe emptying into the forebay (Courtesy of NOAA Fisheries)

\subsection{Study Objectives}

The CI LPS was modified prior to the lamprey migration season in 2013 to imitate a more natural path of travel for lamprey. The structure, however, is a new design at Bonneville Dam and the longest and steepest of its kind in the region (Corbett et al. 2013). Therefore, it is relatively unknown the effects such a modification might have on lamprey behavior and fitness. My study was carried out to evaluate several aspects 
pertaining to the modifications of the structure and how it might affect lamprey use of the LPS and migration behavior following passage. Several objectives were addressed to answer questions and look at any significant affects the modifications may have produced; results may inform further modifications or lead to the installation of other structures of this kind.

The main objectives of the study were to: (1) assess lamprey use of the CI LPS. Specifically, I addressed these questions: (a) what is the overall passage efficiency; (b) how much time do fish spend in the structure; (c) what is the relationship between morphology of fish and travel time in the structure; (d) what is the relationship between environmental factors and travel time in the structure; and (e) do different tagging types have an effect on fish ability to use the structure? And (2) assess if the CI LPS affects lamprey ability to migrate upstream. Specifically, I addressed these questions: (a) how many fish that use the CI LPS migrate through the Bonneville reservoir; (b) how much time does it take fish to migrate through the Bonneville reservoir; (c) what is the relationship between morphology of fish and travel time through the Bonneville reservoir; (d) what is the relationship between environmental factors and travel time through the Bonneville reservoir; (e) does tagging have an effect on migration through the Bonneville reservoir; and (f) are fish migrating upstream from The Dalles Dam? 


\section{Chapter 2: Methods}

\subsection{Study Area}

This study took place on a section of the Columbia River in Washington and Oregon beginning at Bonneville Lock and Dam, located at rkm 235.1. This is a run-ofriver power and navigation dam that extends across three channels, separated by two islands, from the Oregon to Washington border, and consists of two powerhouses, separated by a spillway (Figure 2.1.1) (Keefer et al. 2013b). The primary focus of the study took place at the Cascades Island (CI) LPS, located adjacent to the spillway at the dam (Figure 2.1.1). Tagged fish that successfully passed the CI LPS during the study were then assessed to see if they traveled through the Bonneville reservoir and were detected at The Dalles Dam (Figure 2.1.2); any fish that traveled beyond The Dalles Dam were also assessed (Figure 1.5.1 - see Chapter 1.5 Lamprey and Dams). 


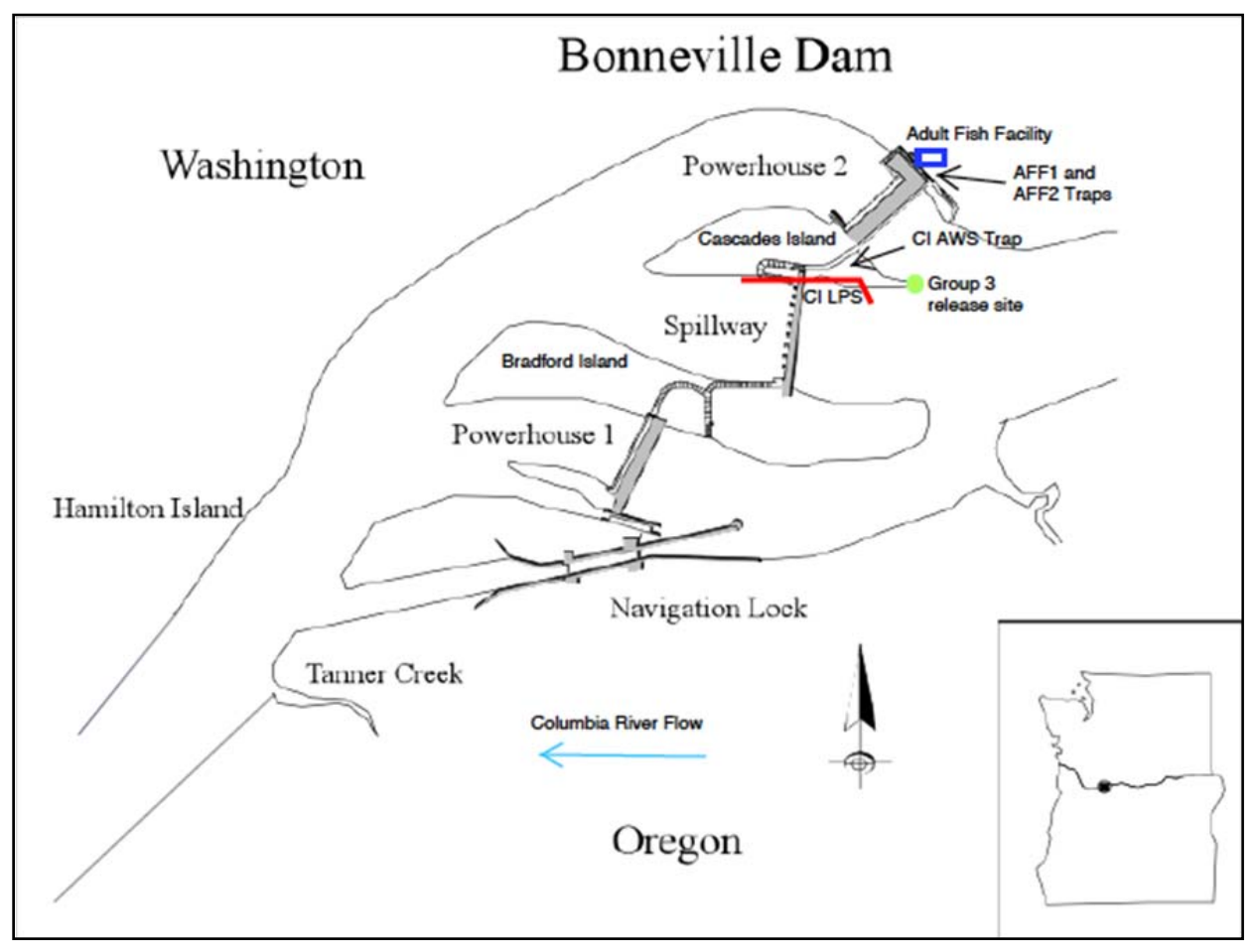

Figure 2.1.1 Overhead view of Bonneville Dam - Cascades Island LPS highlighted in red, Group 3 release site at the end of Cascades Island (green dot), the Adult Fish Facility outlined in blue, and trap locations identified with arrows (structures and locations not drawn to scale, Courtesy of NOAA Fisheries, modified 2014)

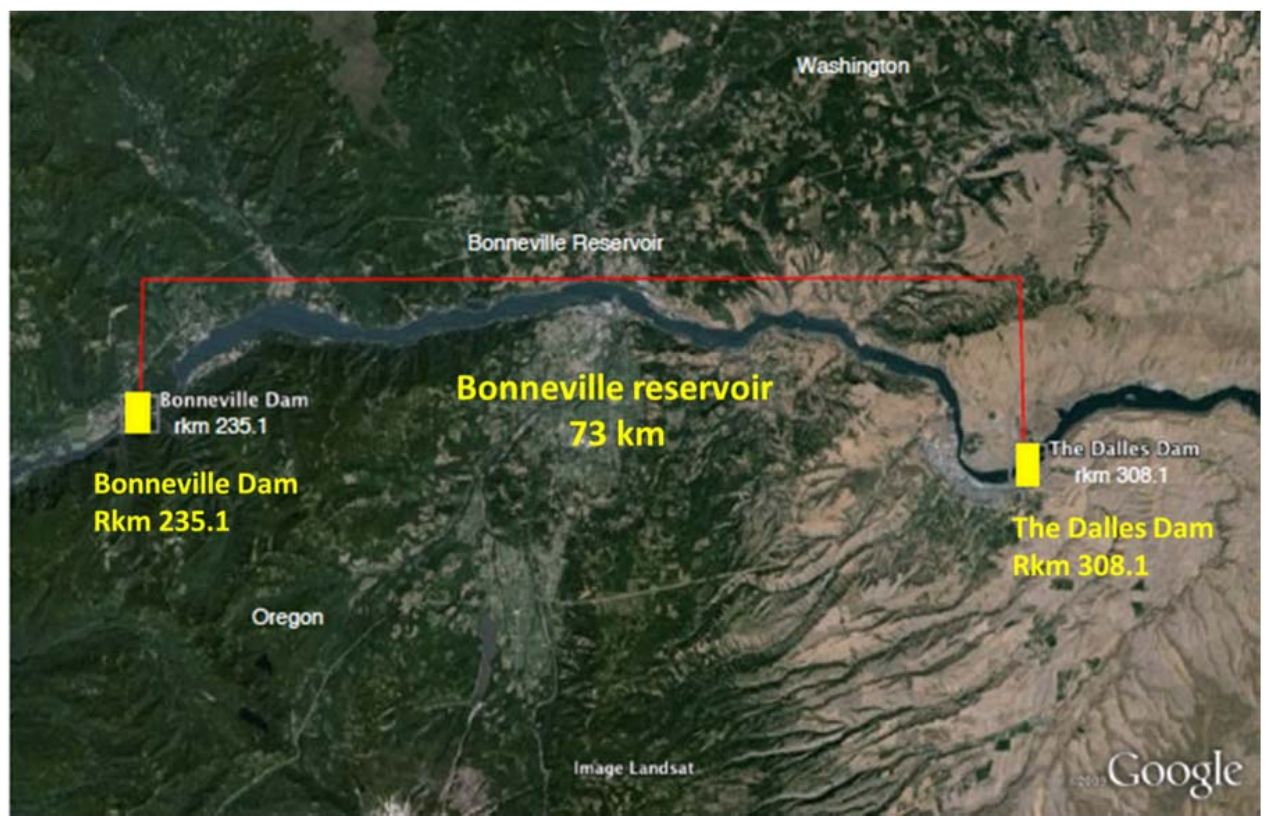

Figure 2.1.2 Image of Bonneville Dam at rkm 235.1, The Dalles Dam at rkm 308.1, and the area considered Bonneville reservoir highlighted (Google Earth) 


\subsection{Study Design}

Prior to the tagging season, permits were obtained from the Washington Department of Fish and Wildlife (WDFW) for 75 fish to be collected, tagged, and released for the purposes of this study (WDFW Fish transport application/permit \#609904-13,WDFW WA State Scientific Collection Permit \#13-153A) . An online course for animal surgical and handling protocols was completed and permission for animal use was granted through the University of Idaho Animal Care and Use Committee (UIACUC Protocol 2012-37 Improving Adult Pacific Lamprey passage and survival at lower Columbia River dams - 2013).

In order to utilize 75 fish the study was divided into five releases, each release consisting of fifteen fish. Within each release, the fifteen fish were divided into three treatment groups: Group 1 was double tagged (received both a passive integrated transponder (PIT) and radio tag) and was released into resting box 3 of the LPS thereby traveling through the upper portion of the structure, Group 2 was single tagged (received only a PIT) and was also released into resting box 3 to travel through the upper portion of the structure as well, and Group 3 was double tagged and released at the end of Cascades Island, thereby bypassing the structure entirely (Table 2.2.1, Figure 2.2.1) 
Table 2.2.1 Study design identifying tag type, release site, and numbers of fish in each Group and Release $(\mathrm{n}=75)$ for the Cascades Island study at Bonneville Dam in 2013

\begin{tabular}{|c|c|c|c|c|c|c|c|c|}
\hline & Tag type & Release site & $\begin{array}{c}\text { Release } \\
1\end{array}$ & $\begin{array}{c}\text { Release } \\
2\end{array}$ & $\begin{array}{c}\text { Release } \\
3\end{array}$ & $\begin{array}{c}\text { Release } \\
4\end{array}$ & \begin{tabular}{|c|} 
Release \\
5
\end{tabular} & $\begin{array}{c}\text { Total } \\
\text { Release }\end{array}$ \\
\hline Group 1 & $\begin{array}{l}\mathrm{PIT} \text { tag + } \\
\text { radio tag }\end{array}$ & $\begin{array}{c}\text { CI LPS - rest } \\
\text { box } 3\end{array}$ & $n=5$ & $n=5$ & $n=5$ & $n=5$ & $n=5$ & $n=25$ \\
\hline Group 2 & PIT tag & $\begin{array}{c}\text { CI LPS - rest } \\
\text { box } 3\end{array}$ & $n=5$ & $n=5$ & $n=5$ & $n=5$ & $n=5$ & $n=25$ \\
\hline Group 3 & $\begin{array}{l}\text { PIT tag + } \\
\text { radio tag }\end{array}$ & $\mathrm{Cl}$ - forebay & $n=5$ & $n=5$ & $n=5$ & $n=5$ & $n=5$ & $n=25$ \\
\hline $\begin{array}{l}\text { Total } \\
\text { Group }\end{array}$ & & & $n=15$ & $n=15$ & $n=15$ & $\mathrm{n}=15$ & $\mathrm{n}=15$ & $n=75$ \\
\hline
\end{tabular}

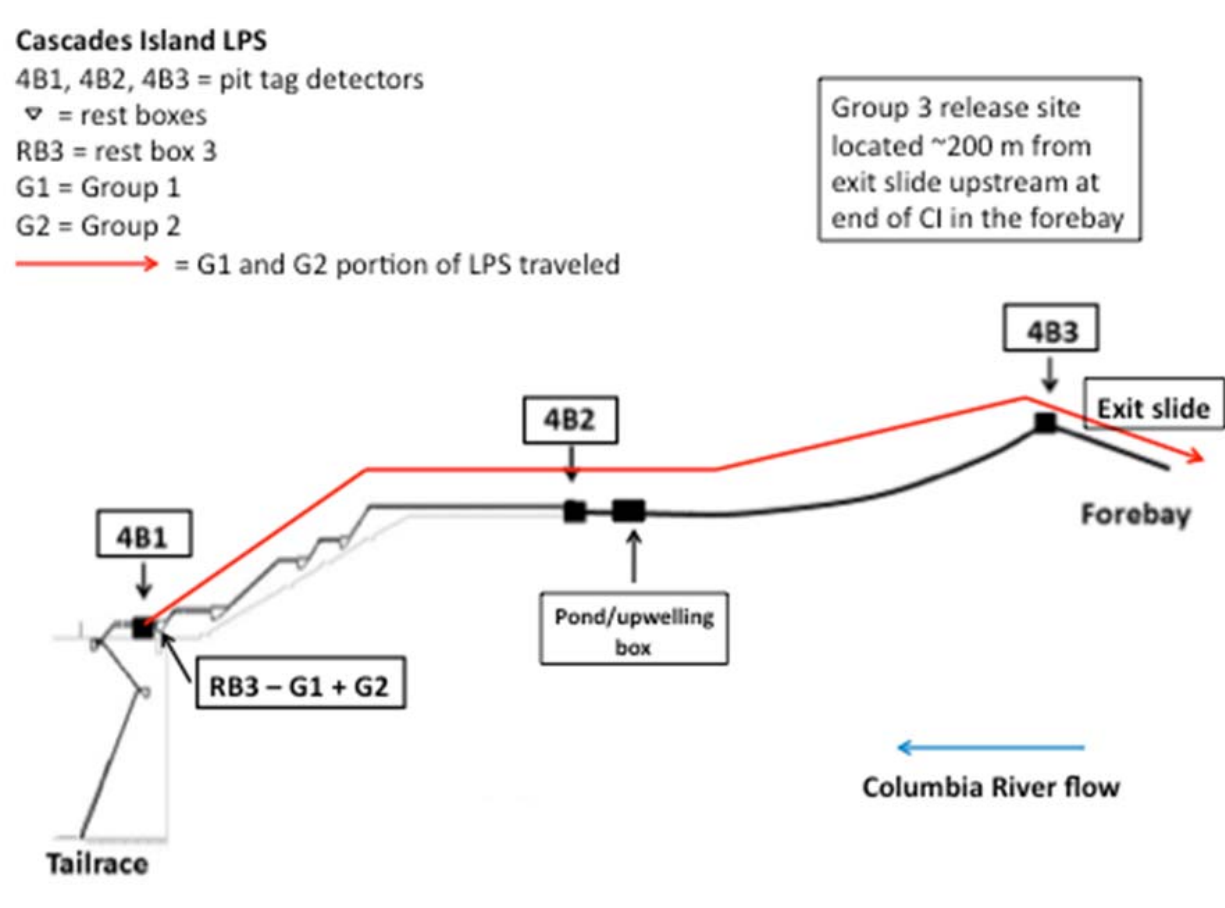

Figure 2.2.1 Side view schematic of CI LPS 2013 study design 
Each treatment group was designed to address different objectives and possible effects of tagging and structure impedance. Group 1 and 2 were released into rest box 3 of the CI LPS to evaluate LPS passage time and efficiency. Group 1 was PIT and radio tagged, and Group 2 was PIT tagged only to test for possible effects of radio tagging on lamprey behavior in the LPS. Group 3 was released $\sim 200$ m upstream from the CI LPS exit slide to test for an effect of the LPS on lamprey ability to travel upstream; this group was PIT and radio tagged.

\subsection{Lamprey Collection}

Fish were captured on five nights spanning the lamprey migration season using passive weir traps or portable funnel traps deployed overnight in the Washington-shore fishway ladder directly adjacent to the Adult Fish Facility (AFF1 and AFF2) or the Cascades Island (CI) Auxiliary Water Supply (AWS) Channel, respectively (Figure 2.1.1 - see Chapter 2.1 Study Area). Passive traps were metal with dimensions $0.6 \mathrm{~m}$ x $0.8 \mathrm{~m}$ $\mathrm{x} 0.8 \mathrm{~m}$ and were lowered into fishways and submerged under water. They were positioned as close to the wall of the fishway as possible (Moser et al. 2002a). The traps were pulled up and checked each following morning around 07:00 am. If the trap being checked contained fish, it was emptied into a 5-gallon $(20 \mathrm{~L})$ plastic bucket or a $57.0 \mathrm{~L}$ plastic cooler and transported to the Adult Fish Facility (AFF) (Figure 2.1.2 - see Chapter 2.1 Study Area). At the AFF, the collected fish were transferred to $1.1 \mathrm{cu} \mathrm{m}$ aluminum tanks containing flow-through river water, equipped with separators to create three holding areas. Fifteen fish were then chosen at random and placed in a compartment of a holding tank, where they were then separated into two different sections: Group 1 and 2 
were held together and Group 3 was held separately, according to the previouslydiscussed experimental design. The rest were placed in a different holding tank and used for studies being carried out by the University of Idaho and NOAA.

\subsection{Tagging}

Fish were collected from traps in the morning and tagged in the afternoon on five dates: July 10, July 16, July 24, July 31, and September 11 of 2013. After fish were separated (as described in 2.3 Lamprey Collection) they were allowed to rest for 3-6 $\mathrm{h}$ prior to surgery.

Half-duplex passive integrated transponder (PIT) tags measuring 4x32 mm and 0.8 g made by Texas Instruments were surgically implanted in all 75 fish (Figure 2.4.1). Indefinite PIT tag life allows researchers to track movement over the life history of many fish species as tagged fish pass within the range of a detector (typically $<10 \mathrm{~cm}$ ).

Radio tags (Lotek Wireless Inc. Model NTC-4-2L, measuring 18.33 mm in length, $8.33 \mathrm{~mm}$ in diameter, and weighing $2.1 \mathrm{~g}$ in water, were surgically implanted in 50 of the fish; each tag transmitted a unique code (Figure 2.4.2). The tag life for this model of tag is 77-456 d (depending on burst frequency); however, these tags were leftover from a previous year's tagging season and so may have experienced a shorter tag life. Radio telemetry is useful for studies such as these due to its ability to capture continuous data when a tag is within the range of a receiver. Thus, the data collected by radio receivers is at a broader spatial scale than that of PIT tag receivers, as receiver range is much greater (up to $500 \mathrm{~m}$ ). 

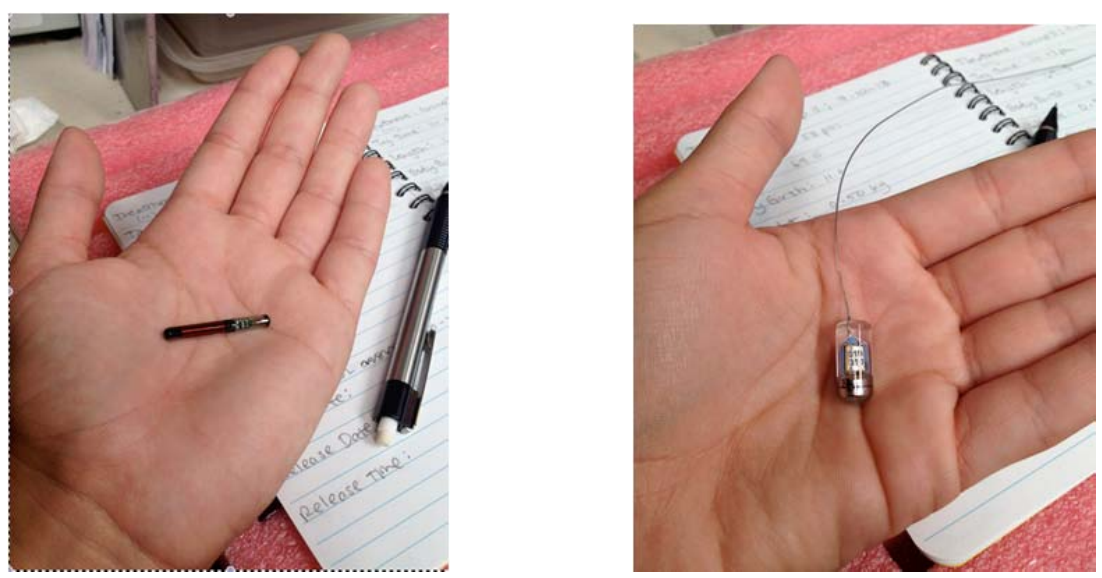

Figure 2.4.1 (Left) Half-duplex passive integrated transponder (PIT) tag implanted in all study fish ( $\mathrm{n}=75$ ) for the CI LPS Study in 2013

Figure 2.4.1 (Right) Radio tag model NTC-4-2L implanted in Group 1 and Group 3 study fish (n=50) for the CI LPS Study in 2013

Fish were anaesthetized for tagging purposes by combining 4.5 milliliter clove oil (eugenol) with approximately 50 milliliter river water in a bottle and vigorously mixing the two to emulsify the oil. This mixture was added to approximately 30 liter of river water in a 57 liter container. Fish were held three at a time in this anaesthetic bath for 5 minutes. When fish were adequately anaesthetized they were removed from the container one at a time to be physically characterized. Prior to surgery fish size was measured and recorded for length to the nearest millimeter (mm), girth to the nearest $\mathrm{mm}$, weight to the nearest gram (g), and any abnormalities were observed and noted.

Once this information was recorded, two different surgeries were required for the different treatment groups in each release. Tools and tags used for the surgeries were sanitized in zephyran chloride solution and rinsed off in water before use. Incisions were made 1 centimeter $(\mathrm{cm})$ off the ventral midline with a 3-mm scalpel according to methods in Moser et al. (2002a) and Johnson et al. (2012). Incision length was dependent on 
which tag was to be implanted. Fish that had only a PIT tag, Group 2, required an incision of around $1.5 \mathrm{~cm}$ and no suture. Fish that received both a PIT and a radio tag, Groups 1 and 3, required a larger incision of around $3.0 \mathrm{~cm}$. PIT tags were inserted first, and then the radio tag and its antenna was threaded through the body wall approximately $3 \mathrm{~cm}$ behind the incision with a cannula. The incision was then closed with a 19-mm needle and 3-4 stitches performed with absorbable surgical suture using simple interrupted surgeon's knots (Moser et al. 2002b). Following tagging, fish were placed back in respective holding tanks to recover for approximately 6-8 hours (h) prior to release.

\subsection{Release}

Fish were released at nightfall. The time between tagging and release (6-8 h) was allowed partly in an attempt to minimize the effects of surgery. It also allowed for the release time to be at nightfall (i.e. in darkness) in hopes that fish would be encouraged to pass the LPS due to their known nocturnal activity patterns at dams (Keefer et al. 2013c).

Originally all releases were planned within a five-week period to avoid possible effects of environmental variability. However, the final release had to be postponed for over a month due to water temperatures above $21.0^{\circ} \mathrm{C}$. According to the U.S. Army Corps of Engineers, this temperature mandates a stoppage of fish handling as it exceeds safe tagging protocols for adult lampreys (Keefer et al. 2009a). Increased water temperatures such as those that postponed the final release for all of August and part of September cause lamprey to experience high amounts of stress and require a great deal of expended energy and can cause mortality (Clemens et al. 2009; USFWS 2011). The 
dates of release were the same as the dates of tagging as follows: July 10, 16, 24, 31, and September 11. The time of releases varied very little between the first four releases in July, with all taking place between $21: 10$ and 21:36. The final release took place at 20:32, nearly an hour earlier due to earlier nightfall.

\subsection{Monitoring}

Using a combination of radio and PIT tags allowed for detection via an existing arrangement of fixed-site antenna arrays for both PIT tags and radio tags at multiple sites in the Columbia River Basin. These arrays exist at different points in fishways at each dam, dam tailraces, and at the mouth of major tributaries (Moser et al. 2002b). There are over 150 fixed-site radio receivers (Lotek Wireless Inc. SRX400) in the Basin equipped with either a four- or nine- element aerial antenna or underwater antennas (Moser et al. 2002b). An additional fixed-site aerial antenna was positioned at the end of Cascades Island at the Group 3 release site for the duration of the study. A mobile tracking receiver was charged prior to each release, placed in a protective box for overnight data collection ( $\sim 12 \mathrm{~h}$ beginning at the time of release) at the site of Group 3 release at the end of CI (Figure 2.1.1 - see Chapter 2.1 Study Area), and then collected each morning for mobile tracking purposes (note this fixed site was not in place for the first release). Radio receivers collect and log date and time information when fish with radio tags are within their reception area. A larger number of radio receivers, covering a large spatial area allowed for nearly continuous observations of fish locations for those within detection distance. There are over 90 PIT tag detectors that were available for tracking purposes in this study that also log continuously. They record the date and time as tagged 
fish pass by their detection field, but fewer arrays and extremely limited fields of detection don't allow the near-continuous observations of fish movement and locations that can be obtained from radio tags.

Passage time and fallback in the CI LPS were assessed via PIT detectors in the structure that were immediately downstream from the release location in Rest Box 3, at forebay elevation (at the pond - Figure 2.2.1 - see Chapter 2.2 Study Design), and at an end point just before the exit slide; incidence of fallback over the spillway following volitional exit or release at the end of CI were assessed via radio receivers at the tip of Cascades Island and downstream from the dam. Migration travel time to subsequent upstream dams was assessed by detections at PIT detectors and radio receivers at The Dalles Dam, John Day Dam, McNary Dam, Priest Rapids Dam, Wanapum Dam, and Rocky Reach Dam, as well as at several major tributaries. Although most of the information is present in the data collected for dams reached upstream from Bonneville Dam, route of passage, time to pass, fallback, and type of structure used were not assessed, because of attrition of lampreys in these reaches decreasing the sample size substantially. Instead, I noted whether fish reached a dam beyond Bonneville Dam and the associated travel time.

\subsection{Data Collection and Analysis}

Physical characteristics and tag information for each fish were recorded during tagging procedures on data sheets that were then transcribed into Excel spreadsheets. Field notes were taken on the morning and evening of releases and pertained to fish collection, tagging, and release, and any other comments necessary. Variables that were 
considered and collected during each release were date, time, and water temperature measured in the LPS moments prior to release with a hand-held thermometer. The velocity in the LPS was obtained via personal communication with a University of Idaho student taking direct measurements from the structure. Environmental data were obtained for the day of each release, for each day over the course of the study that fish were released, traveled through the LPS, and through Bonneville reservoir, and for each week over the duration of the study. Average daily water temperature $\left(\mathrm{C}^{\circ}\right)$ measured in the Bonneville forebay, were obtained from the University of Washington’s Columbia Basin Research site, (http://www.cbr.washington.edu/dart). Average daily flow (thousand cubic feet per second), measured $1.6 \mathrm{~km}$ downstream from The Dalles Dam was also obtained from the University of Washington's Basin Research site. Hourly data for days spanning the study duration for these factors (water temperature, flow) were also collected to calculate a weekly average for reservoir characterization purposes (http://www.cbr.washington.edu/dart). Day length (h) was obtained from the United States Naval Observatory site for Cascade Locks, OR (8.69 km upstream of Bonneville Dam, http://aa.usno.navy.mil/data/docs/Dur_OneYear.php). These data were combined with the previous environmental and physical variables and transcribed to Excel files corresponding to the respective release date and individual fish.

Data from PIT tag detectors on the CI LPS and the fixed-site radio receiver at the end of Cascades Island were downloaded every 1-2 weeks and transferred electronically to databases maintained by the University of Idaho (PIT database) and NOAA Fisheries (radiotelemetry database). PIT detection data were downloaded and provided by the 
University of Idaho as a .txt file and converted to Excel. These detection data included the entire drainage starting at Bonneville Dam and extending up the river system all the way to Priest Rapids Dam. It was received as a "general migration file" and queried for the 75 unique codes that corresponded to my study fish. The relevant lines of data were transferred to a new sheet in Excel where columns that were unnecessary for analysis were removed and/or hidden.

Processed radiotelemetry data were first downloaded as raw data from every radio receiver on the river system from Bonneville Dam to Priest Rapids Dam and provided by NOAA Fisheries as a .txt file that was then converted to .csv form in Excel. The noise records that had not already been identified were then removed. Noise records were any record coded as "999" which signified several fish in the range of the receiver interfering with each other as well as radio interference from other sources. Detections that occurred before the release date and time were also removed. These occurred when the receiver was turned on near the buckets with tagged fish prior to their release. Detections of fish not in this study were also removed. All omitted records were kept in a separate Excel document for future reference.

After noise records were omitted, this file was saved as a .csv database where all records were assigned to individual tagged fish and were considered the clean detection data; this database included 340,000 lines of data. The database was consolidated to a compressed form of the data where a single line of data contained detections for individual fish with no gap greater than 5 min at a specific site/receiver. These 
summarized lines of data were then transferred to an Excel database where columns that were unnecessary for analysis were removed and/or hidden.

Once these three databases were created, all necessary files for analysis were accessible and could be merged, copied, and manipulated as needed. At this point classification of fish movement could begin. A glossary of terms was created that defined what abbreviations meant for certain characteristics, metrics, and sites of fish movement. These abbreviations were used to chronologically code individual fish movements corresponding with the radio and PIT data in each sheet.

Certain lines of radio tag data were not counted as true detections and were omitted by the final evaluator on the basis of their improbable location and/or the number of continuous detections from a given radio receiver. For example, detections at the receiver at the entrance of the CI LPS were not counted if there were less than 10 continuous detections; in this case they were considered noise from tagged lamprey residing in the resting box or experiencing partial fallback in the structure. In contrast, radio receivers that were in locations other than at the dams, namely at tributary mouths or locations on the river bank, were counted as true detections with as few as three hits if they made sense in the time frame and in the sequence of fish movement due to the fact that these receivers with aerial antennas were detecting fish at a great distance in a relatively noise-free environment.

From the chronologically-coded individual fish records one master sheet was created to combine environmental, morphological, and physical movement metrics of study fish. Considering the robust amount of data present for all 75 fish, the data could 
be broken down in many different ways to look closer at particular factors, fish, metrics, and to make comparisons. Environmental and morphological metrics were defined earlier in this section. Physical movement metrics were passage time in the LPS, LPS passage efficiency, partial fallback in the LPS, re-ascension after partial fallback, full fallback to the tailrace from the LPS, fallback over the spillway, overall migration through the Bonneville reservoir, migration time through Bonneville reservoir, and migration to dams upstream from The Dalles Dam. Passage time in the LPS was defined as the time between release into rest box 3 and detection at PIT tag array 4B3 just prior to the exit slide. LPS passage efficiency was defined as the number of lampreys that successfully passed and exited the CI LPS divided by the number of lampreys that were released into rest box 3. Partial fallback in the LPS was defined as a fish that was detected at 4B1 following release into rest box 3. Re-ascension after partial fallback was defined as a fish that was able to move back upstream after partial fallback and that subsequently exited the structure upstream. Full fallback to the tailrace from the LPS was defined as a fish that was detected at 4B1 following release into rest box 3 and then was either detected at a radio receiver in the tailrace, at an array on another part of the dam, or was never detected again. Fallback over the spillway was defined as a fish that passed and exited the LPS (or a fish that was released at the end of CI) and then was detected downstream from Bonneville Dam (Figure 2.2.1 - see Chapter 2.1 Study Design). Overall migration success through the Bonneville reservoir was defined as the number detected at The Dalles Dam divided by the total number of fish from the different subgroups of fish traveling from the Bonneville forebay to the base of The Dalles Dam. 
Migration time through Bonneville reservoir was defined as either the time a fish took from detection at the exit of the LPS to detection at The Dalles Dam, or the time that a fish took from release at the end of CI to detection at The Dalles Dam (see Figure 2.1.2 Chapter 2.1 Study Area). And migration to dams beyond The Dalles Dam was simply denoted for any individual fish that passed The Dalles Dam and succeeded in migrating to dams further up the Columbia River (Figure 1.5.1 - see Chapter 1.5 Lamprey and Dams).

\subsection{Statistical Analysis}

All statistical analyses were performed using Excel 2010 statistical analysis toolpack. Daily averages for all environmental variables over the entire duration of the study (date of first release - date of last detection at The Dalles Dam) were calculated and represented graphically (water temperature, flow, \% of light in each day) to show seasonal variation. Weekly averages for all environmental variables were calculated from hourly data to characterize seasonal variation.

For fish morphology (length, weight, and girth) of all fish tagged in the study the mean, standard deviation, and median was calculated for each group in each release, for the total of each group and release, and for all fish overall. A one-way ANOVA was performed for morphology metrics to test whether means were statistically different among groups and releases.

For passage efficiency in the LPS, a t-test was performed to test whether passage efficiencies were statistically different between groups, and a one-way ANOVA was performed to test for statistical difference among releases. For travel time in the LPS the 
mean, standard deviation, and median were calculated for each group in each release, for the total of each group and release, and for all fish that passed the LPS. A t-test was performed to determine whether the difference between the morphology of fish (e.g., length, weight, and girth) in each group was significant. And a one-way ANOVA was performed to test whether differences in morphology of fish among releases was significant. Mean, standard deviation, and median were calculated for fish morphology in each group in each release, for the total of each group and release, and for all fish overall.

For travel time in the LPS a t-test was performed to compare Group 1 (double tagged) and Group 2 (PIT tagged only). A one-way ANOVA was used to test whether differences in travel time were significant among releases. X-Y scatter plots were created with regression analysis to examine if the relationship of fish morphology (e.g., length, weight, and girth) to travel time was significant. For environmental variables (e.g., water temperature and \% of day light) present while fish traveled through the LPS, X-Y scatter plots were created with regression analysis to examine whether the relationships to travel time in the LPS were significant.

For travel time through Bonneville reservoir, a t-test was performed to compare travel times of fish from Group 1 (double tagged) and Group 2 (PIT tagged only). A ttest was also performed to compare travel times for fish that passed the LPS (Group 1 and Group 2 combined) to those that bypassed the LPS (Group 3). A one-way ANOVA was run to test whether differences among releases for all groups were significant. For morphology (length, weight, girth) of fish that traveled through Bonneville reservoir, the 
mean, standard deviation, and median was calculated for fish in each group in each release, for total of each group and release, and for all fish overall. X-Y scatter plots were created with regression analysis to examine whether the relationship to fish morphology (e.g., length, weight, and girth) was significant. For environmental variables (e.g., water temperature, flow, and \% of daylight) present at the time of LPS exit (Group 1 and Group 2) or release into the forebay (Group 3) (i.e. entrance into Bonneville reservoir), $\mathrm{X}$-Y scatter plots were created to determine whether relationships with migration travel time were significant. No statistical analysis was performed for fish that passed subsequent dams upstream from The Dalles Dam. 


\section{Chapter 3: Results}

\subsection{Environmental Conditions at Bonneville Dam}

Table 3.1.1 Weekly averages of water temperature (degrees celsius) in the Bonneville forebay, and flow (thousand cubic feet per second) downstream from The Dalles Dam over the duration of the study 2013

\begin{tabular}{|c|c|c|c|}
\hline \multicolumn{4}{|c|}{ Environmental Weekly Averages } \\
\hline Week & Date & $\begin{array}{c}\text { Water temperature - } \\
\text { Bonneville forebay }\left({ }^{\circ} \mathrm{C}\right)\end{array}$ & $\begin{array}{c}\text { Flow - The Dalles } \\
\text { downstream (kfcs) }\end{array}$ \\
\hline 1 & $7 / 7-7 / 13$ & 19.68 & 203.35 \\
\hline 2 & $7 / 14-7 / 20$ & 20.38 & 182.19 \\
\hline 3 & $7 / 21-7 / 27$ & 20.98 & 156.52 \\
\hline 4 & $7 / 28-8 / 3$ & 20.97 & 151.37 \\
\hline 5 & $8 / 4-8 / 10$ & 21.80 & 147.19 \\
\hline 6 & $8 / 11-8 / 17$ & 21.89 & 138.69 \\
\hline 7 & $8 / 18-8 / 24$ & 21.97 & 129.11 \\
\hline 8 & $8 / 25-8 / 31$ & 22.00 & 118.16 \\
\hline 9 & $9 / 1-9 / 7$ & 21.93 & 91.97 \\
\hline 10 & $9 / 8-9 / 14$ & 21.96 & 102.13 \\
\hline
\end{tabular}

Water temperature (weekly average) in the Bonneville forebay over the duration of the study steadily increased from $19.68^{\circ} \mathrm{C}$ in week 1 to around $21.96^{\circ} \mathrm{C}$ in week 10 (Table 3.1.1). While the trend was overall increasing, variability did occur on a daily basis; beginning at $19.00^{\circ} \mathrm{C}$ in early July and increasing until it reached above $22.00^{\circ} \mathrm{C}$ in early August where it then fluctuated around $22.00^{\circ} \mathrm{C}$ into mid-September (Figure 3.1.1). Water temperature in the LPS increased by three degrees $\left(18-21^{\circ} \mathrm{C}\right)$ from Release 1 to

Release 5 and was $1-2^{\circ} \mathrm{C}$ cooler than the daily average temperature on release days

(Figure 3.1.1). Flow (weekly average) downstream from The Dalles Dam decreased by 49.77\% over the 10 -week period, from $203.35 \mathrm{kcfs}$ in week 1 to $102.13 \mathrm{kcfs}$ in week 10 (Table 3.1.1). While the trend was overall decreasing, variability did occur on a daily 
basis with peaks and valleys present every few days (Figure 3.1.2). Percent of daylight hours steadily decreased over the course of the study. On the first release around $64 \%$ (15.4 hours) of each day contained daylight, decreasing only slightly over the course of Releases 2, 3, and 4, and falling to 53\% (12.7 hours) by the final release (Figure 3.1.3). The velocity of the CI LPS was $0.34 \mathrm{~m} / \mathrm{sec}$. The flow depth was $4.45 \mathrm{~cm}$, width $19.05 \mathrm{~cm}$ (Zobott 2014).

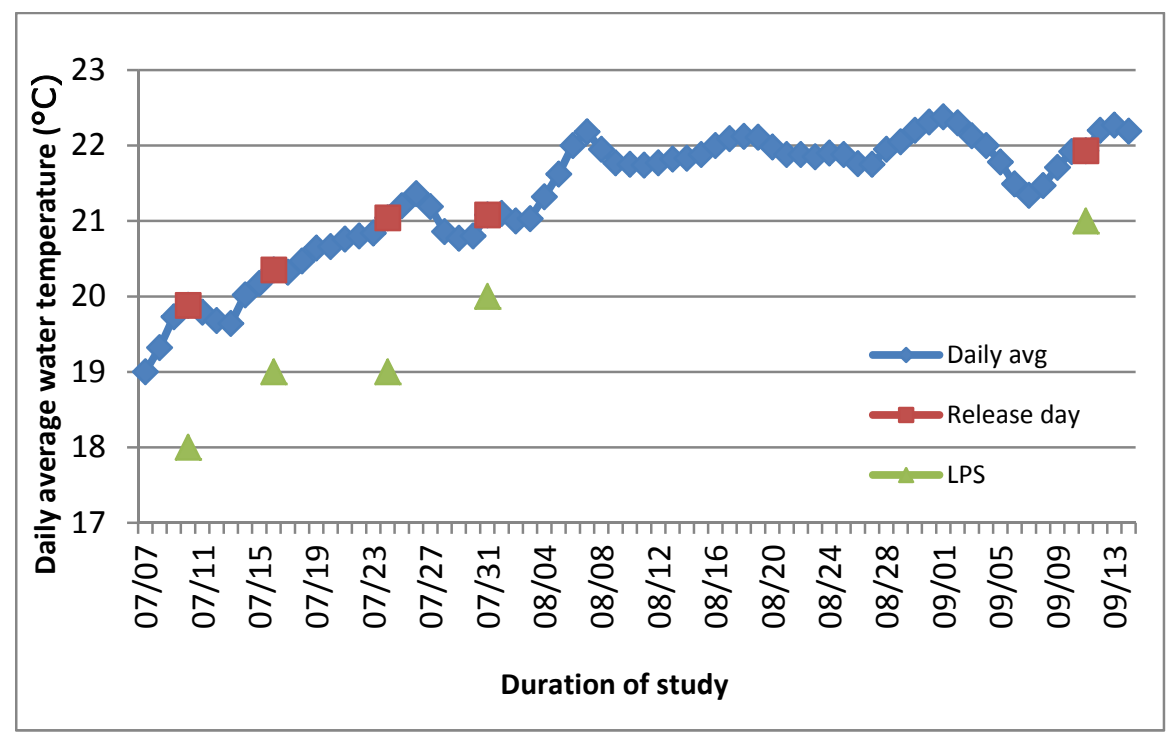

Figure 3.1.1 Daily average water temperature $\left({ }^{\circ} \mathrm{C}\right)$ in the Bonneville Dam forebay from July 7, 2013 to September 14, 2013 (blue diamonds), average water temperature $\left({ }^{\circ} \mathrm{C}\right.$ ) on days of release (red squares) and water temperature $\left({ }^{\circ} \mathrm{C}\right)$ in the CI LPS on release days at time of release (green triangles) 


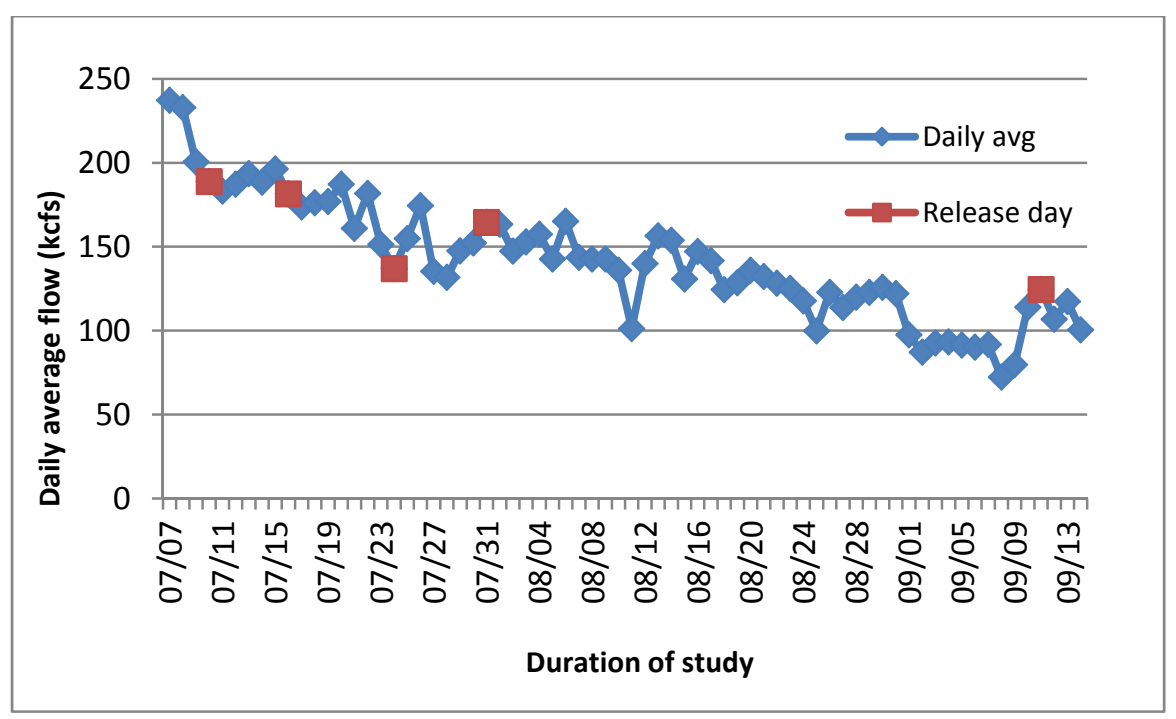

Figure 3.1.2 Daily average flow (thousand cubic feet per second) $1.6 \mathrm{~km}$ downstream from The Dalles Dam from July 7, 2013 to September 14, 2013 (blue diamonds), average flow (thousand cubic feet per second) on days of release (red squares)

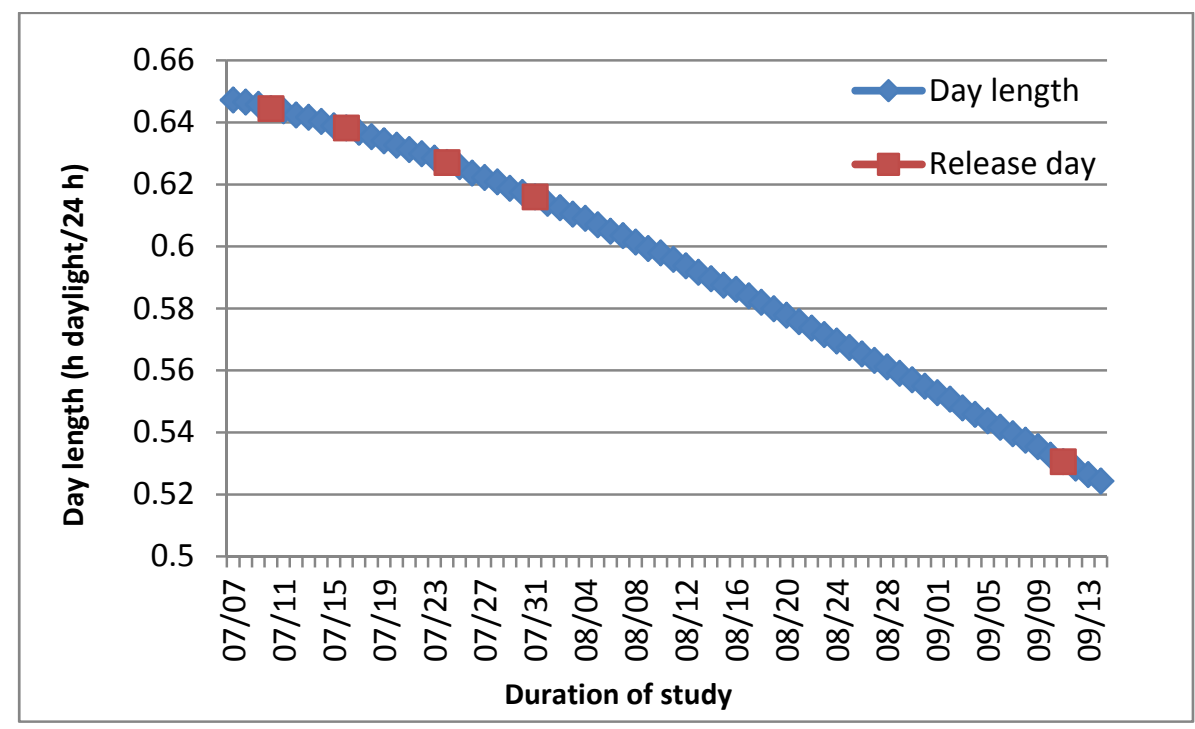

Figure 3.1.3 Day length (hours of daylight/24 h) in Cascade Locks, OR from July 7, 2013 to September 14, 2013 (blue diamonds), day length (hours of daylight/24 h) on days of release (red squares) 


\subsection{Morphology of Lampreys}

Overall mean length for the 75 fish tagged and released was $64.94 \mathrm{~cm}$, with a standard deviation of $3.80 \mathrm{~cm}$. There was very little variation in the mean among groups; Group 1 mean length was 65.80 cm, Group 2 mean was 63.76c m, and Group 3 was $65.90 \mathrm{~cm}(\mathrm{P}=0.13, \mathrm{n}=75)$. There was more variation among releases; Release 1 mean was $67.30 \mathrm{~cm}$, Release 2 was $64.26 \mathrm{~cm}$, Release 3 was $66.43 \mathrm{~cm}$, Release 4 was 64.40 $\mathrm{cm}$, and Release 5 was $62.33 \mathrm{~cm}(\mathrm{P}=0.002, \mathrm{n}=75)$ (Table 3.2.1). The minimum for all study fish was $52.50 \mathrm{~cm}$ and the maximum was $74.00 \mathrm{~cm}$.

Table 3.2.1 Length (centimeters) of groups and releases for all fish tagged at Bonneville Dam for use in the Cascades Island LPS 2013 study (Mean, standard deviation, and median)

\begin{tabular}{|c|c|c|c|c|c|c|c|}
\hline \multicolumn{7}{|c|}{ All tagged fish - Length (cm) } \\
\hline & Statistic & Release 1 & Release 2 & Rlease 3 & Release 4 & Release 5 & Total Group \\
\hline Group 1 & $\overline{\mathrm{x}}=$ & 65.70 & 65.70 & 65.00 & 66.00 & 63.50 & 65.80 \\
\hline & $\mathrm{SD}=$ & 2.31 & 1.99 & 0.79 & 2.50 & 3.41 & 2.34 \\
\hline & $\mathrm{M}=$ & 65.00 & 66.00 & 65.00 & 65.50 & 65.00 & 65.00 \\
\hline & $\mathrm{n}=$ & 5 & 5 & 5 & 5 & 5 & 25 \\
\hline Group 2 & $\overline{\mathrm{x}}=$ & 68.70 & 62.60 & 67.30 & 60.20 & 60.00 & 63.76 \\
\hline & $\mathrm{SD}=$ & 3.56 & 2.56 & 2.84 & 3.29 & 4.66 & 4.85 \\
\hline & $\mathrm{M}=$ & 68.50 & 61.50 & 68.50 & 60.50 & 62.00 & 63.50 \\
\hline & $\mathrm{n}=$ & 5 & 5 & 5 & 5 & 5 & 25 \\
\hline Group 3 & $\overline{\mathrm{x}}=$ & 67.50 & 64.50 & 67.00 & 67.00 & 63.50 & 65.90 \\
\hline & $\mathrm{SD}=$ & 3.02 & 1.46 & 4.23 & 3.76 & 5.35 & 3.82 \\
\hline & $\mathrm{M}=$ & 69.50 & 64.50 & 67.50 & 68.00 & 63.00 & 65.00 \\
\hline & $\mathrm{n}=$ & 5 & 5 & 5 & 5 & 5 & 25 \\
\hline Total Release & $\overline{\mathrm{x}}=$ & 67.30 & 64.26 & 66.43 & 64.40 & 62.33 & 64.94 \\
\hline & $\mathrm{SD}=$ & 3.06 & 2.31 & 2.95 & 4.31 & 4.54 & 3.87 \\
\hline & $\mathrm{M}=$ & 66.00 & 64.50 & 66.00 & 64.50 & 63.00 & 65.00 \\
\hline & $\mathrm{n}=$ & 15 & 15 & 15 & 15 & 15 & 75 \\
\hline
\end{tabular}

Overall mean weight was $436.80 \mathrm{~g}$ with a standard deviation of $74.01 \mathrm{~g}$. The mean weight among groups was comparable; Group 1 mean weight was 436.80 g, Group 2 was $418.80 \mathrm{~g}$, and Group 3 was $455.04 \mathrm{~g}(\mathrm{P}=0.22, \mathrm{n}=75)$. Among releases the fifth 
release (382.50 g) was 21.29\% lower than the first which had the largest mean (486.00 g), the difference among releases was significant $(\mathrm{P}=0.001, \mathrm{n}=75)$ (Table 3.2.2). There was a very large range in weight; the minimum weight for all tagged fish was $278.00 \mathrm{~g}$ and the maximum was $640.00 \mathrm{~g}$.

Table 3.2.2 Weight (grams) of groups and releases for all fish tagged at Bonneville Dam for use in the Cascades Island LPS 2013 study 9 (Mean, standard deviation, and median)

\begin{tabular}{|c|c|c|c|c|c|c|c|}
\hline \multicolumn{8}{|c|}{ All tagged fish - Weight (g) } \\
\hline & Statistic & Release 1 & Release 2 & Rlease 3 & Release 4 & Release 5 & Total Group \\
\hline Group 1 & $\overline{\mathrm{x}}=$ & 448.00 & 441.20 & 430.80 & 466.00 & 398.00 & 436.80 \\
\hline & $\mathrm{SD}=$ & 45.50 & 47.21 & 34.66 & 21.31 & 61.95 & 46.49 \\
\hline & $\mathrm{M}=$ & 460.00 & 422.00 & 422.00 & 458.00 & 398.00 & 440.00 \\
\hline & $\mathrm{n}=$ & 5 & 5 & 5 & 5 & 5 & 25 \\
\hline Group 2 & $\overline{\mathrm{x}}=$ & 516.00 & 414.00 & 470.00 & 344.40 & 349.60 & 418.80 \\
\hline & $\mathrm{SD}=$ & 80.19 & 79.75 & 74.82 & 78.35 & 45.92 & 95.44 \\
\hline & $\mathrm{M}=$ & 520.00 & 450.00 & 464.00 & 322.00 & 346.00 & 440.00 \\
\hline & $\mathrm{n}=$ & 5 & 5 & 5 & 5 & 5 & 25 \\
\hline Group 3 & $\overline{\mathrm{x}}=$ & 494.00 & 422.80 & 473.60 & 484.80 & 400.00 & 455.04 \\
\hline & $\mathrm{SD}=$ & 68.04 & 52.87 & 44.21 & 76.01 & 76.93 & 70.23 \\
\hline & $\mathrm{M}=$ & 500.00 & 442.00 & 488.00 & 524.00 & 376.00 & 446.00 \\
\hline & $\mathrm{n}=$ & 5 & 5 & 5 & 5 & 5 & 25 \\
\hline Total Release & $\overline{\mathrm{x}}=$ & 486.00 & 426.00 & 458.13 & 431.73 & 382.50 & 436.80 \\
\hline & $\mathrm{SD}=$ & 67.91 & 58.23 & 53.89 & 87.65 & 63.02 & 74.01 \\
\hline & $\mathrm{M}=$ & 460.00 & 442.00 & 464.00 & 456.00 & 382.00 & 442.00 \\
\hline & $\mathrm{n}=$ & 15 & 15 & 15 & 15 & 15 & 75 \\
\hline
\end{tabular}

Overall mean girth was $10.59 \mathrm{~cm}$ with a standard deviation of $0.66 \mathrm{~cm}$. Mean girth among groups had very little variation; Group 1 was $10.54 \mathrm{~cm}$, Group 2 was 10.50 $\mathrm{cm}$, and Group 3 was $10.74 \mathrm{~cm}(\mathrm{P}=0.38, \mathrm{n}=75)$. Among releases the mean girth showed more variation, especially between Release $1(10.59 \mathrm{~cm})$ and Release $5(10.27 \mathrm{~g})$, similar to length and weight the difference was significant $(\mathrm{P}=0.02, \mathrm{n}=75)$ (Table 3.2.3). The minimum girth was $9.00 \mathrm{~cm}$ and the maximum was $12.00 \mathrm{~cm}$. 
Table 3.2.3 Girth (centimeters) of groups and releases for all fish tagged at Bonneville Dam for use in the Cascades Island LPS 2013 study (Mean, standard deviation, and median)

\begin{tabular}{|c|c|c|c|c|c|c|c|}
\hline \multicolumn{7}{|c|}{ All tagged fish - Girth (cm) } \\
\hline & Statistic & Release 1 & Release 2 & Release 3 & Release 4 & Release 5 & Total Group \\
\hline Group 1 & $\overline{\mathrm{X}}=$ & 10.70 & 10.20 & 10.50 & 11.00 & 10.30 & 10.54 \\
\hline & $\mathrm{SD}=$ & 0.45 & 0.27 & 0.71 & 0.00 & 0.45 & 0.50 \\
\hline & $\mathrm{M}=$ & 11.00 & 10.00 & 10.00 & 11.00 & 10.00 & 10.50 \\
\hline & $\mathrm{n}=$ & 5 & 5 & 5 & 5 & 5 & 25 \\
\hline Group 2 & $\overline{\mathrm{X}}=$ & 11.10 & 10.50 & 11.00 & 9.70 & 10.20 & 10.50 \\
\hline & $\mathrm{SD}=$ & 0.42 & 0.71 & 0.71 & 1.04 & 0.57 & 0.84 \\
\hline & $\mathrm{M}=$ & 11.00 & 11.00 & 11.00 & 9.50 & 10.00 & 11.00 \\
\hline & $\mathrm{n}=$ & 5 & 5 & 5 & 5 & 5 & 25 \\
\hline & $\overline{\mathrm{X}}=$ & 10.90 & 10.40 & 11.00 & 11.10 & 10.30 & 10.74 \\
\hline & $\mathrm{SD}=$ & 0.55 & 0.65 & 0.00 & 0.65 & 0.45 & 0.58 \\
\hline & $\mathrm{M}=$ & 11.00 & 10.50 & 11.00 & 11.00 & 10.00 & 11.00 \\
\hline & $\mathrm{n}=$ & 5 & 5 & 5 & 5 & 5 & 25 \\
\hline Total Release & $\overline{\mathrm{X}}=$ & 10.59 & 10.37 & 10.83 & 10.60 & 10.27 & 10.59 \\
\hline & $\mathrm{SD}=$ & 0.47 & 0.55 & 0.59 & 0.93 & 0.46 & 0.66 \\
\hline & $\mathrm{M}=$ & 11.00 & 10.50 & 11.00 & 11.00 & 10.00 & 11.00 \\
\hline & $\mathrm{n}=$ & 15 & 15 & 15 & 15 & 15 & 75 \\
\hline
\end{tabular}

\subsection{Passage Efficiency in the LPS}

Passage efficiency overall was $74 \%$ for the study. Thirty-seven out of fifty lampreys successfully passed and exited the LPS. It is important to note that there were three mortalities that occurred within Release 4. Two fish were found and removed from resting box 3 and one was found and removed from resting box 4 the day following this release. Twenty-one of the fish that passed the LPS were from Group 1 (double-tagged) and 16 of them were from Group 2 (PIT tagged only). Group $1(n=25)$ passage efficiency was 84\% while Group $2(n=25)$ passage efficiency was 64\%; therefore Group 1 had 20\% more fish pass than Group 2, however this difference was not significant $(\mathrm{P}=0.07)$. By release, $80 \%$ passed from Release 1 , the same for Release 2, 70\% from Release 3, 50\% from Release 4, and 90\% from Release 5 passed; the difference also was not significant 
( $\mathrm{P}=0.46, \mathrm{n}=37$ ) (Table 3.3.1). Release 4 had the fewest fish pass; this is when the 3

mortalities occurred.

Table 3.3.1 Numbers of fish in groups and releases that successfully passed and exited the CI LPS after release into rest box 3 in 2013

\begin{tabular}{|c|c|c|c|c|c|c|}
\hline \multicolumn{7}{|c|}{ Passage - Cascades Island LPS (number of fish) } \\
\hline & Release 1 & Release 2 & Release 3 & Release 4 & Release 5 & Total Release \\
\hline Group 1 & 4 & 4 & 4 & 4 & 5 & 21 \\
\hline Group 2 & 4 & 4 & 3 & 1 & 4 & 16 \\
\hline Total Group & 8 & 8 & 7 & 5 & 9 & 37 \\
\hline
\end{tabular}

\subsection{Fallback}

Of the 50 fish released into resting box 3 during the study, 10 lampreys (20\%) experienced fallback within the LPS to the tailrace of the dam. Fallback between groups was comparable and was not significant $(\mathrm{P}=0.09)$; fallback among releases was also comparable and not significant $(\mathrm{P}=0.39)$ (Table 3.4.1).

Table 3.4.1 Number of fish in groups and releases that experienced fallback within the LPS to the tailrace of Bonneville Dam after release into rest box 3 at CI LPS in 2013

\begin{tabular}{|c|c|c|c|c|c|c|}
\hline \multicolumn{7}{|c|}{ Fallback to tailrace - Cascades Island LPS (number of fish) } \\
\hline & Release 1 & Release 2 & Release 3 & Release 4 & Release 5 & Total Group \\
\hline Group 1 & 1 & 1 & 1 & 1 & 0 & 4 \\
\hline Group 2 & 1 & 1 & 2 & 1 & 1 & 6 \\
\hline Total Release & 2 & 2 & 3 & 2 & 1 & 10 \\
\hline
\end{tabular}

Seven fish partially fell back from rest box 3 in the LPS but were able to reascend the structure rather than falling back to the tailrace. However, only six (12\%, n=50) of these fish successfully passed and exited the LPS; five were from Group 1 and one from Group 2 (Table 3.4.2), one was a mortality collected from resting box 4 the day 
following release 4. Only one fish of the 37 that exited the LPS experienced fallback over the spillway, back to the tailrace of the dam (2.7\%).

Table 3.4.2 Numbers of fish in groups and releases that experienced partial fallback after release into rest box 3 at CI LPS but were able to re-ascend and exit the CI LPS in 2013

\begin{tabular}{|c|c|c|c|c|c|c|}
\hline \multicolumn{6}{|c|}{ Partial fallback and re-ascension - Cascades Island LPS (number of fish) } \\
\hline & Release 1 & Release 2 & Release 3 & Rlease 4 & Release 5 & Total Group \\
\hline Group 1 & 1 & 3 & 0 & 1 & 0 & 5 \\
\hline Group 2 & 1 & 0 & 0 & 0 & 0 & 1 \\
\hline Total Release & 2 & 3 & 0 & 1 & 0 & 6 \\
\hline
\end{tabular}

Five $(50 \%, n=10)$ of the fish that experienced full fallback to the tailrace from the structure attempted to re-ascend Bonneville Dam via other routes. Three of these five fish (one from Release 1 Group 2, one from Release 3 Group 2, and one from Release 5 Group 2) passed over Bonneville Dam via another route $(60 \%, n=5)$, while the other two attempted, but were unsuccessful. The single fish (from Release 2 Group 2) that experienced fallback over the spillway also succeeded in ascending Bonneville Dam via a different route.

\subsection{Travel Time in the LPS}

The mean travel time for all fish that successfully passed and exited the CI LPS was $12 \mathrm{~h}$ with a standard deviation of $0.6 \mathrm{~d}(\mathrm{n}=37)$. Group 1 (double-tagged) mean travel time was $0.49 \mathrm{~d}(\mathrm{n}=21)$, while Group 2 (PIT tagged only) mean travel time was $0.52 \mathrm{~d}$ ( $n=16)$, travel time between groups was not significant, showing no tagging effect on travel time $(\mathrm{P}=0.47)$. However, the variation in travel time among releases was significantly different, mean travel time of Release 1 fish was 15.84 h slower than that of 
Release 5 fish $(\mathrm{P}=0.02, \mathrm{n}=37)$ (Table 3.5.1). The minimum travel time to negotiate the LPS was $2.4 \mathrm{~h}$ and the maximum was $3.05 \mathrm{~d}$.

Table 3.5.1 Travel time (days) of groups and releases for all fish that successfully passed and exited the CI LPS after release into rest box 3 in 2013 (Mean, standard deviation, and median)

\begin{tabular}{|c|c|c|c|c|c|c|c|}
\hline \multicolumn{7}{|c|}{ Travel time (d) - Cascades Island LPS } \\
\hline & Statistic & Release 1 & Release 2 & Rlease 3 & Release 4 & Release 5 & Total Group \\
\hline Group 1 & $\overline{\mathrm{X}}=$ & 1.11 & 0.68 & 0.17 & 0.20 & 0.35 & 0.49 \\
\hline & $\mathrm{SD}=$ & 1.36 & 0.50 & 0.07 & 0.04 & 0.37 & 0.69 \\
\hline & $\mathrm{M}=$ & 0.62 & 0.68 & 0.15 & 0.18 & 0.20 & 0.20 \\
\hline & $\mathrm{n}=$ & 4 & 4 & 4 & 4 & 5 & 21 \\
\hline Group 2 & $\overline{\mathrm{X}}=$ & 0.95 & 0.48 & 0.17 & 0.27 & 0.40 & 0.51 \\
\hline & $\mathrm{SD}=$ & 0.44 & 0.46 & 0.04 & $\mathrm{na}$ & 0.48 & 0.46 \\
\hline & $\mathrm{M}=$ & 1.12 & 0.26 & 0.16 & 0.27 & 0.18 & 0.26 \\
\hline & $\mathrm{n}=$ & 4 & 4 & 3 & 1 & 4 & 16 \\
\hline Total Release & $\overline{\mathrm{X}}=$ & 1.03 & 0.58 & 0.17 & 0.21 & 0.37 & 0.50 \\
\hline & $\mathrm{SD}=$ & 0.94 & 0.46 & 0.06 & 0.05 & 0.39 & 0.59 \\
\hline & $\mathrm{M}=$ & 1.06 & 0.28 & 0.16 & 0.18 & 0.19 & 0.23 \\
\hline & $\mathrm{n}=$ & 8 & 8 & 7 & 5 & 9 & 37 \\
\hline
\end{tabular}

\section{Effect of Fish Morphology on Travel Time in LPS}

The overall mean length of lampreys that successfully passed and exited the LPS was $64.55 \mathrm{~cm}$, with a standard deviation of $0.51 \mathrm{~cm}(\mathrm{n}=37)$ (Table 3.5.2). Mean lengths between groups was comparable; Group 1 was $65.31 \mathrm{~cm}$, and Group 2 was $63.56 \mathrm{~cm}$, this was not statistically different, again no tagging effect was present $(\mathrm{P}=0.07)$. The variation in average length among releases showed more variation, mean fish length from Release $1(66.81 \mathrm{~cm})$ was $5.25 \mathrm{~cm}$ longer than that of Release $5(61.56 \mathrm{~cm})$, this difference was significant $(\mathrm{P}=0.02, \mathrm{n}=37)$. When plotted against time in the LPS, length had a positive relationship that was not significant $\left(r^{2}=0.12, P=0.06, n=37\right)$ (Figure 3.5.1). 
Table 3.5.2 Length (centimeters) of groups and releases for all fish that successfully passed and exited the CI LPS after release into rest box 3 in 2013 (Mean, standard deviation, and median)

\begin{tabular}{|c|c|c|c|c|c|c|c|c|}
\hline \multicolumn{7}{|c|}{ Length (cm) - Cascades Island LPS } \\
\hline & Statistic & Release 1 & Release 2 & Rlease 3 & Release 4 & Release 5 & Total Group \\
\hline Group 1 & $\overline{\mathrm{X}}=$ & 66.25 & 65.375 & 65.25 & 66.63 & 63.50 & 65.31 \\
\hline & $\mathrm{SD}=$ & 2.25 & 2.14 & 0.65 & 2.39 & 3.41 & 2.46 \\
\hline & $\mathrm{M}=$ & 65.5 & 65.25 & 65.25 & 66.00 & 65.00 & 65.50 \\
\hline & $\mathrm{n}=$ & 4 & 4 & 4 & 4 & 5 & 21 \\
\hline Group 2 & $\overline{\mathrm{x}}=$ & 67.38 & 62.88 & 66.67 & 59.50 & 59.13 & 63.56 \\
\hline & $\mathrm{SD}=$ & 2.29 & 2.87 & 3.62 & na & 4.89 & 4.64 \\
\hline & $\mathrm{M}=$ & 67.25 & 63.25 & 68.50 & 59.50 & 60.25 & 64.25 \\
\hline & $\mathrm{n}=$ & 4 & 4 & 3 & 1 & 4 & 16 \\
\hline Total Release & $\overline{\mathrm{X}}=$ & 66.81 & 64.13 & 65.86 & 65.20 & 61.56 & 64.55 \\
\hline & $\mathrm{SD}=$ & 2.19 & 2.70 & 2.27 & 3.80 & 4.48 & 3.62 \\
\hline & $\mathrm{M}=$ & 66.00 & 64.75 & 65.50 & 65.50 & 62.00 & 65.00 \\
\hline & $\mathrm{n}=$ & 8 & 8 & 7 & 5 & 9 & 37 \\
\hline
\end{tabular}

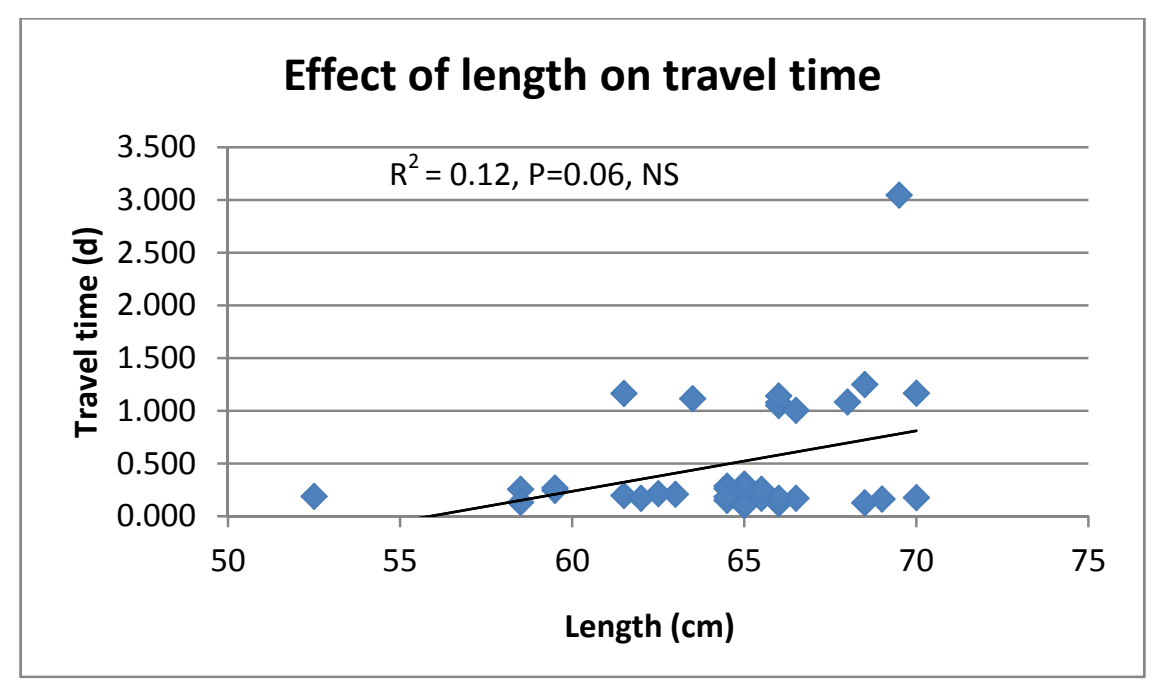

Figure 3.5.1 Length (centimeters) and travel time (days) simple linear regression analysis for all fish that successfully passed and exited the CI LPS after release into rest box 3 in 2013

The overall mean weight of lampreys that successfully passed the LPS was 427.41 g, with a standard deviation of $69.57 \mathrm{~g}(\mathrm{n}=37)$. For Group 1 (double-tagged) the mean length was $438.95 \mathrm{~g}(\mathrm{n}=21)$, while Group 2 (PIT tagged only) was $412.25 \mathrm{~g}(\mathrm{n}=16)$, 
these were not significantly different $(\mathrm{P}=0.12)$. Mean weight of Release 1 (473.75 g) was $103.08 \mathrm{~g}$ heavier than that of Release 5 (370.67 g), mean weight among releases was significantly different $(\mathrm{P}=0.02, \mathrm{n}=37)$ (Table 3.5.3). When plotted against time in the LPS, there was a positive correlation, but it was not significant $\left(r^{2}=0.09, P=0.33, n=37\right)$ (Figure 3.5.2).

Table 3.5.3 Weight (grams) of groups and releases for all fish that successfully passed and exited the CI LPS after release into rest box 3 in 2013 (Mean, standard deviation, and median)

\begin{tabular}{|c|c|c|c|c|c|c|c|}
\hline \multicolumn{7}{|c|}{ Weight (g) - Cascades Island LPS } \\
\hline & Statistic & Release 1 & Release 2 & Rlease 3 & Release 4 & Release 5 & Total Group \\
\hline Group 1 & $\overline{\mathrm{X}}=$ & 462.5 & 446 & 426.00 & 472.50 & 398.00 & 438.95 \\
\hline & $\mathrm{SD}=$ & 36.86 & 53.09 & 38.05 & 17.99 & 61.95 & 49.58 \\
\hline & $\mathrm{M}=$ & 460 & 438 & 416.00 & 472.00 & 398.00 & 454.00 \\
\hline & $\mathrm{n}=$ & 4 & 4 & 4 & 4 & 5 & 21 \\
\hline Group 2 & $\overline{\mathrm{X}}=$ & 485.00 & 398.50 & 468.00 & 312.00 & 336.50 & 412.25 \\
\hline & $\mathrm{SD}=$ & 46.55 & 82.94 & 105.36 & $\mathrm{na}$ & 40.84 & 88.92 \\
\hline & $\mathrm{M}=$ & 485.00 & 391.00 & 458.00 & 312.00 & 336.00 & 413.00 \\
\hline & $\mathrm{n}=$ & 4 & 4 & 3 & 1 & 4 & 16 \\
\hline & $\overline{\mathrm{X}}=$ & 473.75 & 422.25 & 444.00 & 440.40 & 370.67 & 427.41 \\
\hline & $\mathrm{SD}=$ & 40.69 & 69.29 & 70.20 & 73.45 & 59.96 & 69.57 \\
\hline & $\mathrm{M}=$ & 460.00 & 436.00 & 422.00 & 458.00 & 382.00 & 440.00 \\
\hline & $\mathrm{n}=$ & 8 & 8 & 7 & 5 & 9 & 37 \\
\hline
\end{tabular}




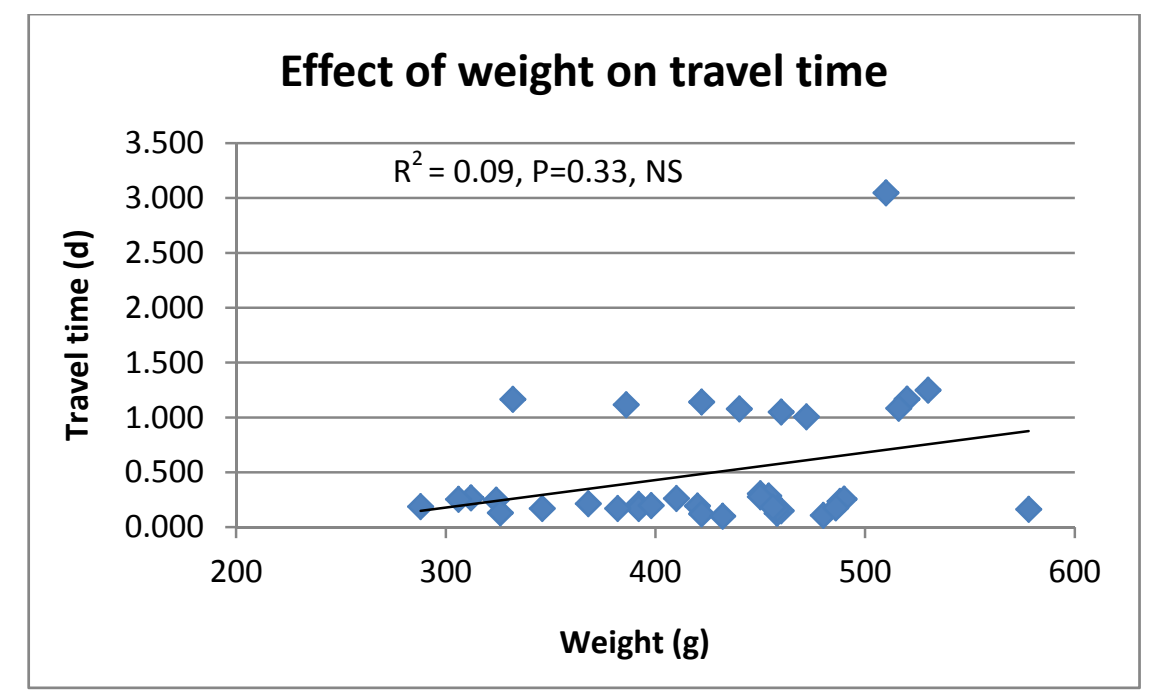

Figure 3.5.2 Weight (grams) and travel time (days) simple linear regression analysis for all fish that successfully passed and exited the CI LPS after release into rest box 3 in 2013

The overall mean girth of lampreys that successfully passed the LPS was 10.51 cm with a standard deviation of $0.62 \mathrm{~cm}(\mathrm{n}=37)$. Group 1 (double-tagged) mean girth was $10.52 \mathrm{~cm}(\mathrm{n}=21)$, while Group 2 (PIT tagged only) was $10.50 \mathrm{~cm}(\mathrm{n}=16)$, the difference was not significant $(\mathrm{P}=0.45)$. The variation in mean girth among releases did not vary greatly and was not significantly different $(\mathrm{P}=0.11, \mathrm{n}=37)$ (Table 3.5.4). When plotted against time in the LPS, there was a slightly positive correlation. When girth was plotted against travel time in the LPS there was no correlation, and the relationship was not significant $\left(r^{2}=0.001, P=0.94, n=37\right)$. 
Table 3.5.4 Girth (cm) of groups and releases for all fish that successfully passed and exited the CI LPS after release into rest box 3 in 2013 (Mean, standard deviation, and median)

\begin{tabular}{|c|c|c|c|c|c|c|c|c|}
\hline \multicolumn{7}{|c|}{ Girth (cm) - Cascades Island LPS } \\
\hline & Statistic & Release 1 & Release 2 & Rlease 3 & Release 4 & Release 5 & Total Group \\
\hline Group 1 & $\overline{\mathrm{X}}=$ & 10.75 & 10.25 & 10.38 & 11.00 & 10.30 & 10.52 \\
\hline & $\mathrm{SD}=$ & 0.5 & 0.29 & 0.75 & 0.00 & 0.45 & 0.51 \\
\hline & $\mathrm{M}=$ & 11 & 10.25 & 10.00 & 11.00 & 10.00 & 10.50 \\
\hline & $\mathrm{n}=$ & 4 & 4 & 4 & 4 & 5 & 21 \\
\hline Group 2 & $\overline{\mathrm{x}}=$ & 11.00 & 10.38 & 11.00 & 9.50 & 10.00 & 10.50 \\
\hline & $\mathrm{SD}=$ & 0.41 & 0.75 & 1.00 & na & 0.41 & 0.75 \\
\hline & $\mathrm{M}=$ & 11.00 & 10.50 & 11.00 & 9.50 & 10.00 & 10.50 \\
\hline & $\mathrm{n}=$ & 4 & 4 & 3 & 1 & 4 & 16 \\
\hline Total Release & $\overline{\mathrm{x}}=$ & 10.88 & 10.31 & 10.64 & 10.70 & 10.17 & 10.51 \\
\hline & $\mathrm{SD}=$ & 0.44 & 0.53 & 0.85 & 0.67 & 0.43 & 0.62 \\
\hline & $\mathrm{M}=$ & 11.00 & 10.25 & 10.00 & 11.00 & 10.00 & 10.50 \\
\hline & $\mathrm{n}=$ & 8 & 8 & 7 & 5 & 9 & 37 \\
\hline
\end{tabular}




\section{Environmental Effect on Travel Time in LPS}

The relationship between water temperature at the time of release, measured in the LPS, and travel time was negative and significant $\left(\mathrm{r}^{2}=0.12, \mathrm{P}=0.01, \mathrm{n}=37\right)$ (Figure 3.5.3). The relationship between day length on release day and travel time was slightly positively correlated, but not significant $\left(\mathrm{r}^{2}=0.04, \mathrm{P}=0.36, \mathrm{n}=37\right)$ (Figure 3.5.4).

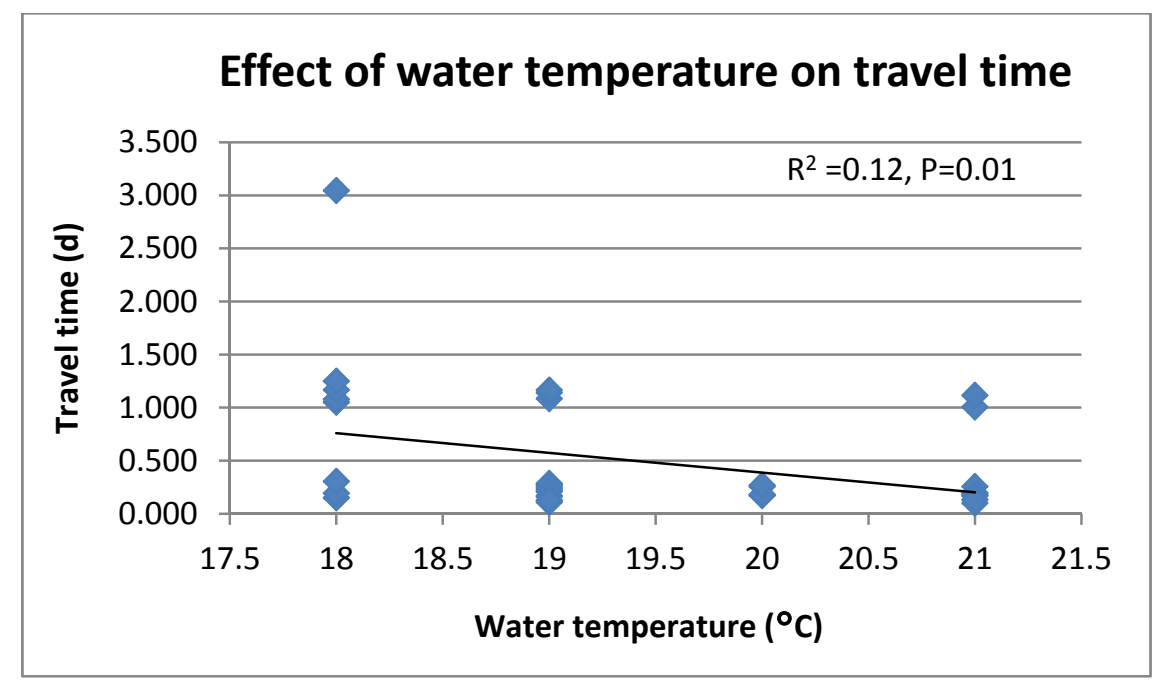

Figure 3.5.3 Water temperature (degrees celcius) and travel time (days) simple linear regression analysis for all fish that successfully passed and exited the CI LPS after release into rest box 3 in 2013

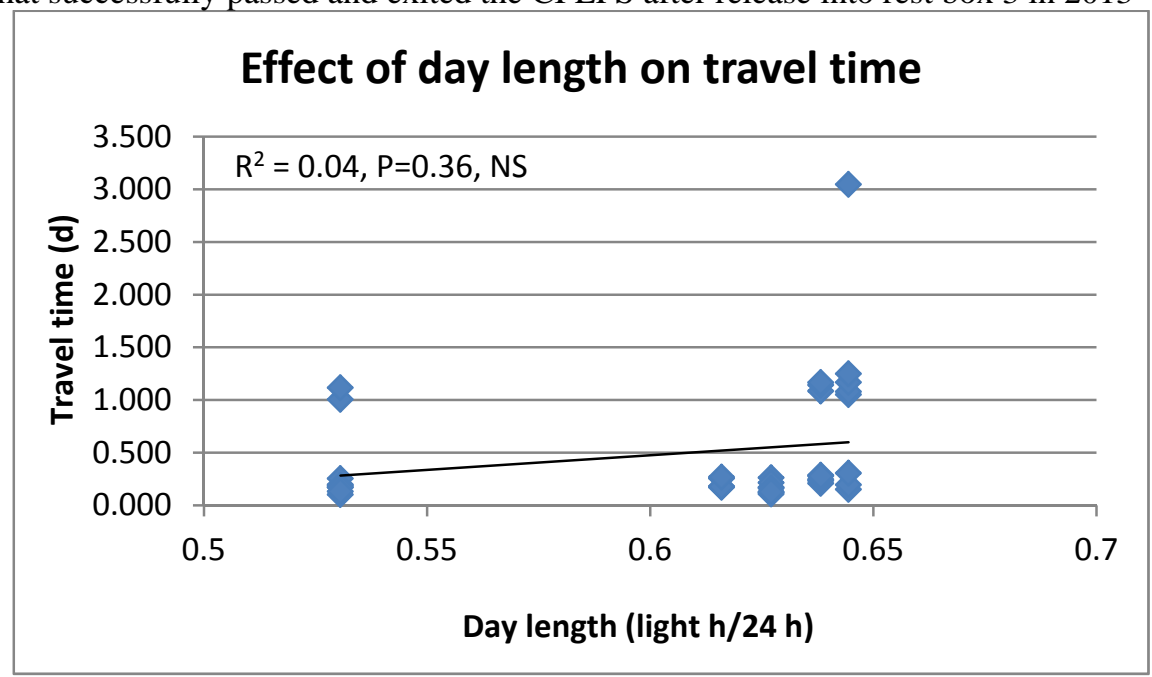

Figure 3.5.4 Day length (day light hours/24 hours) and travel time (days) simple linear regression analysis for all fish that successfully passed and exited the CI LPS after release into rest box 3 in 2013 


\subsection{Migration through Bonneville Reservoir}

Over the course of the study 28 lampreys migrated through the Bonneville Reservoir and reached The Dalles Dam. Eighteen of these were fish that successfully passed and exited the CI LPS (48.6\%, $n=37)$. Twelve of these fish belonged to Group 1, and six belonged to Group 2. Therefore, twice as many Group 1 fish (double tagged) made it to The Dalles Dam than Group 2 fish (PIT tagged only). Forty percent of fish from Group 3, which was released directly into the forebay bypassing use of the LPS entirely, migrated to The Dalles Dam.

There were three lampreys that re-ascended Bonneville Dam after fallback, migrated through Bonneville Reservoir, and were detected at The Dalles Dam. The single fish that experienced fallback over the spillway after exiting the structure also ascended Bonneville Dam via another route, migrated through Bonneville reservoir, and successfully traveled to The Dalles Dam.

\subsection{Travel Time through Bonneville Reservoir}

For fish that passed the LPS the mean travel time was $7.59 \mathrm{~d}(\mathrm{n}=18)$; the Group 1 mean travel time was $7.06 \mathrm{~d}(\mathrm{n}=12)$, while Group 2 was $8.66 \mathrm{~d}(\mathrm{n}=6)$, mean travel time between groups was not significant, again no tagging effect was present $(\mathrm{P}=0.27)$. Group 3 had a mean travel time of $9.69 \mathrm{~d}$ with a standard deviation of $10.82 \mathrm{~d}(\mathrm{n}=10)$, this group did not exhibit any pattern. Instead Release 1 had no fish reach The Dalles Dam, Release 2 had an extremely low mean passage time (1.36 d, n=2), Release 3 had an enormous increase (24.52 d, n=3), and Release 4 and 5 dropped back down drastically (Release 4: 4.12 d, n=4; Release 5: $4.11 \mathrm{~d}, \mathrm{n}=1$ ) (Table 3.7.1). 
Table 3.7.1 Travel time (days) for groups and releases of all fish that successfully passed the Bonneville reservoir after release in 2013 (Mean, standard deviation, and median)

\begin{tabular}{|l|c|c|c|c|c|c|c|}
\hline \multicolumn{7}{|c|}{ Travel time (d) - Bonneville Reservoir } \\
\hline & Statistic & Release 1 & Release 2 & Rlease 3 & Release 4 & Release 5 & Total Group \\
\hline Group 1 & $\overline{\mathrm{X}}=$ & 9.085 & 7.362 & 2.625 & 5.432 & 12.848 & 7.06 \\
\hline & $\mathrm{SD}=$ & 1.425 & 3.069 & 0.575 & 0.756 & 8.334 & 4.58578341 \\
\hline & $\mathrm{M}=$ & 9.085 & 5.995 & 2.884 & 5.432 & 12.848 & 5.981 \\
\hline & $\mathrm{n}=$ & 2 & 3 & 3 & 2 & 2 & 12 \\
\hline Group 2 & $\overline{\mathrm{X}}=$ & 15.152 & 9.236 & 4.136 & na & na & 8.66 \\
\hline & $\mathrm{SD}=$ & 8.099 & $\mathrm{na}$ & 2.079 & na & na & 6.64 \\
\hline & $\mathrm{M}=$ & 15.152 & 9.236 & 4.281 & na & na & 7.69 \\
\hline & $\mathrm{n}=$ & 2 & 1 & 3 & 0 & 0 & 6 \\
\hline Group 3 & $\overline{\mathrm{X}}=$ & $\mathrm{na}$ & 1.361 & 24.521 & 4.132 & 4.114 & 9.69 \\
\hline & $\mathrm{SD}=$ & $\mathrm{na}$ & 0.415 & 6.444 & 2.429 & na & 10.82 \\
\hline & $\mathrm{M}=$ & $\mathrm{na}$ & 1.361 & 27.741 & 3.449 & 4.114 & 4.24389468 \\
\hline & $\mathrm{n}=$ & 0 & 2 & 3 & 4 & 1 & 10 \\
\hline
\end{tabular}

Group 1 and 2 fish were grouped together since there was no significant difference

between mean travel times. These fish were deemed LPS fish and were compared

against Group 3 which was deemed the bypass group.

Table 3.7.2 Travel time (days) for fish that passed the CI LPS and traveled through Bonneville reservoir and for fish that bypassed the CI LPS and traveled through the Bonneville reservoir in a 2013 CI LPS study (Mean, standard deviation, and median)

\begin{tabular}{|c|c|c|c|c|c|c|c|}
\hline \multicolumn{7}{|c|}{ Bonneville reservoir - Travel time (d) } \\
\hline & Statistic & Release 1 & Release 2 & Rlease 3 & Release 4 & Release 5 & Total Group \\
\hline CI LPS & $\overline{\mathrm{X}}=$ & 12.12 & 7.83 & 3.38 & 5.43 & 12.85 & 7.59 \\
\hline & $\mathrm{SD}=$ & 5.90 & 2.68 & 1.60 & 0.76 & 8.33 & 5.21 \\
\hline & $\mathrm{M}=$ & 9.76 & 7.62 & 2.95 & 5.43 & 12.85 & 6.07 \\
\hline & $\mathrm{n}=$ & 4 & 4 & 6 & 2 & 2 & 18 \\
\hline Bypass & $\overline{\mathrm{X}}=$ & $\mathrm{na}$ & 1.36 & 24.52 & 4.13 & 4.11 & 9.69 \\
\hline & $\mathrm{SD}=$ & $\mathrm{na}$ & 0.41 & 6.44 & 2.43 & na & 10.82 \\
\hline & $\mathrm{M}=$ & $\mathrm{na}$ & 1.36 & 27.74 & 3.45 & 4.11 & 4.24 \\
\hline & $\mathrm{n}=$ & 0 & 2 & 3 & 4 & 1 & 10 \\
\hline
\end{tabular}




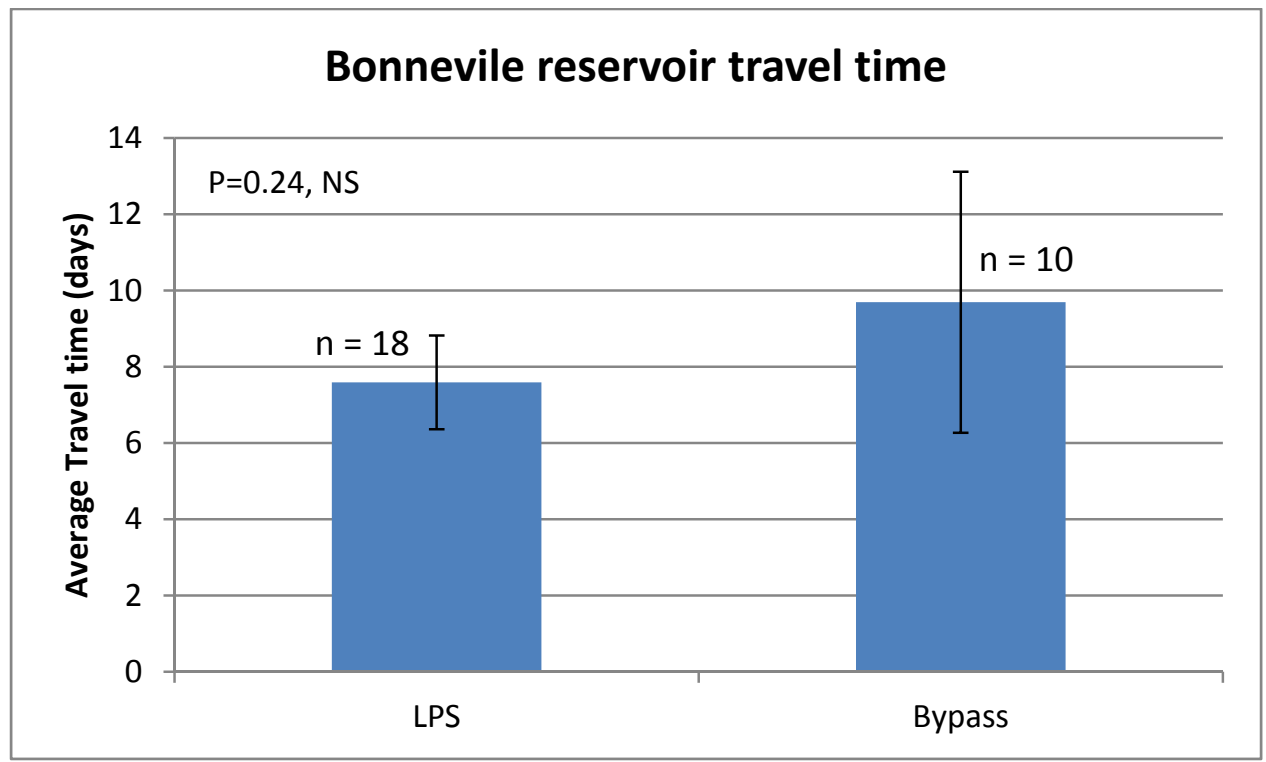

Figure 3.7.1 Average travel time (days) and standard error for fish that passed the CI LPS and traveled through Bonneville reservoir and for fish that bypassed the CI LPS and traveled through the Bonneville reservoir in a 2013 CI LPS study

Mean travel time between LPS and Bypass fish was not significant $(\mathrm{P}=0.24)$

(Figure 3.7.2). Mean travel time also was not significant among releases $(\mathrm{P}=0.419$, $\mathrm{n}=28$ ). Fish were pooled together and divided into sets identified by bins of time it took them to travel through the Bonneville Reservoir, fish that made it between $<5 \mathrm{~d}, 5-10 \mathrm{~d}$, and $>10 \mathrm{~d}$. Twelve lampreys traveled within the first block, nine within the second, and seven within the third (Table 3.7.3, Figure 3.7.2). 
Table 3.7.3 Bins of travel time ( $<5$ days, 5-10 days, and $>10$ days) with numbers of fish for all groups and releases for fish that passed the Bonneville reservoir in a 2013 CI LPS study

\begin{tabular}{|c|c|c|c|c|c|c|}
\hline \multicolumn{7}{|c|}{ Days - Bonneville reservoir (number of fish) } \\
\hline \multicolumn{7}{|c|}{$<5 d$} \\
\hline & Release 1 & Release 2 & Release 3 & Release 4 & Release 5 & Total Group \\
\hline Group 1 & 0 & 0 & 3 & 1 & 0 & 4 \\
\hline Group 2 & 0 & 0 & 2 & 0 & 0 & 2 \\
\hline Group 3 & 0 & 2 & 5 & 4 & 1 & 6 \\
\hline Total Release & 0 & 2 & 5 & 4 & 1 & 12 \\
\hline \multicolumn{7}{|c|}{$5-10 d$} \\
\hline Group 1 & 1 & 2 & 0 & 1 & 1 & 5 \\
\hline Group 2 & 1 & 1 & 1 & 0 & 0 & 3 \\
\hline Group 3 & 0 & 0 & 0 & 1 & 0 & 1 \\
\hline Total Release & 2 & 3 & 1 & 2 & 1 & 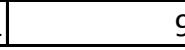 \\
\hline \multicolumn{7}{|c|}{$>10 \mathrm{~d}$} \\
\hline Group 1 & 1 & 0 & 0 & 0 & 1 & 2 \\
\hline Group 2 & 1 & 1 & 0 & 0 & 0 & 2 \\
\hline Group 3 & 0 & 0 & 3 & 0 & 0 & 3 \\
\hline Total Release & 2 & 1 & 3 & 0 & 1 & 7 \\
\hline \multicolumn{7}{|c|}{ All } \\
\hline Total & 4 & 6 & 9 & 6 & 3 & 28 \\
\hline
\end{tabular}

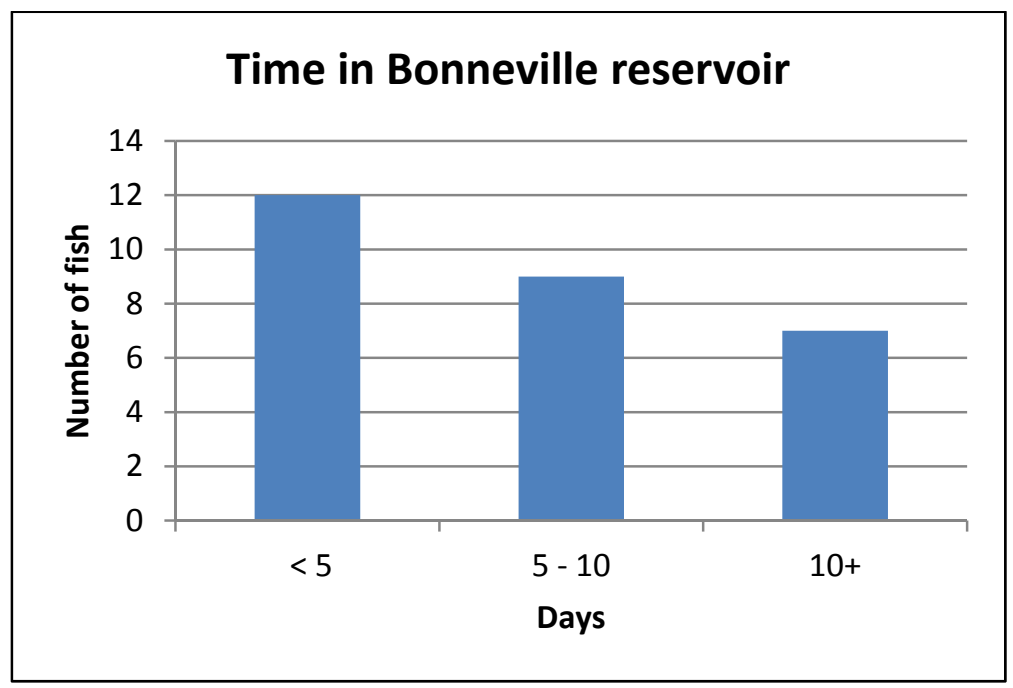

Figure 3.7.2 Numbers of fish that passed the Bonneville reservoir in each bin of travel time ( $<5$ days, 5-10 days, and >10 days) for fish that passed the Bonneville reservoir in a 2013 CI LPS study 
Fish Morphology Effect on Travel Time through Bonneville Reservoir

The overall mean length of lampreys that passed through Bonneville Reservoir and reached The Dalles Dam was $66.21 \mathrm{~cm}$ with a standard deviation of $3.37(\mathrm{n}=28)$. The means were comparable among groups. Among releases mean fish length in Release $1(67.25 \mathrm{~cm})$ was $4.75 \mathrm{~cm}$ longer than for Release $5(62.5 \mathrm{~cm})$. The maximum mean length was $67.25 \mathrm{~cm}$ (Release 1, $\mathrm{n}=4$; Release $4, \mathrm{n}=6$ ), and the minimum was $62.50 \mathrm{~cm}$ (Release 5, n=3) (Table 3.7.4). Travel time for fish that passed through Bonneville Reservoir had a positive correlation with length, but the relationship was not significant $\left(r^{2}=0.11, P=0.15, n=28\right)$ (Figure 3.7.3).

Table 3.7.4 Length (centimeters) of groups and releases for all fish that successfully passed the Bonneville reservoir after release in 2013 (Mean, standard deviation, and median)

\begin{tabular}{|c|c|c|c|c|c|c|c|}
\hline \multicolumn{7}{|c|}{ Bonneville reservoir - Length (cm) } \\
\hline & Statistic & Release 1 & Release 2 & Rlease 3 & Release 4 & Release 5 & Total Group \\
\hline Group 1 & $\overline{\mathrm{x}}=$ & 65.25 & 65.67 & 65.00 & 68.25 & 65.50 & 65.83 \\
\hline & $\mathrm{SD}=$ & 1.06 & 2.52 & 0.50 & 2.47 & 0.71 & 1.80 \\
\hline & $\mathrm{M}=$ & 65.25 & 66.00 & 65.00 & 68.25 & 65.50 & 65.75 \\
\hline & $\mathrm{n}=$ & 2 & 3 & 3 & 2 & 2 & 12 \\
\hline Group 2 & $\overline{\mathrm{x}}=$ & 69.25 & 61.50 & 66.67 & na & na & 66.67 \\
\hline & $\mathrm{SD}=$ & 1.06 & $\mathrm{na}$ & 3.62 & $\mathrm{na}$ & $\mathrm{na}$ & 3.67 \\
\hline & $\mathrm{M}=$ & 69.25 & 61.50 & 68.50 & $\mathrm{na}$ & $\mathrm{na}$ & 68.50 \\
\hline & $\mathrm{n}=$ & 2 & 1 & 3 & 0 & 0 & 6 \\
\hline Group 3 & $\overline{\mathrm{x}}=$ & $\mathrm{na}$ & 65.50 & 69.83 & 66.75 & 56.50 & 66.40 \\
\hline & $\mathrm{SD}=$ & $\mathrm{na}$ & 1.41 & 2.02 & 4.29 & $\mathrm{na}$ & 4.72 \\
\hline & $\mathrm{M}=$ & $\mathrm{na}$ & 65.50 & 71.00 & 66.75 & 56.50 & 67.00 \\
\hline & $\mathrm{n}=$ & 0 & 2 & 3 & 4 & 1 & 10 \\
\hline Total Release & $\overline{\mathrm{X}}=$ & 67.25 & 64.92 & 67.17 & 67.25 & 62.50 & 66.21 \\
\hline & $\mathrm{SD}=$ & 2.47 & 2.40 & 2.98 & 3.59 & 5.22 & 3.37 \\
\hline & $\mathrm{M}=$ & 67.25 & 65.25 & 67.50 & 67.75 & 65.00 & 66.00 \\
\hline & $\mathrm{n}=$ & 4 & 6 & 9 & 6 & 3 & 28 \\
\hline
\end{tabular}




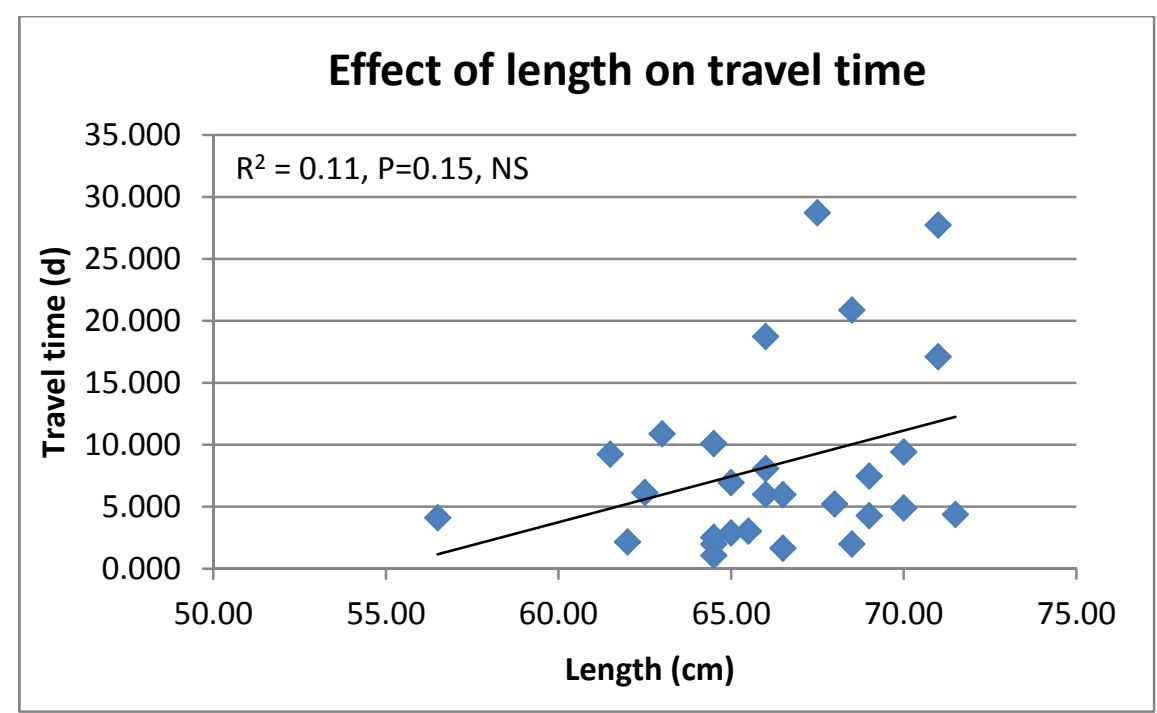

Figure 3.7.3 Length (centimeters) and travel time (days) simple linear regression for all fish that successfully migrated through the Bonneville reservoir in 2013

The overall mean weight of fish that passed through Bonneville Reservoir was $453.38 \mathrm{~g}$ with a standard deviation of $66.00 \mathrm{~g}(\mathrm{n}=28)$. The means were comparable among groups, and releases, although Release 5 had a lower mean than the rest. The maximum weight recorded for all releases was $492.5 \mathrm{~g}$ (Release 1, n=4), and the minimum was $375.6 \mathrm{~g}$ (Release 5, $\mathrm{n}=3$ ) (Table 3.7.5). Travel time for fish that passed through Bonneville Reservoir had a positive correlation with weight, but the relationship was not significant $\left(\mathrm{r}^{2}=0.05, \mathrm{P}=0.77\right)$ (Figure 3.7.3). 
Table 3.7.5 Weight (grams) of groups and releases for all fish that successfully passed the Bonneville reservoir after release in 2013 (Mean, standard deviation, and median)

\begin{tabular}{|c|c|c|c|c|c|c|c|}
\hline \multicolumn{8}{|c|}{ Bonneville reservoir - Weight (g) } \\
\hline & Statistic & Release 1 & Release 2 & Release 3 & Release 4 & Release 5 & Total Group \\
\hline Group 1 & $\overline{\mathrm{X}}=$ & 460.00 & 443.33 & 427.33 & 472.00 & 407.00 & 440.83 \\
\hline & $\mathrm{SD}=$ & 0.00 & 64.69 & 46.49 & 19.80 & 35.36 & 42.50 \\
\hline & $\mathrm{M}=$ & 460.00 & 422.00 & 410.00 & 472.00 & 407.00 & 445.00 \\
\hline & $\mathrm{n}=$ & 2 & 3 & 3 & 2 & 2 & 12 \\
\hline Group 2 & $\overline{\mathrm{X}}=$ & 525.00 & 332.00 & 468.00 & na & na & 464.33 \\
\hline & $\mathrm{SD}=$ & 7.07 & $\mathrm{na}$ & 105.36 & $\mathrm{na}$ & na & 97.12 \\
\hline & $\mathrm{M}=$ & 525.00 & 332.00 & 458.00 & $\mathrm{na}$ & na & 489.00 \\
\hline & $\mathrm{n}=$ & 2 & 1 & 3 & 0 & 0 & 6 \\
\hline Group 3 & $\overline{\mathrm{X}}=$ & $\mathrm{na}$ & 454.00 & 500.67 & 473.00 & 316.00 & 461.80 \\
\hline & $\mathrm{SD}=$ & $\mathrm{na}$ & 11.31 & 14.19 & 82.31 & na & 72.47 \\
\hline & $\mathrm{M}=$ & $\mathrm{na}$ & 454.00 & 498.00 & 464.00 & 316.00 & 475.00 \\
\hline & $\mathrm{n}=$ & 0 & 2 & 3 & 4 & 1 & 10 \\
\hline Total Release & $\overline{\mathrm{x}}=$ & 492.50 & 428.33 & 465.33 & 472.67 & 376.67 & 453.36 \\
\hline & $\mathrm{SD}=$ & 37.75 & 62.88 & 66.17 & 64.37 & 58.18 & 66.00 \\
\hline & $\mathrm{M}=$ & 490.00 & 434.00 & 480.00 & 472.00 & 382.00 & 459.00 \\
\hline & $\mathrm{n}=$ & 4 & 6 & 9 & 6 & 3 & 28 \\
\hline
\end{tabular}

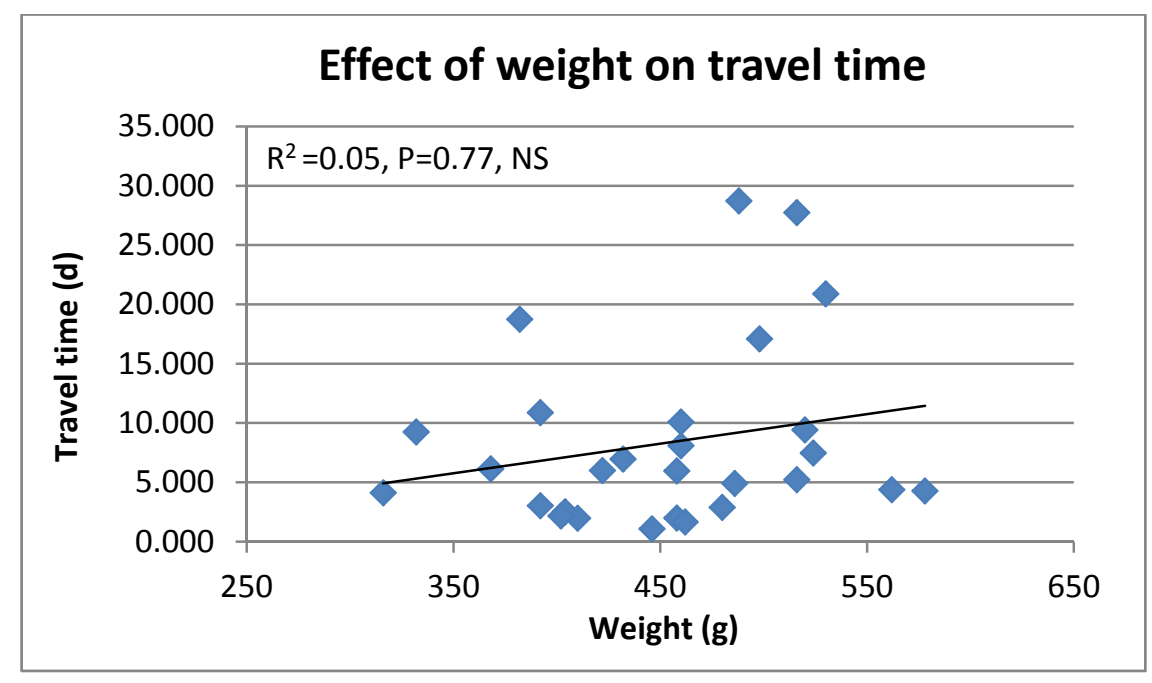

Figure 3.7.3 Weight (grams) and travel time (days) simple linear regression analysis for all fish that successfully migrated through the Bonneville reservoir in 2013 
The overall mean girth of fish that passed through Bonneville Reservoir was $10.75 \mathrm{~cm}$ with a standard deviation of $0.60(\mathrm{n}=28)$. The means were comparable among groups, and among releases. The maximum mean girth among groups was $11.12 \mathrm{~cm}$ (Release 1, $\mathrm{n}=4$ ) and the minimum was $10.00 \mathrm{~cm}$ (Release 5, $\mathrm{n}=3$ ) (Table 3.7.6). Travel time for fish that passed through Bonneville Reservoir was very weakly positively correlated with lamprey girth, and was not significant $\left(r^{2}=0.001, P=0.89, n=27\right)$.

Table 3.7.6 Girth (centimeters) for groups and releases of all fish that successfully passed the Bonneville reservoir after release in 2013 (Mean, standard deviation, and median)

\begin{tabular}{|c|c|c|c|c|c|c|c|}
\hline \multicolumn{7}{|c|}{ Bonneville reservoir - Girth (cm) } \\
\hline & Statistic & Release 1 & Release 2 & Release 3 & Release 4 & Release 5 & Total Group \\
\hline Group 1 & $\overline{\mathrm{X}}=$ & 11.000 & 10.333 & 10.500 & 11.000 & 10.000 & 10.542 \\
\hline & $\mathrm{SD}=$ & 0.000 & 0.289 & 0.866 & 0.000 & 0.000 & 0.542 \\
\hline & $\mathrm{M}=$ & 11.000 & 10.500 & 10.000 & 11.000 & 10.000 & 10.500 \\
\hline & $\mathrm{n}=$ & 2 & 3 & 3 & 2 & 2 & 12 \\
\hline Group 2 & $\overline{\mathrm{x}}=$ & 11.250 & 10.000 & 11.000 & na & na & 10.917 \\
\hline & $\mathrm{SD}=$ & 0.354 & $\mathrm{na}$ & 1.000 & na & na & 0.801 \\
\hline & $\mathrm{M}=$ & 11.250 & 10.000 & 11.000 & na & na & 11.000 \\
\hline & $\mathrm{n}=$ & 2 & 1 & 3 & 0 & 0 & 6 \\
\hline Group 3 & $\overline{\mathrm{X}}=$ & $\mathrm{na}$ & 11.000 & 11.000 & 11.000 & 10.000 & 10.900 \\
\hline & $\mathrm{SD}=$ & $\mathrm{na}$ & 0.000 & 0.000 & 0.707 & na & 0.516 \\
\hline & $\mathrm{M}=$ & $\mathrm{na}$ & 11.000 & 11.000 & 10.750 & 10.000 & 11.000 \\
\hline & $\mathrm{n}=$ & 0 & 2 & 3 & 4 & 1 & 10 \\
\hline Total Release & $\overline{\mathrm{x}}=$ & 11.125 & 10.500 & 10.833 & 11.000 & 10.000 & 10.75 \\
\hline & $\mathrm{SD}=$ & 0.250 & 0.447 & 0.707 & 0.548 & 0.000 & 0.60092521 \\
\hline & $\mathrm{M}=$ & 11.000 & 10.500 & 11.000 & 11.000 & 10.000 & 11 \\
\hline & $\mathrm{n}=$ & 4 & 6 & 9 & 6 & 3 & 28 \\
\hline
\end{tabular}

\section{Environmental Effects on Travel Time through Bonneville Reservoir}

When considering the reservoir environment that fish experienced, I used the day that the fish entered the Bonneville forebay for environmental data. These data were then compared with travel time for all fish that reached The Dalles Dam, regardless of whether 
they were released into the LPS and passed it or into the forebay (bypassing the structure).

When average daily water temperature was plotted against travel time through the Bonneville Reservoir there was hardly any relationship, and it was not significant $\left(\mathrm{r}^{2}=\right.$ $1 \times 10^{-6}, \mathrm{P}=0.87, \mathrm{n}=28$ ) (Figure 3.7.4). When daily average flow downstream from The Dalles Dam was plotted against travel time for fish that passed through the Bonneville Reservoir there was a negative and significant relationship $\left(\mathrm{r}^{2}=0.12, \mathrm{P}=0.012, \mathrm{n}=28\right)$ (Figure 3.7.5). When day length was plotted against travel time for fish that passed through Bonneville Reservoir there was a slightly negative relationship that was not significant $\left(r^{2}=0.0008, P=0.88\right)$ (Figure 3.7.6).

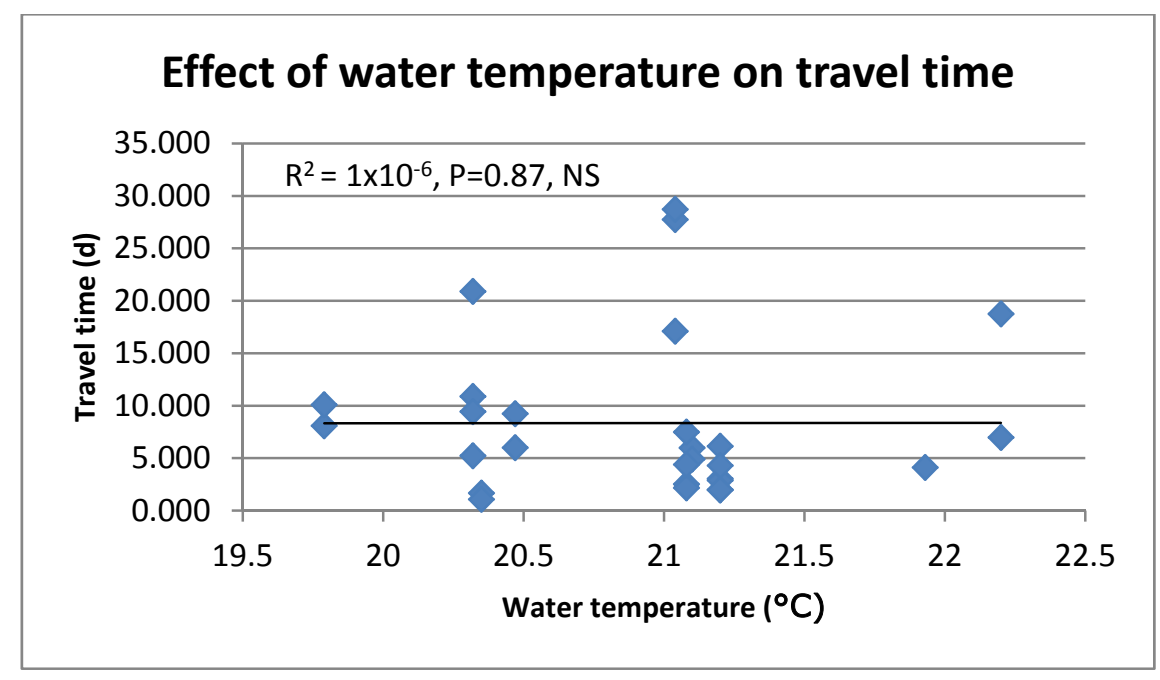

Figure 3.7.4 Water temperature (degrees Celsius) and travel time (days) simple linear regression analysis for all fish that successfully migrated through the Bonneville reservoir in 2013 


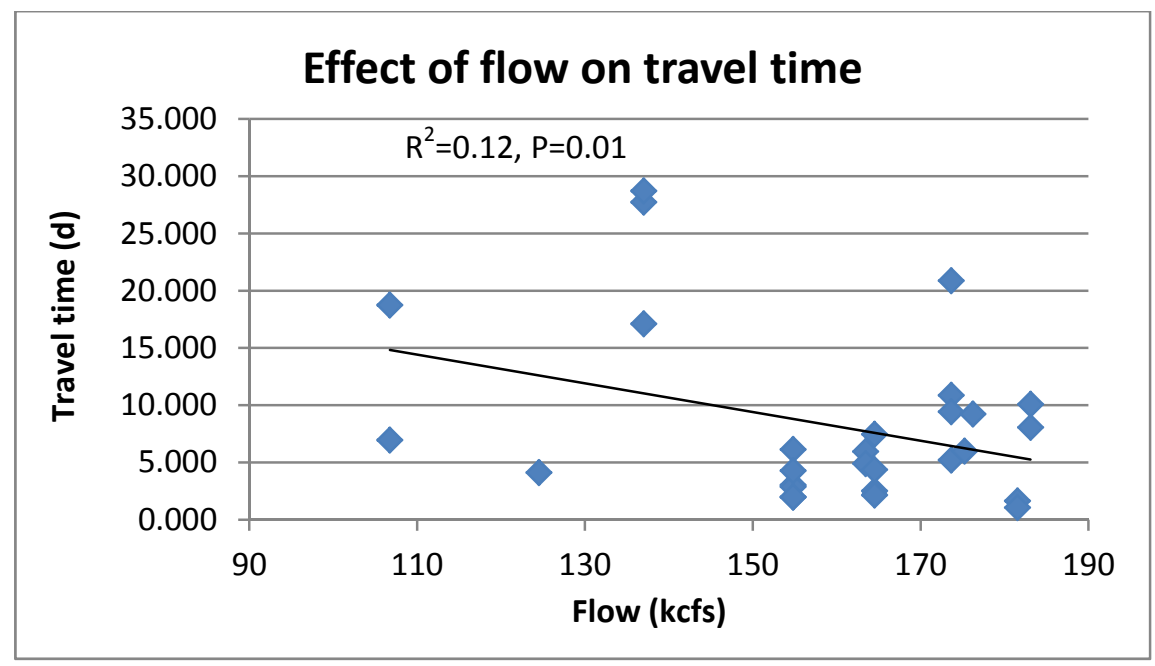

Figure 3.7.5 Flow (thousands of cubic feet per second) downstream from The Dalles Dam and travel time (days) simple linear regression analysis for all fish that successfully migrated through the Bonneville reservoir in 2013

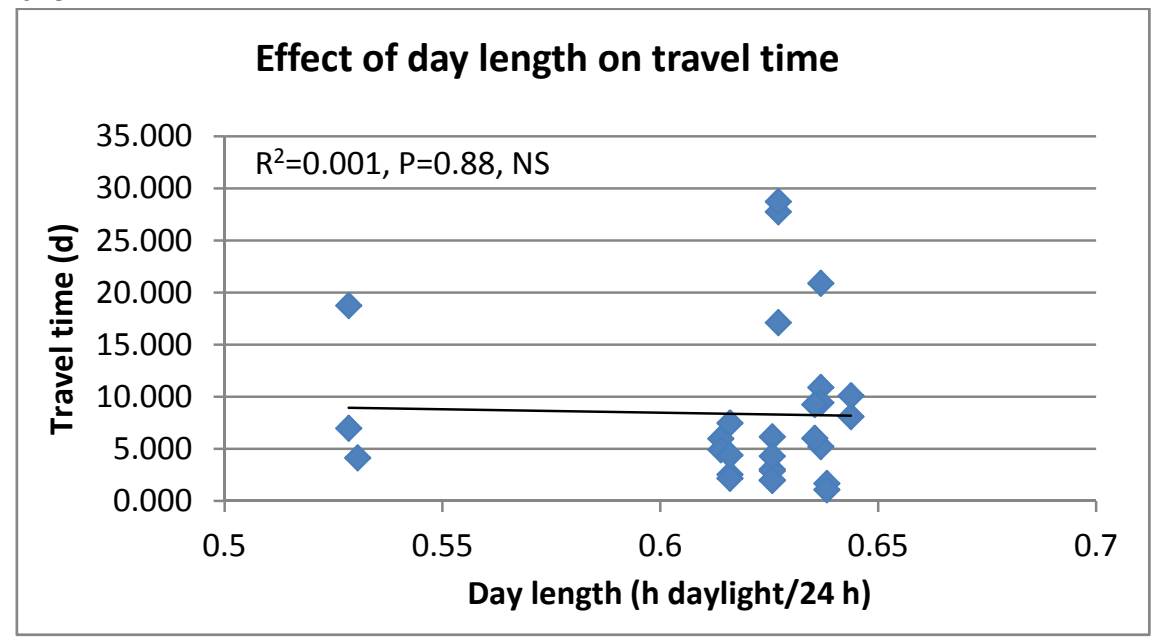

3.7.6 Day length (hours of day light/24 hours) and travel time (days) simple linear regression analysis for all fish that successfully migrated through the Bonneville reservoir in 2013

\subsection{Migration Upstream from The Dalles Dam}

Eleven lampreys made it to John Day Dam; one from Group 1, four from Group 2, and six from Group 3. None of these were from Release 5, and only one Group 3 fish was from Release 4. Six continued to McNary Dam; one from Group 1, four from Group 
2, and one from Group 3. Beyond that, four fish made it to Priest Rapids, all of which were from Group 2. Two of these were from Release 1 Group 2, and the other 2 from Release 3 Group 2. These same four fish migrated even further to Wanapum Dam, and finally only one of them made it to Rocky Reach Dam. No fish were detected in the Snake River. 


\section{Chapter 4: Discussion}

\subsection{Passage Efficiency in the LPS}

Outside of the study fish, relatively few lampreys used the CI LPS in 2013. It was reported in Corbett et al. (2014) that 155 fish passed the structure, 118 of these were volitional entries, and three of them were PIT-tagged fish released downstream from Bonneville Dam as part of another study. Of these three tagged fish, only two passed the LPS. This is very low considering that in 2012, the migration season prior to the exit pipe extension; over 2,000 fish used the structure. And compared to the first years of operation of the Bradford Island LPS (96\% passage efficiency from 2004-2005) and Washington Shore LPS (100\% passage efficiency from 2007-2008), the Cascades Island LPS had relatively low passage efficiency (74\%) as well (Moser et al. 2011a). Although it was not the first year of operation, the modification that took place extended the structure to nearly twice as long and drastically change the route of passage for fish. Thus structurally and functionally the LPS was in its first year.

The low collection efficiency at CI LPS $(n=155)$ in 2013 compared to the previous year $(n=>2,000)$ and the other LPSs $(n=>6,441-14,975)$ could be explained by the lamprey's incredible olfactory sensitivity. Moser et al. (2011a) found that both the Bradford Island and Washington shore LPS collection efficiencies, defined as the number of lamprey that entered each structure divided by the number in the adjacent channel, increased over time. Corbett et al. (2013) also found that numbers of fish using the CI LPS prior to the 2013 modification increased over the first three years of experimental operation. This suggests that as the structure ages, it becomes more attractive for 
lampreys to enter. New metal and PVC, such as that installed at the CI LPS upper end in 2013, could have deterred fish from entering, similar materials were used in the construction of Bradford Island and Washington Shore LPSs. This might explain the drastic change from 2,000 fish in 2012 (after 3 years of operation) and 155 in 2013 (first year of operation with exit pipe), especially considering that PVC had not been used anywhere on this structure previously (Corbett et al. 2013). If this is the case, use of the CI LPS could improve after several years of operation of the modified LPS. Another possible reason for the overall lack of volitional entrances at the CI LPS in the 2013 migration season is its proximity to the spillway, which could create extremely turbulent conditions near the fishway entrance, thereby deterring fish from choosing this route (Moser et al. 2002b). However, considering that the structure experienced significantly higher collection in the previous migration season, this explanation is less likely to be the driving factor.

The low passage efficiency of my study fish compared to passage efficiencies at Bradford Island and Washington Shore LPSs could be due to a number of reasons. Moser et al. (2011a) found that short, steep ramps are ideal for lamprey climbing behavior after a single long (3.8 $\mathrm{m})$, steep $\left(40^{\circ}\right)$ ramp was modified to two shorter (1.4 m), steep $\left(45^{\circ}\right)$ ramps at the Bradford Island LPS. The shorter ramps decreased overall median passage time by $>50 \%$ and slightly increased passage efficiency. The CI LPS includes a series of long $(3-10+\mathrm{m})$, steep $\left(30-45^{\circ}\right)$ ramps, thus presenting a challenging climb for lampreys and possibly slowing them down and decreasing passage efficiency. It is also possible that the new portion of the structure is discouraging fish from passing 
once they're in the structure as they do not sense that fish have used it previously. Of the tagged fish that volitionally entered the LPS, $66 \%(n=3)$ passed the structure, this number is lower than for our study fish, however the sample size makes it difficult to compare.

While passage in the CI LPS does not mirror the higher efficiencies seen at the other lamprey specific structures at Bonneville Dam, it is much higher than efficiencies experienced in traditional fishways at Bonneville Dam. Keefer et al. (2009a) presented a 3-year study in which 42-53\% of over 3,500 lampreys were able to pass Bonneville Dam via traditional fishways, as well as a 10-year study (Keefer et al. 2013b) which found passage efficiencies of $41-57 \%$, and Moser et al. (2002a) which showed $<50 \%$ passage at all entrances and fishways ( $n=197-299$ from 1997-2000). Hence, while it seems that improvements at the CI LPS may be necessary to increase passage efficiency when compared to other LPSs, it is clearly an improvement over traditional passage routes at the dam.

\subsection{Fallback}

Only $2.7 \%$ (1 of 37) of my study fish experienced fallback to the tailrace over the spillway after passing and exiting the LPS. Similarly Moser et al. (2002b) found that less than $5 \%$ of study fish were detected downstream from the dam after passing through traditional fishways. Thus my findings were on par and perhaps even a bit better than for fish that successfully passed traditional fishways. Despite the small sample size in my study, the observation that only one fish experienced fallback over the spillway after using the exit slide is promising. It means that the slide is located far enough upstream to 
prevent excessive fallback. My results indicate that a significant number of fish aren’t using energy to pass the structure to ultimately fallback to the tailrace of the dam.

Corbett et al. (2013) found that prior to modification of the CI LPS, some study fish planted in rest box 3 fellback in the structure, meaning they were detected at a PIT array downstream from restbox 3 , and then re-ascended to the terminal trap box. The fallback rate was 20\% (4 of 20) in 2011 and 8\% (4 of 50) in 2012. My findings fell within those: $16 \%$ (8 of 50) of fish experienced fallback within the structure and then succeeded in turning around, re-ascending, and exiting the LPS. It seems that the CI LPS is able to provide a path for some fish to successfully continue ascending the structure even after brief fallback.

There was a group of ten fish (20\%) in my study that were not able to successfully ascend the CI LPS after fallback and did in fact fall all the way out of the structure to the tailrace. Of the tagged fish that volitionally entered in 2013, 33\% (1 of 3) fellback (Corbett et al. 2014), while studies on the CI LPS prior to the modification found fallback to the tailrace of 20\% (4 of 20) in 2011 and 18\% (9 of 50) in 2012 (Corbett et al. 2013). Moser et al. (2011a) found via PIT detections that fish climbing the Bradford Island structure did so in a "unidirectional” manner, suggesting that no fish fell back. They surmised that this was due to the narrow rest box funnels that were present in that structure and are different from the fykes in the CI LPS (Moser 2014). Thus, the difference in the entrance fyke leading into the rest box could be allowing fish to fallback at the CI LPS. This could be prevented by modifying the entrance fykes to something 
more similar to the ones at Bradford Island, or testing a new technology such as a oneway flap gate. This design is currently being tested on rest box 4 at the CI LPS.

It is clear that fallback is a problem in the CI LPS. However, it is promising that several of these fallback fish, including the tagged volitional entrance fish, were able to re-orient in the tailrace and ascend the dam via traditional fishways, LPSs, and/or possibly the lock. Fifty percent of fallback fish (5 of 10) attempted to ascend the dam via other routes. Thirty percent ( 3 of 10 ) persisted and were able to ascend the dam via other routes. Successful routes included the Washington Shore fish ladder. Two fish that ascended via other routes presumably passed via the unmonitored navigation lock, as they were detected at upstream sites but not at any other locations at Bonneville Dam. This represents 4\% of all fish that were placed into Resting Box 3 (2 of 50). Moser et al. (2002b) found that 1\% of 950 tagged study fish passed Bonneville Dam via the navigation lock, which is lower than what I found; but, that study had a much larger sample size. The two fish that were unsuccessful attempted to pass via the underground migration tunnel at the Washington Shore ladder, and the Cascades Island Fishway. Interestingly both failed routes were via traditional fishways upstream from the CI LPS, implying that these fish may not have had the energetic reserves after failing at the LPS and entering such environments. It is not surprising however, that other fallback fish persisted at passing locations other than the CI LPS, as the turbulence and noise created by the spillway can reduce use of the Cascades Island fishway entrance (Moser et al. 2002b). 
Moser et al. (2002b) revealed that lampreys often made several attempts at passage in traditional fishways despite failed attempts. This same behavior was found but at a larger scale for fish that experienced fallback. Lampreys seem to be persistent in their attempts at passage and ascending structures such as dams. My data supports this general behavior. Thus, fallback does not always mean the end of migration for a fish, as they have been shown to continue to attempt to pass at other locations. However, preventing fallback will both reduce energetic expenditures, migration delay and losses of fish that don't find another route.

According to previous studies, passage efficiencies at dams further upstream were 50-72\% at The Dalles Dam, 27-55\% at John Day Dam, and 50-80\% at McNary Dam (Keefer et al. 2013a). Moreover, passage at Willamette Falls fishways on the Willamette River was only 34\% (Mesa et al. 2010). While some of these numbers are similar to or even higher than those found at the CI LPS, others are very low. It will be important to continue monitoring of collection, passage, and fallback at the CI LPS to see if it increases over time; such a result would make the installation of LPSs at other dams a subject for scientists and managers in the region to advocate and allocate monies for.

\subsection{Travel Time in the LPS}

Travel times in the CI LPS far exceeded those of the Bradford Island and Washington Shores LPS's. Mean passage time at some sections of the Bradford Island LPS was about $0.5 \mathrm{~h}(\mathrm{n}=>1500,2004-2008)$ (Moser et al. 2011a) and about $0.5 \mathrm{~h}$ through most of the Washington Shore LPS ( $n=44,2007-2008)$ (Moser et al. 2007). This is compared to the mean travel time that I found at the CI LPS of about $12 \mathrm{~h}(\mathrm{n}=37$, 
2013). In contrast, one tagged volitional entry from a different study had a $1.6 \mathrm{~h}$ passage time (Corbett et al. 2014). Moser et al. (2011a) found that of the fish with $>1 \mathrm{~h}$ passage times at the Bradford Island LPS, most of the time was spent on the $3.8 \mathrm{~m}$ long steep portion. My study showed that the mean passage time from rest box 3 to the pond, the steep portion of the structure encountered by fish, was $9.36 \mathrm{~h}$ ( $22.5 \mathrm{~m}$ long x $11 \mathrm{~m}$ high). The volitional entry spent $1.5 \mathrm{~h}$ on the lower portion including the steepest portion of the structure (Corbett et al. 2014). Fish traveling the completely flat portion of the structure between the pond and the exit pipe was, on average, $3.84 \mathrm{~h}$. The volitional entry spent $0.2 \mathrm{~h}$ on this portion (Corbett et al. 2014). Thus my fish and the volitional entry with PIT detections also spent a majority of the time traveling the steep portion of the structure.

The size and configuration of the CI LPS is very different than that of Bradford Island and Washington Shore. Recall that Bradford Island LPS is $35 \mathrm{~m}$ long x $8 \mathrm{~m}$ high and Washington Shore LPS is $19 \mathrm{~m}$ long x $9 \mathrm{~m}$ high. In comparison, the CI LPS reaches from the tailrace to the forebay and is $181 \mathrm{~m}$ long x $27 \mathrm{~m}$ high; making it more than 5 times longer and 3 times higher than either previously installed LPS at Bonneville Dam. It also features a series of long, steep switchbacks, as previously discussed, that are not present at either Bradford Island or Washington Shore The length and steepness alone could explain the extremely increased passage times, but it is important also to note that the newness of the structure may have also slowed fish down or discouraged them from moving immediately.

Despite the relatively slow travel times recorded at the CI LPS compared to much shorter and less steep LPSs, CI LPS travel times were still much lower than median travel 
time at traditional fishways at Bonneville Dam. At traditional fishways median travel times were found to be 4.4-5.7 d ( $\mathrm{n}=950)$ in a 2002 passage efficiency study (Moser et al. 2002a). Compare this number to median travel time in the CI LPS of $5.5 \mathrm{~h}$ and the CI LPS, again, far outperforms traditional fishways. Hence, LPSs whether long and steep or short and less steep are aiding in faster lamprey passage, which could save energetic reserves for traveling upstream.

Very interestingly, the passage time and travel time comparisons between Group 1 (PIT and radio tagged) and Group 2 (PIT tagged only) were not significantly different. This suggests that there was no tagging effect. The results indicate that Group 1 (PIT and radio tagged) fish actually had a higher passage efficiency and faster travel time; while not statistically significant the passage efficiency comparison was very close. Group 2 experienced three mortalities in Release 4, while no radio-tagged fish were known to have died. This is extremely counterintuitive to what one would expect for the two tagging methods. Group 2 was double tagged with a PIT and radio tag, which required a larger incision, a surgery that is 2-4 times longer and necessitated 3-4 stitches. The two tags take up more space in the body cavity, an antenna drags behind the fish, and the tags weigh 3 times more than Group 1's PIT tag only. Thus Group 2 might be expected to perform worse than Group 1. The finding that there is no tagging effect and that Group 2 actually preformed slightly better means that double-tagging is not having an effect on lamprey ability to negotiate the structure and could be important for future studies when deciding which tagging technique will address certain questions. Passage time among releases was found to be significantly different. This finding is supported by the fact that 
fish moved very slowly in the first release of the study and then sped up through Release 2 and 3 before slightly slowing down again in Release 4 and 5.

Fish were released at the onset of darkness and data showed that they also ascended and exited the LPS during hours of darkness. It was clear however that a bimodal population was present, with one outlier. Seventy-three percent $(n=37)$ of fish ascended the night that they were released, $24.3 \%(n=37)$ ascended the following night, and $2.7 \%(n=37)$ ascended over the course of four nights. The propensity of some fish to wait before travelling through the structure could be explained by a few mechanisms. First, it is possible that some fish took longer to recover from the effects of surgery and thus did not move the same night as they were released. However, this does not explain why fish consistently passed the structure during the nighttime. That is, if lamprey didn't pass the first night they waited out the entire next day and passed that night.

Keefer et al. (2013c) discussed how the time of day that lamprey move is contextdependent. In reservoir habitats, which are considered more natural, water flow is lower and avoidance of predators is easier because of the darkness of depths traveled by lampreys. In these environments lamprey were found to be active during most hours of the day. At dams, which are not a natural habitat setting, hydraulic complexity is high, high gradient flows exist, and an abundance of predators are present. Lampreys were found to shift to mostly nocturnal behavior in these settings. Such behavior at dams could explain why fish waited until the following night to pass rather than doing so in the daytime. Although the structure is enclosed and mimics a more natural path for lamprey to travel, small cracks in the structure may allow the presence of sunlight. Warming 
during the daytime, the presence of metal and PVC, and the CI LPS proximity to the loud and turbulent spillway probably also cued fish not to move during the day. This is most likely the mechanism behind the bimodal distribution I observed, with all fish moving strictly during the nighttime.

These findings by Keefer et al. (2013c) lead me to examine my population of fish in a different manner. By subtracting the daytime hours from travel times of fish that traveled the LPS on subsequent nights I was able to come up with travel times that only addressed times when fish were actually ascending the structure. However, when these values were used to test for relationships with physical and environmental factors, the same relationships were found to be statistically significant and they did not always improve $\mathrm{r}^{2}$.

Fish Morphology Effect on Travel Time in LPS

Two studies by Keefer et al. (2013a, 2013b) using large radiotelemetry datasets over three $(n=>300)$ and $10(n=>2,000)$ years found that larger bodied lampreys were more likely to pass traditional fishways at dams. Passage studies at LPSs located at Bonneville Dam did not asses length, weight, or girth, as possible factors affecting passage, perhaps because passage efficiencies were so high (Moser et al. 2011a, 2011b; Corbett et al. 2013, 2014). This does not allow for comparison between size effects at other LPSs and the CI LPS. Length did not have a significant effect $(\mathrm{P}=0.06)$, however if the slowest fish had traveled faster, a significant effect may have been present. Weight and girth had no statistically significant effect on travel time in the LPS. However, the relationships that were found were contradictory to previous studies and what I might 
expect. Both positive relationships, although not significant, supported the fact that longer and heavier (larger) fish took longer to pass the LPS. It is possible that larger fish must use more energy to move and may then move slower through an unnatural setting such as an LPS. The results could also be a factor of timing considering that the final release was significantly shorter and lighter and experienced warmer temperatures, which might have motivated them to move faster, creating this pattern.

Length and weight varied much more than girth in our study fish. Thus it is not surprising that girth did not have a significant effect and that it had the weakest relationship to travel time in the LPS. Other studies have not tested for its effect specifically. However, the girth of the fish is very important in the reduction of tag effects. Moser et al. (2007) found that for Pacific lamprey surgically implanted with radio tags, greater girth yielded higher passage efficiencies and shorter times to approach the dam after release. This paper did not address how tagging would affect time to pass the dam, but girth of tagged fish clearly is important for reduction of tag effects. Some studies have selected larger fish for tagging purposes so that the body cavities would have enough room to carry larger tags. This was not done for my study due to tag miniaturization and the generally large lamprey sizes captured.

\section{Environmental Effect on Travel Time in LPS}

Studies that included water temperature as a factor in lamprey movement have been numerous. Keefer et al. (2009b) found that despite warming of water temperatures over the last few decades, the timing of lamprey migration relative to temperature has stayed the same. From 2005-2007 half of the lamprey run had passed Bonneville Dam by 
the time water temperatures fluctuated around $19^{\circ} \mathrm{C}$, and about $80 \%$ had passed by the time temperatures were between $21-23^{\circ} \mathrm{C}$; the same trend was found for visual counts during the years 1939-1969 and 1998-2007 (Keefer et al. 2009b). Studies at Bonneville Dam and The Dalles Dam showed that lampreys moved faster through the tailrace and fishways as water temperatures increased (Keefer et al. 2009a, 2009b). Similarly, in general, lamprey passage increased at Willamette Falls and in the John Day River as water temperature increased, and decreased as water temperature decreased (Moser and Mesa 2009). Robinson and Bayer (2005) also found, as previously mentioned, that fish halted migration in September when temperatures peaked and that they did not move for six months. Clemens et al. (2012) also found that lamprey in the Willamette River halted migrations when peak summer temperatures occurred.

When Group 1 and 2 were combined (due to no significant tagging effect) and assessed for average CI LPS travel time, there was a significant difference among releases. While four of the five releases occurred in July, release dates were a proxy for temperature because as the migration season progressed, temperature increased. Thus travel times were significantly different as the temperature progressed over the season. Akin to previous studies which showed faster movement as temperatures increased, significant effects of water temperature on travel times in my study supported the general relationship that as temperature increases, travel time decreases. However, for Release 5, which occurred in September when temperatures peaked between $21-23^{\circ} \mathrm{C}$, lamprey movement through the LPS began to slow down. This is similar to seasonal effects reported by Robinson and Bayer (2005), who found that lamprey halted movement in 
September. This could explain why fish in the CI LPS were trending toward slower passage in Release 5 in anticipation of stopping to overwinter.

When addressing the bimodal population it was discovered that none of these fish were from Release 3 or Release 4 . This could be due to the fact that for these release, ideal temperatures for lamprey occurred, as we saw the fastest travel times in these two releases. The slowest fish was a part of Release 1; this could be due to the lower temperature not cueing fish to move as fast.

Water temperature in the LPS was unexpectedly between 1 and 2 degrees lower than that in the forebay. This could be explained by the pumps feeding the LPS being located deeper in the forebay than where temperature gauges are present. Alternatively, the evening point checks made in the CI LPS may not have been indicative of daily averages (represented by forebay temperature recordings). Nevertheless, this temperature difference might have actually aided in passage during the warmer temperatures by keeping the LPS slightly cooler than river water temperatures. However the three mortalities during Release 4 lead me to question this hypothesis.

Although it was not one of the strongest relationships, day length did account for a small amount of the variation in CI LPS passage time. The overall trend for day length over the migration season was decreasing, as was the travel time in the LPS, with some fish slowing down substantially in September. The relationship between day length and travel time generally indicated that when there were more daylight hours (earlier on in the summer) fish traveled slower, and when daylight hours got shorter (later on in the summer) fish traveled faster. This is interesting in that fish are traveling faster when they 
have more night time hours. This supports the idea that lamprey are highly nocturnal when moving through complex and unnatural environments such as LPSs (Keefer et al. 2013c; Moser et al. 2013).

\subsection{Migration through Bonneville Reservoir}

Keefer et al. (2009a) found that 28-33\% $(n=3,598)$ of tagged fish made it to The Dalles Dam after using traditional fishways. Despite a small sample size in my study, 36\% (18 of 50) of my overall sample was detected at The Dalles Dam, while 48.6\% (18 of 37) that passed through the CI LPS were able to do so. Of the bypass fish (Group 3), 40\% $(\mathrm{n}=25)$ made it to The Dalles Dam. These numbers seem low; but could be so for a number of reasons. A radio tag study on the tributaries branching from the Bonneville Reservoir found that almost no fish entered following their passage at Bonneville Dam (Keefer et al. 2009a). However, several Noyes et al. (2012, 2014) studies using a different tagging technology found that fish in the Bonneville Reservoir were using tributaries more than expected. Fish were found entering the White Salmon, Hood, and Klickitat Rivers which are tributaries to the Bonneville Reservoir (Noyes et al. 2012, 2014). My study revealed that one fish from Release 5 Group 3 made it to the Hood River, a tributary of the Bonneville reservoir. Thus, the 19 fish that passed the LPS and did not make it to The Dalles Dam may have traveled into tributaries. It is also possible that they overwintered in the reservoir, experienced pre-spawning mortality, or spawned in the small amount of suitable habitat in Bonneville Reservoir (Noyes et al. 2014).

Twice as many fish from Group 1 (PIT and radio tagged) made it to The Dalles Dam than Group 2 (PIT tagged only) and they did so at a faster rate. Again, this is 
interesting considering that Group 1 was double tagged. It is possible that more radio tagged fish were detected than PIT-only fish, which would account for this discrepancy. When these groups were combined they still exhibited faster average travel time than the bypass group. Based on these findings, it appears that the CI LPS is not impeding passage to the next upstream dam and that it may actually be aiding lamprey migration.

An interesting finding from Moser et al. (2011a) was that fish that passed through the Bradford and Washington shore LPSs exhibited lower detection rates at upstream sites relative to those that passed through the traditional fishways. However, my findings do not necessarily support this. As LPSs are still a new and changing technology we may see more fish being detected at upstream dams as LPSs are further improved and weathered. Although my study only found that $48.6 \%$ of fish that passed the LPS also reached The Dalles Dam, it is important to note that detection efficiencies at upstream dams are not perfect. For example, The Dalles Dam was found to have the lowest detection efficiency (76\%) of the four lower Columbia River dams (Keefer et al. 2009a). So it is possible that more fish actually reached The Dalles Dam before finding spawning habitat, stopping migration movement, or dying.

It is also promising that all fish that navigated the dam via other routes after fallback were detected at The Dalles Dam. Although measures to reduce fallback need to be addressed, it seems that some of these fish are still able to migrate successfully upstream after being unsuccessful in using the CI LPS. Improvements at traditional fishways, which several of these fish attempted to use, are vital to passing more fish upstream. Operational changes such as changing flow velocities at nighttime (Johnson et 
al. 2012) and structural changes such as rounded sharp edges (Keefer et al. 2010) could ensure that more fallback fish are able to ascend the dam following failed attempts.

\subsection{Travel Time through Bonneville Reservoir}

Group 1 and 2 exhibited a similar trend in mean travel times to those they exhibited in the LPS. However, as discussed previously there was no tagging effect found for fish that traveled through the LPS, so Bonneville Reservoir travel times for Group 1 and 2 were pooled together and compared to Group 3 (fish that completely bypassed the structure and were released directly into the Bonneville Dam forebay at the start of the Bonneville Reservoir). It is possible that passing an LPS with such a dramatic climb could produce a slowed migration after they exit the structure (Moser and Mesa 2009). Fish that used the LPS took $7.5 \mathrm{~d}$ on average to move through the Bonneville Reservoir while fish that bypassed the LPS took $9.7 \mathrm{~d}$, and moved at a mean rate of 14 $\mathrm{km} / \mathrm{d}$, which is consistent with the average ground speed of $11-20 \mathrm{~km} / \mathrm{d}$ reported by Moser and Mesa (2009). Hence, slowed migration for CI LPS users was not present. Although travel time between LPS and bypass fish was not significantly different, it is sensational that fish that used the LPS traveled, on average, faster than those that did not use the structure at all. Such a result could suggest that using the LPS does not slow lamprey down and actually might aid or motivate faster passage to upstream dams.

No significant difference between CI LPS and bypass travel times through the reservoir allowed for pooling of these groups. Doing so presented a pattern consistent with other studies of extremely variable passage times through reservoirs, in which some fish took on the order of days while others took months to pass through reservoirs 
(Keefer et al. 2009b; Moser et al. 2013). This type of movement is erratic and one might expect that certain passage times could be associated with certain times of the migration season. However, this is not the case. After pooling the data, categories of fast, intermediate, and slow moving fish resulted, but there was no clear pattern among groups or releases within any category. Moser et al. (2013) found that lampreys are temperamental. Specifically, when presented with obstacles to migration, such as that of an LPS, individual temperament may be amplified. The temperament of fish followed the categories I found when my data were pooled; some fish were poor performers and swam slowly and probably did not pass to the furthest reaches, while others were strong performers that swam quickly. While genetic and physical factors could play a role in these differences, environmental experience seems a likely determining factor. Fish with exposure to riskier environments, higher predation, or recent interaction with a host species may perform better at sites such as dams and LPSs. They also might recover and swim rapidly after passage. These are the stronger performers. Fish that have overwintered, are timid, or move primarily at night might become a part of the weak performers (Moser et al. 2013). Such behaviors are consistent with those seen in my study and could explain the extreme variation in travel rates.

\section{Fish Morphology Effects on Travel Time through Bonneville Reservoir}

According to previous radiotelemetry studies described by Keefer et al. (2009b), the heaviest lamprey traveled the furthest in the Columbia Basin. Larger fish may experience less effect of handling and tagging than smaller fish (Keefer et al. 2009a). Similarly, Moser et al. (2007) found that the tag burden for fish with smaller girth 
resulted in slower times to approach Bonneville Dam after release downstream. Our study did not reflect this and instead found that length and weight had positive but not significant relationships with travel time, and that girth had a very weak relationship. The relationship however, is again, contradictory to previous studies in that larger fish were found to be traveling slower. My reasoning is that steep climbing required by the LPS favors smaller sized fish (they have less mass). However, I would expect that large fish might move more easily in the reservoir, since it’s a natural habitat. Nevertheless, fish seemed to be performing the same in the LPS as they did in the reservoir. The smaller size of Release 5 lampreys during warm temperatures could, however, have affected the distribution. Further study is needed to elucidate this point.

\section{Environmental Effects on Travel Time through Bonneville Reservoir}

Severe attrition between Bonneville and The Dalles Dam s drastically decreased an already small sample size, making it hard to detect strong relationships between environmental factors and travel time through the reservoir. The findings for studies that evaluated temperature as a factor in lamprey passage also apply to reservoir travel time. Keefer et al. (2009b) found that migration rates of lamprey were positively correlated with water temperature; thus as water temperature increased so too did the speed of migrating lampreys, while colder water temperatures resulted in slower migration. I did see a positive correlation of travel time and temperature, although it was not statistically significant. Similarly, Moser et al. 2013 did not find a significant relationship between temperature and reservoir passage time. 
Keefer et al (2009b) found that migration rates were negatively correlated with river flow; thus as river flow increased fish took more days to travel through study reaches. This is similar to what I found and was the only significant effect of environment on travel time in Bonneville reservoir in my study. High flow events, usually during the spring and early summer, could slow fish down by presenting increased water velocity and more hydraulic complexity. Additionally, high flow events increase river volume, thus the presence of pheromones could be diluted by higher flows. The absence of these important olfactory cues could be confusing to upstream migrating fish. This could cause fish to become disoriented and travel more slowly (Yun et al. 2011).

Day length effects on travel time were not significant and my results actually indicated that it did not account for any variation in travel time. However, several studies (Keefer et al. 2013c; Moser et al. 2013) have identified significant effects of time of day fish travel, suggesting that my sample size may have been too small to detect such an effect.

\subsection{Migration Upstream from The Dalles Dam}

Over the duration of the Keefer et al. (2009a) study in which tagged fish were released downstream from Bonneville Dam (n=3,598), 17-19\% made it to John Day Dam, 4-5\% made it to McNary Dam, and around 1\% made it to Ice Harbor Dam. Moser et al. (2002b) similarly found that 3\% of tagged fish over a 3 year study ( $n=>300$ ) reached the John Day Reservoir. Over the duration of my study, of the fish released into the CI LPS, $14 \%(n=50)$ made it to John Day Dam, 10\% to McNary Dam, $8 \%$ to Priest 
Rapids Dam, 8\% to Wanapum Dam, and 2\% to Rocky Reach Dam. My results were comparable to those obtained for John Day Dam and the Columbia River upstream from McNary Dam by Keefer et al. (2009a). My results actually indicated higher escapement than reported by Moser et al. (2002b), suggesting that the CI LPS is not impeding fish from continuing to migrate to further upstream reaches of the Columbia River. In fact, the CI LPS may actually be aiding upstream passage of these fish.

Of the lamprey that migrated into the upper part of the drainage, none were from Release 5. This release occurred in September when temperatures were the highest but when lamprey migration has been shown to halt for overwintering (Bayer and Robinson 2005). This release date may represent a threshold for determining if fish passing Bonneville Dam will reach beyond The Dalles Dam or not in the same year. There were no fish detected upstream from The Dalles Dam from Release 4. This release occurred just before high temperatures required a halt in tagging and when mortalities were present following release. Hence, fish from this group may have been more stressed and could have experienced reduced capability for upstream movement.

In the CI LPS and through the Bonneville Reservoir, Group 1 (double tagged) fish performed better than those with just a PIT tag; the opposite was true upstream from The Dalles Dam. Fifty-seven percent (n=7) of fish that reached John Day Dam were from Group 2 (PIT tagged only), 80\% (n=5) of fish that reached McNary were from Group 2, and $100 \%$ of fish that made it to Priest Rapids $(n=4)$, Wanapum $(n=4)$, and Rocky Reach $(\mathrm{n}=1)$ were from Group 2. So, while the double tagged fish performed slightly better initially (not significant), the PIT tag only fish performed far better over time and 
traveled further upstream in the system. This result challenges the finding that there was no tagging effect, and instead suggests that there is no tagging effect over shorter distances, but that over longer distances lamprey start to exhibit an effect of carrying the radio tag. Studies by Noyes et al. (2012, 2014) using Juvenile Acoustic Telemetry tags, which are larger and require a more invasive surgery similar to radio tagging, and PIT tags also found no tagging effect between groups travel upstream of Bonneville Dam. Those studies found the same, however for groups traveling upstream from The Dalles Dam as well. Therefore, studies that employ two methods of tagging should continue to examine this possibility of tagging effects through different reaches of the Columbia River.

As stated previously it is assumed that when fish were no longer detected at subsequent dams that they either experienced mortality or found suitable habitat for spawning on the main stem or in a tributary. A study of 950 tagged lampreys showed that $25-30 \%$ of these fish entered the Deschutes River tributary; and my study found that one fish from Release 4 Group 3 made it to the Deschutes River mouth, and one from Release 4 Group 1 made it further up the Deschutes River to Shearars Falls (rkm 396.3). This is promising for fish in our study that passed The Dalles Dam and did not make it to John Day Dam (Moser et al. 2002a). However, it is also important to recognize that some of these fish may have simply stopped their migration due to timing and temperature to overwinter (Keefer et al. 2009a, 2013a). Battery life of the transmitters used for studies such as these is not long enough to monitor for overwintering behavior, nor are detection arrays operated in the winter months, so it is difficult to determine 
whether fish resumed migration after over-wintering (Keefer et al. 2013a). However a few tagging studies have revealed that fish are overwintering in the tributaries in addition to mainstem sites (Bayer and Robinson 2005; Noyes et al. 2012, 2014). Studies such as these should continue and could make use of different tagging methods to address this question at different spatial scales.

\subsection{Conclusions and Implications for Lamprey Management}

The most important findings from my study were that: 1) lampreys are passing the CI LPS successfully, 2) seasonality has an effect on travel time in the LPS, 3) radiotagging does not affect ability to travel in the LPS or in the Bonneville reservoir, but might affect migration beyond The Dalles Dam, and perhaps most importantly 4) the CI LPS does not affect the ability of lampreys to migrate to the upper Columbia River basin. The findings are very promising considering the size and design of the CI LPS, which is larger and contains steep angles and more switchbacks than any other LPS to date.

There exists a need for prioritization of projects to increase lamprey passage on the Columbia River. Methods such as those presented by Nunn and Cowx (2012) and Keefer et al. (2014), which prioritize existing structures for passage improvement using a scoring system, can provide insight for future management. Keefer et al. (2014) applied specifically to The Columbia River dams, whereas Nunn and Cowx (2012) applied similar methods to a different geographic region. However their methods could also apply to lamprey on the Columbia River.

An area lacking studies is that of lamprey migration to tributaries of the Columbia River. Although there have been a handful of detections, it is clear that the fate of fish 
that do not pass dams, where most detection arrays are located, are subject to no further detections. Projects on tributaries could help to clarify migration routes, population counts, and eliminate assumptions about overwintering habitat. As tagging technologies continue to develop and are able to capture finer scale movements, it is important to consider using finer scaled metrics and variables to support passage analyses (Keefer et al. 2009a). Our study was limited in that fish were released directly into the structure rather than entering volitionally, so we could only test against a handful of variables that applied to passage. Thus we could not examine variables for finer scaled analysis suggested by Keefer et al. (2009a) such as velocity, and tailrace elevation.

Interestingly, considering the known negative effects of high dissolved gas levels on salmonid species, the effect of high dissolved gas levels around dams has not been the subject of study for Pacific lamprey (Moser and Mesa 2009). Although my fish did not experience high dissolved gas in the CI LPS, this is a factor that could easily be assessed for lamprey tagged and released downstream from the dam.

Study design put many restraints on my results. For the future, and if funding and other constraints did not exist, it would be beneficial to tag and release thousands of fish downstream from the dam each migration season over numerous years to assess choices of passage routes and LPSs by tagged fish. In doing so, the elimination of a severe outlier (as seen in my study), which could contribute to skewed results, may be possible. A larger sample size could also potentially eliminate Type II error from occurring, and statistical significance would potentially exist where I had not detected it in this study. Utilizing PIT, radio, and JSAT tags would allow for many different questions to be 
addressed, since each tag allows examination of different temporal and spatial scales, while simultaneously allowing for assessment of tagging effects.

While there still exists a critical need to continue to determine passage criteria for all life stages of Pacific lamprey, my research gives insight into new LPS designs (i.e. the length and elevation of CI LPS). Although research has lagged, studies such as this can encourage new questions to be asked. These findings spark new interest in looking at how such a structure could be installed and monitored at other dams to aid lamprey passage and its potential effects on upstream movement.

If managers and decision makers can continue to prioritize and fund LPS projects, both new projects and improvements to existing projects, and monitor their use by lamprey, it is possible that numbers of lamprey traveling up the Columbia River system to spawn in its furthest reaches will increase. While improvements at Bonneville Dam have proved to increase passage efficiency over the dam, if fish continue to migrate up the system they will still encounter traditional fishways elsewhere. My results indicate that LPS projects should be considered at all major hydropower dams in an effort to provide more passage routes for this imperiled fish. 


\section{References}

Beamish, R.J.1980. Adult Biology of the River Lamprey (Lampetra ayresi) and the Pacific Lamprey (Lampetra tridentata) from the Pacific Coast of Canada. Canadian Journal of Fisheries and Aquatic Sciences 37:1906-1923.

Beamish, R. J., and T. G. Northcote. 1989. Extinction of a Population of Anadromous Parasitic lamprey, Lampetra tridentata, Upstream of an Impassable Dam. Canadian Journal of Fisheries and Aquatic Sciences 56:420-425.

Clemens, B. J., S. van de Wetering, S. A. Sower, and C. B. Schreck. 2013. Maturation characteristics and life-history strategies of the Pacific lamprey, Entosphenus tridentatus. Canadian Journal of Zoology 91:775-788.

Clemens, B. J., S. van de Wetering, J. Kaufman, R. A. Holt, and C. B. Schreck. 2009. Do summer temperatures trigger spring maturation in Pacific lamprey, Entosphenus tridentatus? Ecology of Freshwater Fish 18:418-426.

Clemens, B. J., M. G. Mesa, R. J. Magie, D. A. Young, and C. B. Schreck. 2012. Prespawning migration of adult Pacific lamprey, Entosphenus tridentatus, in the Willamette River, Oregon. U.S.A. Environmental Biology of Fishes 93:245-254. 
Close, D. A., M. S. Fitzpatrick, and H. W. Li. 2002. The Ecological and Cultural Importance of a Species at Risk of Extinction, Pacific Lamprey. Fisheries 27(7):19-25.

Corbett, S., M. L. Moser, B. Wassard, M L. Keefer, and C. C. Caudill. 2013. Development of Passage Structures of Adult Pacific Lamprey at Bonneille Dam, 2011-2012. Report to Portland District Corps of Engineers. NOAA Fisheries Science Center, Seattle, Washington.

Corbett, S., M. L. Moser, K. E. Frick, B. Wassard, M L. Keefer, and C. C. Caudill. 2014. Development of Passage Structures for Adult Pacific Lamprey at Bonneville Dam, 2013. Report to Portland District Corps of Engineers. NOAA Fisheries Science Center, Seattle, Washington.

CRITFC (Columbia River Intertribal Fish Commission). 2011. Tribal Pacific lamprey restoration plan for the Columbia River Basin. Nez Perce, Umatilla, Warm Springs, and Yakam tribes. (www.critfc.org/wpcontent/uploads/2012/12/lamprey_plan.pdf). Portland, OR.

Crow, E. 2013. Personal Communication. Yakama Nation Fisheries. 
Johnson, E. L., C. C. Caudill, M. L. Keefer, T. S. Clabough, C. A. Peery, M. A. Jepson, and M. L. Moser. 2012. Movement of radio-tagged adult Pacific lampreys during a large-scale fishway velocity experiment. Transactions of the American Fisheries Society 141:571-579.

Keefer, M. L., M. L. Moser, C.T. Boggs, W.R. Daigle, and C.A. Peery. 2009a. Effects of Body Size and River Environment on the Upstream Migration of Adult Pacific Lampreys (Lampetra tridentata). North American Journal of Fisheries Management 29:1214-1224.

Keefer, M. L, M L. Moser, C T. Boggs. W. R. Daigle, and C. A. Peery. 2009b. Variability in migration timing of adult Pacific lamprey (Lampetra tridentata) in the Columbia River, U.S.A. Environmental Biology of Fishes 85:253-264.

Keefer, M. L., C. Y. Boggs, C. A. Peery, and C. C. Caudill. 2013a. Factors affecting dam passage and upstream distribution of adult Pacific lamprey in the interior Columbia River basin. Ecology of Freshwater Fish 22:1-10.

Keefer, M. L., C. C. Caudill, T. S. Clabough, M. A. Jepson, E. L. Johnson, C. A. Peery, M. D. Higgs, and M. L. Moser. 2013b. Fishway passage bottleneck identification and prioritization: a case study of Pacific lamprey at Bonneville Dam. Canadian Journal of Fishes and Aquatic Science 70:1551-1565. 
Keefer, M. L, C. C. Caudill, C. A. Peery, and M. L. Moser. 2013c. Context-dependent diel behavior of upstream-migrating anadromous fishes. Environmental Biology of Fishes 96:691-700.

Keefer, M. L., W. R. Daigle, C. A. Peery, H. T. Pennington, S. R. Lee, and M. L. Moser. 2010. Testing Adult Pacific Lamprey Performance at Structural Challenges in Fishways. North American Journal of Fisheries Management 30:376-385.

Keefer, M. L., C. C. Caudill, and M. L. Moser. 2014. Fishway Bottleneck Relief Models: a Case Study using Radio-Tagged Pacific Lampreys. Transactions of the American Fisheries Society 143:1049-1060.

Kostow, K. Oregon Lampreys: Natural history status and analysis of management issues. 2002. Oregon Department of Fish and Wildlife, Portland, Oregon.

Mesa, M. G., R. J. Magie, and E. S. Copeland. 2010. Passage and Behavior of RadioTagged Adult Pacific Lampreys (Entosphenus tridentatus) at the Willamette Falls Project, Oregon. Northwest Science 84(3);233-242.

Moser, M. L., and D. A. Close. 2003. Assessing Pacific Lamprey Status in the Columbia River Basin. Northwest Science 77(2):116-125. 
Moser, M. L., P. A. Ocker, L. C. Stuehrenberg, and T. C. Bjornn. 2002a. Passage Efficiency of Adult Pacific Lampreys at Hydropower Dams on the Lower Columbia River, USA. Transactions of the American Fisheries Society 131:956965.

Moser, M. L., and M. G. Mesa. 2009. Passage Considerations for Anadromous Lampreys. American Fisheries Society, Symposium 72.

Moser, M. L., A. L. Matter, L. C. Stuehrenberg, and T. C. Bjornn. 2002b. Use of an extensive radio receiver network to document Pacific lamprey (Lampetra tridentata) entrance efficiency at fishways in the Lower Columbia River, USA. Hydrobiologia 483:45-53.

Moser, M. L., M. L. Keefer, H. T. Pennington, D. A. Ogden, and J. E. Simonson. 2011a. Development of Pacific lamprey fishways at a hydropower dam. Fisheries Management and Ecology18:190-200.

Moser, M. L. 2014. Personal Communication. NOAA Fisheries Research Fishery Biologist. 
Moser, M. L., D. A. Ogden, and B. P. Sandford. 2007. Effects of surgically implanted transmitters on anguilliform fishes: lessons from lamprey. Journal of Fish Biology $71: 1847-1852$

Moser, M. L., D. A. Ogden, H. T. Pennington, M. L. Keefer, and C. C. Caudill. 2011b. Development of Passage Structures for Adult Pacific Lamprey, 2009-2010. Report to Portland District Corps of Engineers. NOAA Fisheries Science Center, Seattle, Washington.

Moser, M. L., M. L. Keefer, C. C. Caudill, and B. J. Burke. 2013. Migratory Behavior of Adult Pacific Lamprey and Evidence for Effects of Individual Temperament on Migration Rate. Pages 130-149 in Katsumi Tsukamoto, editor. Physiology and Ecology of Fish Migration. CRC Press.

Murauskas, J. G., A. M. Orlov, and K. A. Siwicke. 2013. Relationships between the Abundance of Pacific Lamprey in the Columbia River and Their Common Hosts in the Marine Environment. Transactions of the American Fisheries Society 142(1):143-155.

Nilsen, E., and W. Temple. 2012. Emerging and Legacy Contaminants in Juvenile Pacific lamprey in the Columbia River Basin. U.S. Geological Survey, Portland, OR. Prepared for Columbia River Intertribal Fish Commission, Portland, OR. 
Noyes, C. J., C. C. Caudill, T. S. Clabough, D. C. Joosten, E. L. Johnson, M. L. Keefer, and G. P. Naughton. 2012. Adult Pacific Lamprey Migration Behavior and Escapement in the Bonneville Reservoir and Lower Columbia River Monitored Using the Juvenile Salmonid Acoustic Telemetry System (JSATS), 2011. Report to Portland District Corps of Engineers. Department of Fish and Wildlife Sciences, Moscow, ID.

Noyes, C. J., C. C. Caudill, T. S. Clabough, D. C. Joosten, E. L., and M. L. Keefer. 2014. Adult Pacific Lamprey Migration Behavior and Escapement in the Bonneville Reservoir and Lower Columbia River Monitored Using the Juvenile Salmonid Acoustic Telemetry System (JSATS), 2013. Report to Portland District Corps of Engineers. Department of Fish and Wildlife Sciences, Moscow, ID.

Nunn, A. D., and I. G. Cowx. 2012. Restoring River Connectivity: Prioritizing Passage Improvements for Diadromous Fishes and Lampreys. AMBIO 41:402-409.

Reinhardt, U. G., L. Eidietis, S. E. Friedl, and M. L. Moser. 2008. Pacific lamprey climbing behavior. Canada Journal of Zoology 86:1264-1272. 
Robinson, T.C, J. M Bayer. 2005. Upstream Migration of Pacific Lampreys in the John Day River, Oregon: Behavior, Timing, and Habitat Use. Northwest Science 79(2\&3): 106-199.

Ruiz-Campos, G. and S. Gonzalez-Guzman. 1996. First freshwater record of Pacific lamprey, Lampetra tridentata, from Baja California, Mexico. California Fish and Game 82(3):144-146.

Senos, R., F. K. Lake, N. Turner, and D. Martinez. 2006. Traditional Ecological Knowledge and Restoration Practice. Pages 393-426 in D. Apostol and M. Sinclair, editors. Restoring the Pacific Northwest: The art and Science of Ecological Restoration in Cascadia. The Science and Practice of Ecological Restoration Series. Island Press, Washington DC.

Sheoships, G. Personal Communication. Oregon State University.

USACE (U.S. Army Corps of Engineers), U.S. Bureau of Reclamation (USBOR), Bonneville Power Administration (BPA). 2001. The Columbia River System: Inside Story, $2^{\text {nd }}$ Edition. BPA, Portland, Oregon. 
USFWS (U.S. Fish and Wildlife Service). 2011. Pacific lamprey (Entosphenus tridentatus) assessment and template for conservation measures. USFWS, Portland, Oregon.

United States Naval Observatory. 2013. Duration of daylight/darkness table for one year. Astronomical Applications Department of the United States Naval Observatory. Available: http://aa.usno.navy.mil/data/docs/Dur_OneYear.php (September 2014.)

USFWS (U.S. Fish and Wildlife Service). 2011. Pacific lamprey (Entosphenus tridentatus) Assessment and Template for Conservation Measures. U.S. Fish and Wildlife Service, Portland, OR.

University of Washington. 2013. Columbia River data access in real time: river environment. School of Aquatic and Fishery Sciences, University of Washington, Seattle, WA. Available: http://www.cbr.washington.edu/dart (September 2014.)

Yun, S., A. J. Wildbill, M. J. Siefkes, M. L. Moser, A. H. Dittman, S. C. Corbett, W. Li, and D. A. Close. 2011. Identification of putative migratory pheromones from Pacific lamprey (Lampetra tridentata). Canadian Journal of Aquatic Sciences 68: 2194-2203.

Zobott, H. 2014. Personal Communication. University of Idaho. 
Zhu, Q., M. Moser, and P. Kemp. 2011. Numerical analysis of a unique mode of locomotion: vertical climbing by Pacific lamprey. Bioinspiration \& Biomimetics 6:1-9. 